\title{
أثر العلاقات الأمريكية على دول حوض النيل (تحليل جغرافي)
}

\section{د/ حسن محمد إبراهيم حسونة}

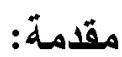

بعد إقليم حوض النيل واحدة من الأفاليم الجيوستراتيجية في التثسيم الجيوبولنبكي العالمي،

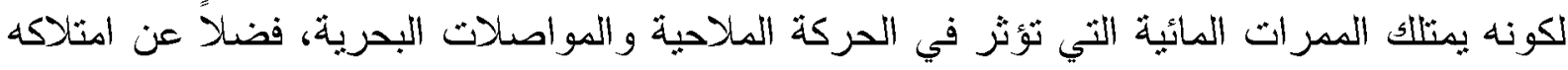
الثروات طيبعية تجعله ذات مكانة مثميزة وموضع اهثمام من القوى العظمى الكبرى في العالم. يعد الإفليم أكثر انساعاً، واثند ثاثيراً من الناحية الاستراتيجية في الجغرافية، ذلك أنها على الصعيد

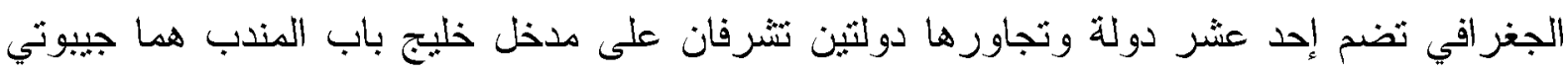

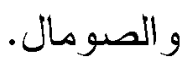

أما على المستوى الجيوسياسي، فإن الأقليم بضم العديد من الدول والقوى التي تثناعل ونثبادل علاقات

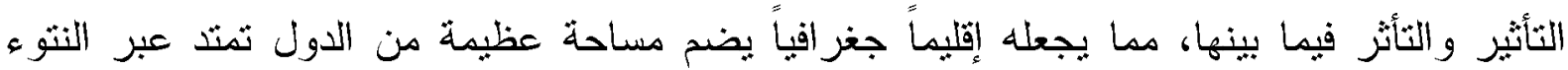

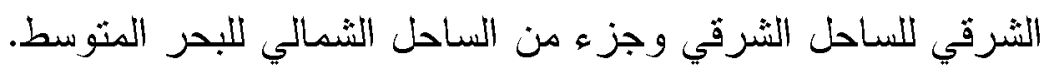

أي أن الأقليم بيستد قدراً عظيماً من الأهمية السياسية ناجمة عن قيمته الاستر اتيجية لارتباطها الوثثق

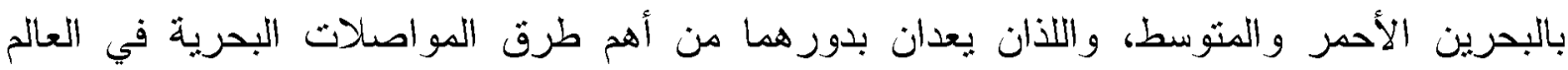

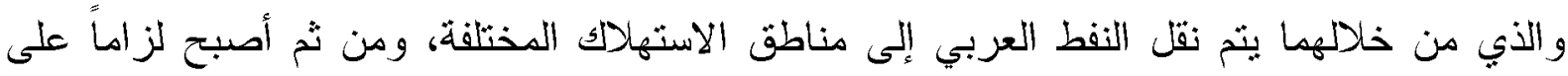
الدول العظىى ثوفير التأمين لأمن الطاقة العالمبية بالمنطقة.

شها إقليم حوض النيل نطورات مهمة لم تقتصر نأثيراتها على دولها فقط، إنما امندت إلى سباسات

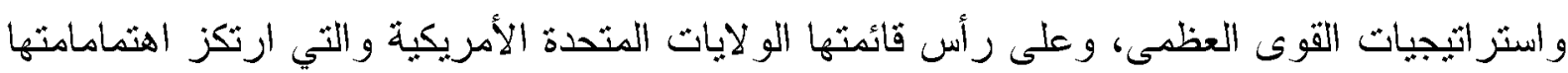

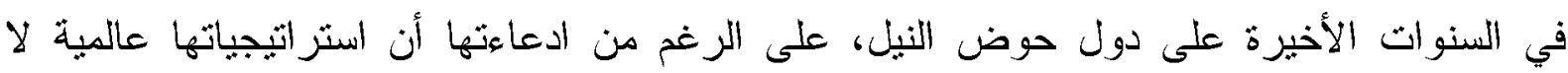

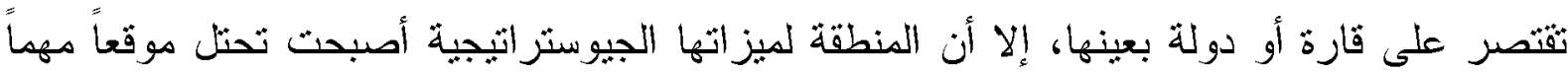

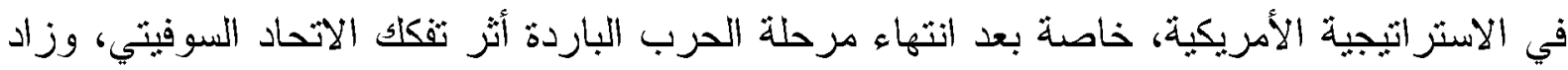
الأمر صعوبة ظهور عملاق سياسي وهي الصين التي نتافس الولايات المتحدة اقتصادياً في أقليم

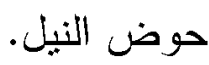




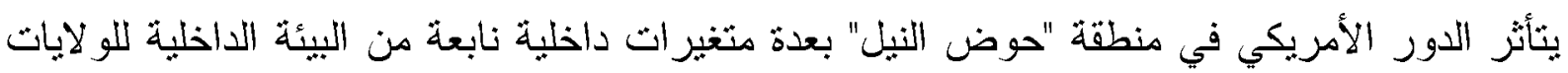

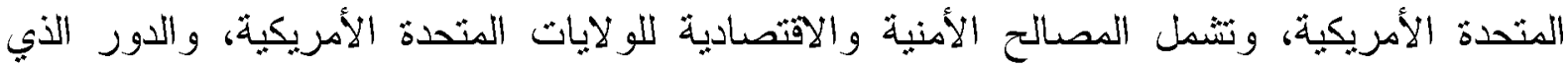

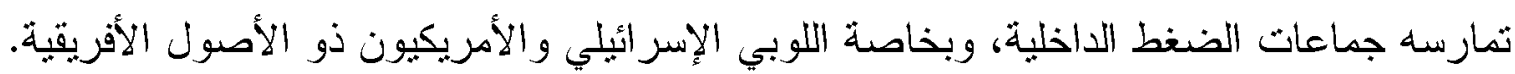
إثتكالية البحث:

لانثك أن الإشكالية تنطوي على مجموعة من التساؤ لات الفرضية:

- إلى أب مدى ساهمت استر اتيجية منطقة حوض النيل في قائمة المصالح الأمريكية؟

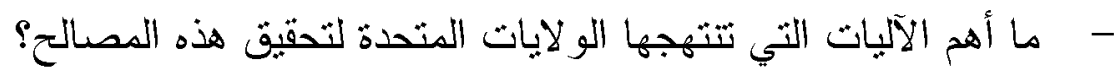

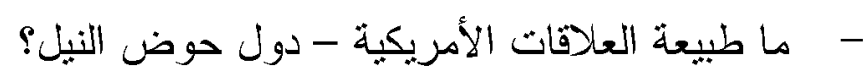

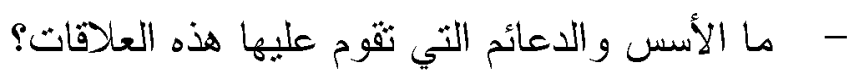

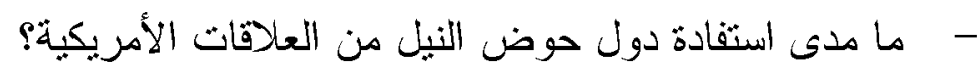

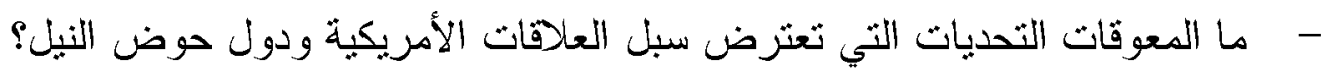

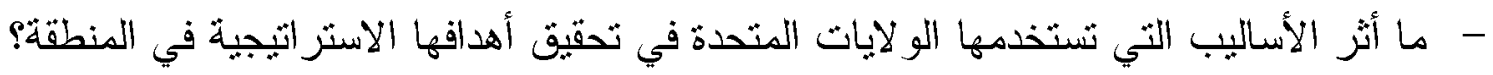

\section{فرضيات الادراسة:}

$$
\text { للإجابة عن إثكالية البحث تم طرح الفرضيات الآثية: }
$$

1- اعتماد الو لايات المتحدة الأمريكية على منهج النعامل الانتقائي في علاقتها بدول الحوض بما يخدم مصالحها القومية.

r- التنافس الغربي والصيني والتزكي والإيراني على دول حوض النيل بعرقل سبل العلاقات الأمريكية بدول حوض النيل. ب- انطلاقاً من سعي الولايات المتحدة بأن نكون القوة الرئيسة في العالم، فهي تسعى لتأمين حضور فاعل في المنطقة لتحقيق مكاسب اقتصادية وسياسية استراتيجية.

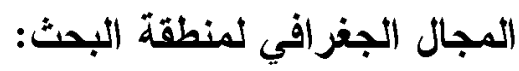

ستكون الحدود الجغر افية المكانية لهذه الدراسة في منطقة حوض النيل وفق الرؤية الأمريكية

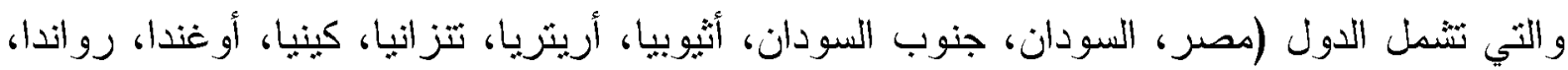

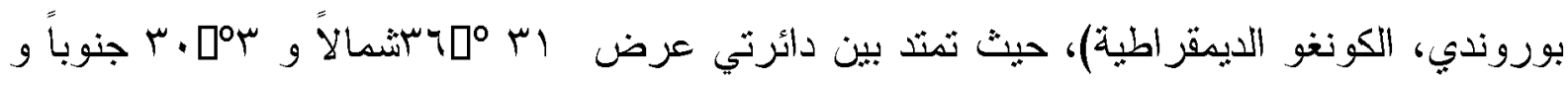

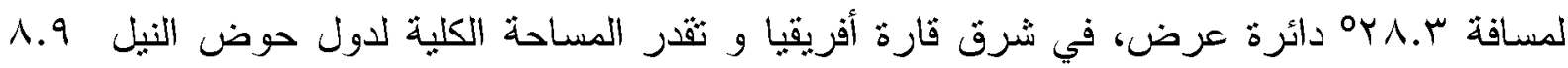




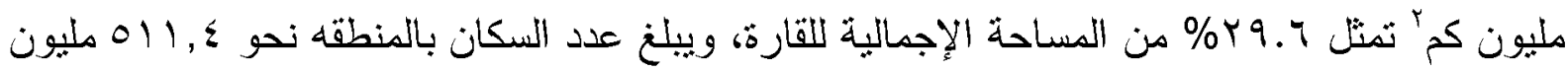

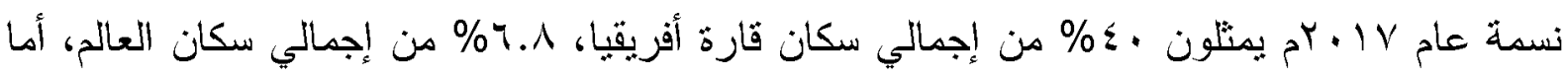

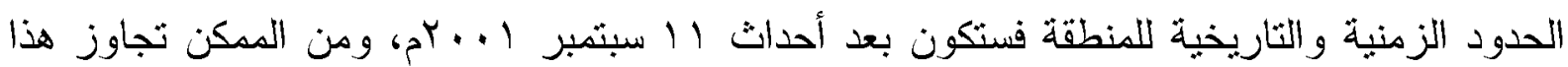
التاريخ حسب الحاجة في موضوعات الدراسة.

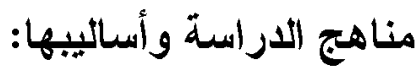

تطلب هذا البحث انباع المناهج و الأساليب الآتية:

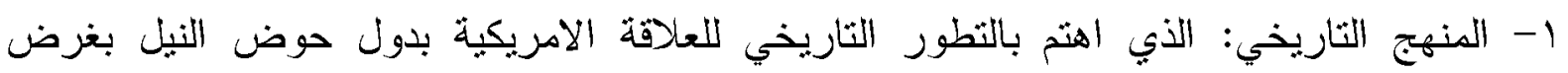
الوصول إلى تحليل الأحداث في الحاضر و المستقبل.

r- المنهج التحليلي: الذي يهدف إلى إدرالك أثر المتغيرات الداخلية الدافعة لتوجه الولايات المتحدة لدول حوض النيل و تفسير نتائج هذا النتخل.

ب- التحليل الإحصائي: بِتخدم في تحليل البيانات تحليلاً إحصائياً رياضياً للخروج بنتائج محددة

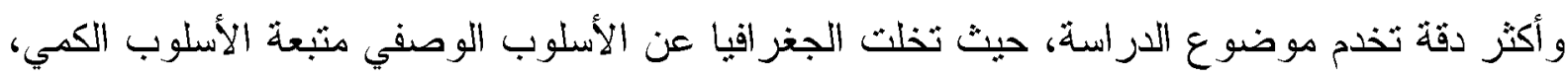
وبناء النماذج وما إلى ذللك.

\section{الاراسات السابقة}

رغم الهيمنة الأمريكية على كل دول العالم لم يعالج الموضوع إقليمياً سوى القليل من الجغرافيين

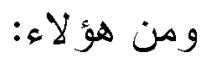

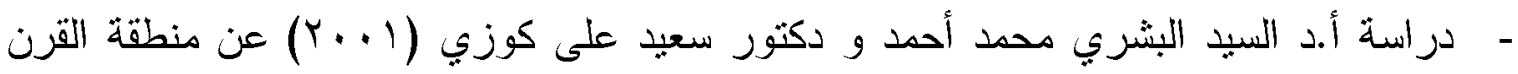

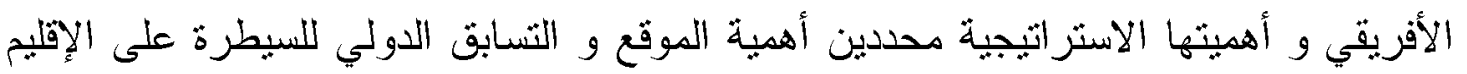

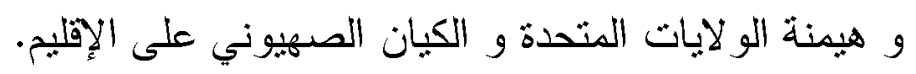

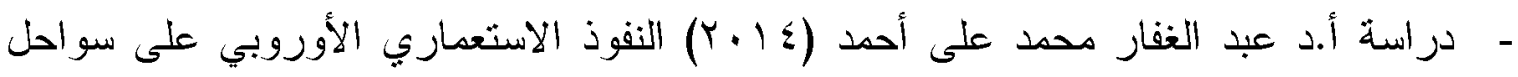
البحر الأحمر الغربية وأثر ذلك على العلاقات السودانية.

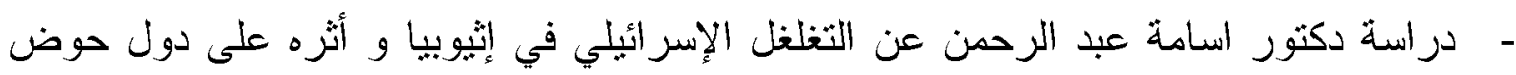

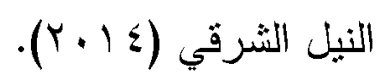

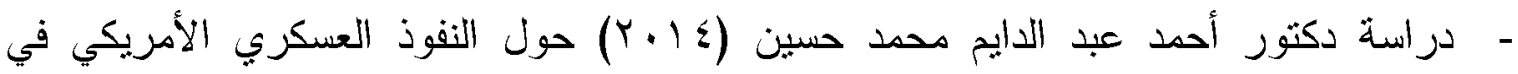
إثيوبيا في خمسينات القرن العشرين ونتاول فيه صور و ندخل النفوذ الأمريكي في إثيوبيا

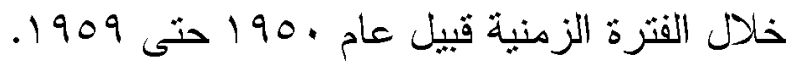




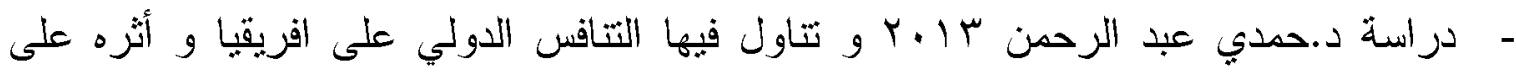

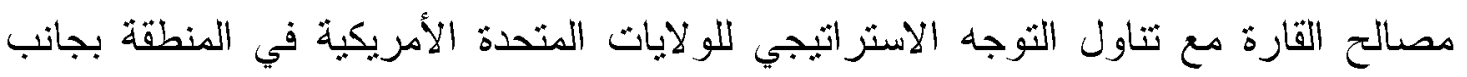

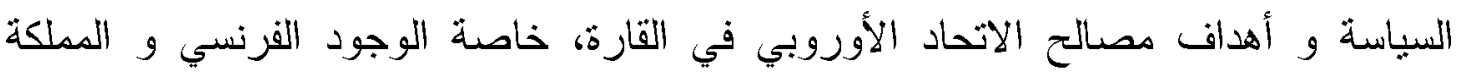
المتحدة مع إبراز جزء خاص عن العلاقات الصينبة الأفريقية. المناقتشة و التحليل

سينم منافشة موضوع الدراسه من محاور فى النقاط الثاليه : - التطور التاريخي للعلاقات الامريكية بدول حوض النيل.

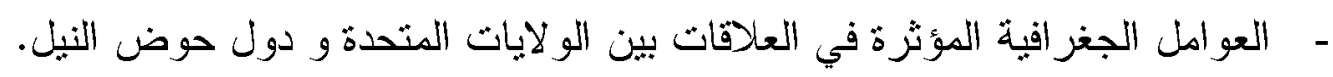
- مور التخخل الامريكي في دول حوض النيل.

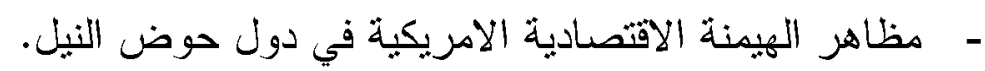

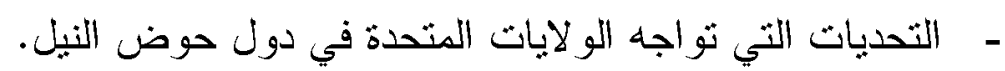

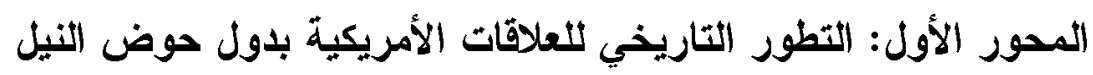

لم تهتم سياسات الولايات المتحدة بمد جذور العلاقات بينها وبين دول حوض النيل بل عانت

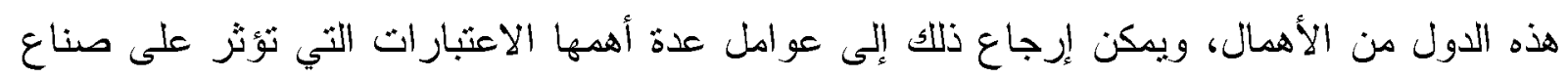
القرار الأمريكي سواء كانت داخلية أم خارجية والتي تثتعلق بطبيعة النظام الدولي و البيئة الدولية. ويهنم هذا المبحث بدراسة مراحل العلاقات الأمريكبة بدول حوض النيل في فنرات زمنية ثلاث منطابقة كالثالي:

1- الفترة الأولى: ما قبل الحرب الباردة وأثنائها:

لاثكك بأن زيادة أهمية الموقع الجغرافي لدول حوض النيل بجانب ثرواتها، أسهم في استغلال

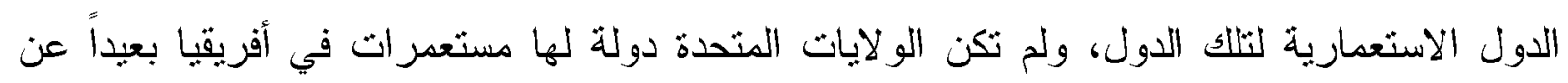

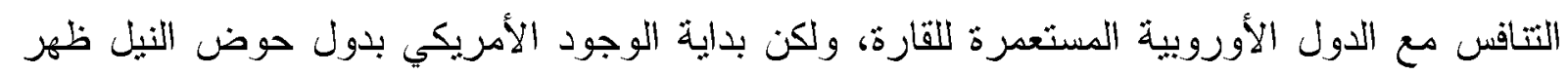

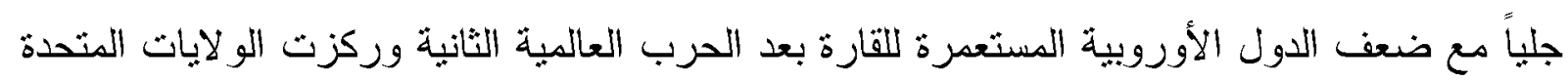

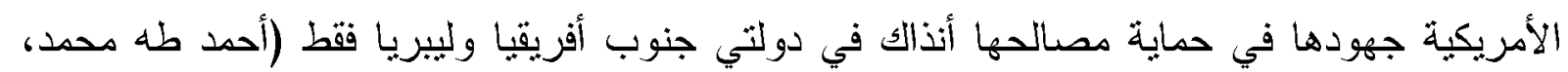

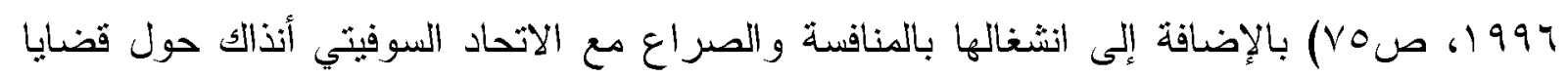
الحرب الباردة، حيث واجهت الدبلوماسية الأمريكية تجاه دول حوض النيل والنيل ثنلاث مشكلات أساسية: 
أولها: عدم اهتمامها في التذخل في القضايا الخاصة بالأقليم بشكل مبانشر، وثنانيها: إيمانها بالدور

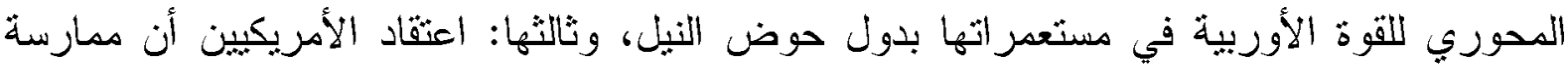

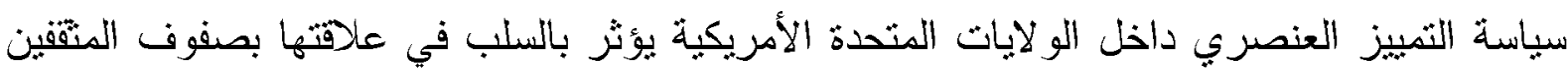

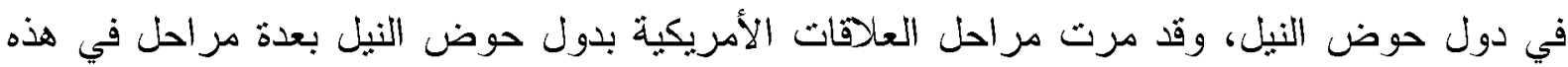

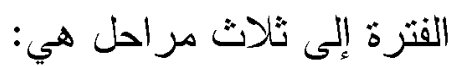

$$
\text { (المرحلة الأولى (19 (1997) }
$$

لم تكن أفريقيا ودول الأقليم وقضاياها من بين أولويات السباسة الخارجية الأمريكية حفاظاً على هلى

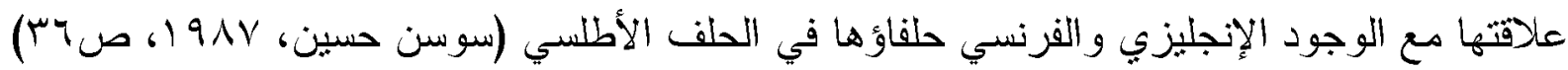

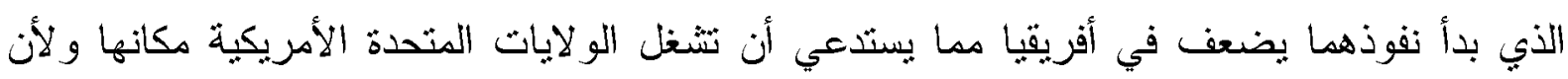

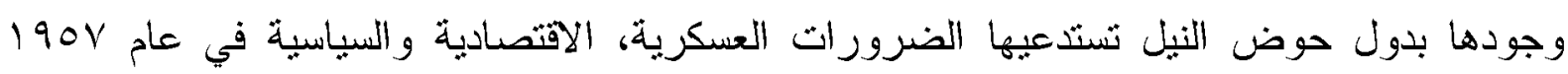

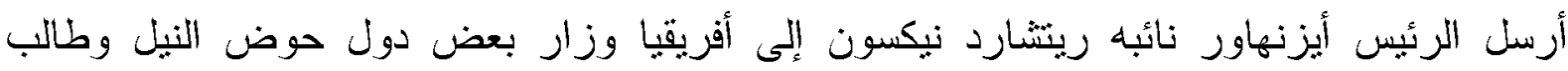

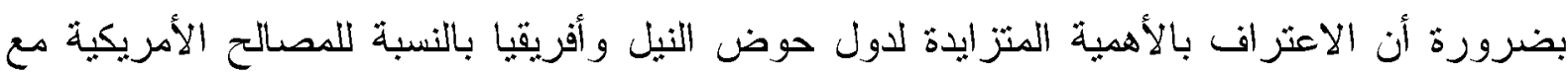

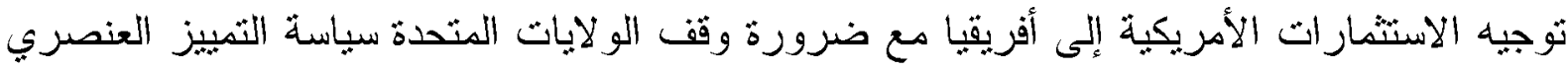

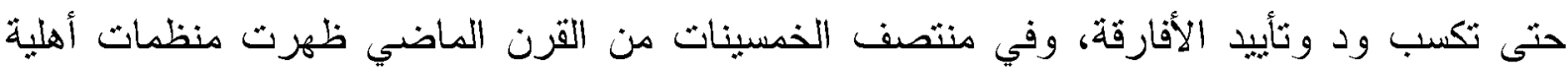

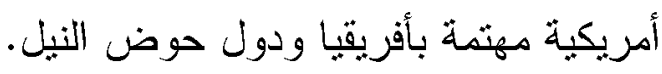

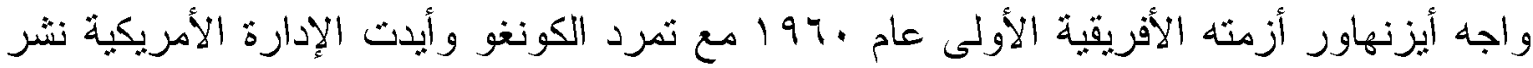

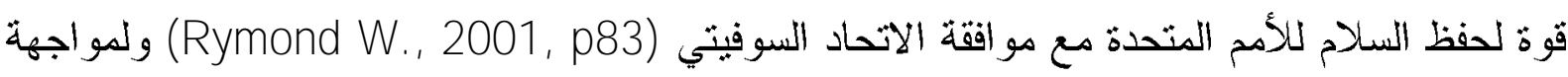

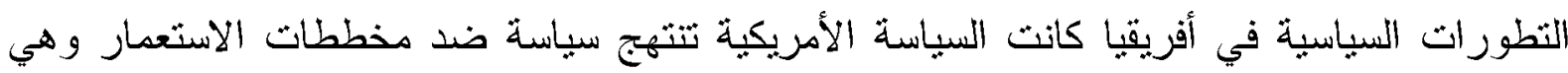
الصديق الوفي للثعوب الأفريقية.

اهنم كيندي بالثعوب الأفريقية موضحاً أن مستقبل أفريقيا سيؤثز على مستقبل الولايات

المتحدة الأمريكية وعمل على إرضاء الأطراف الأفريقية.

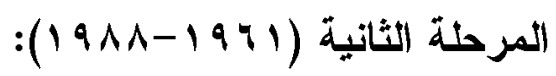

في سنة ل197ام استقبل البيت الأبيض رؤساء 11 دولة أفريقية ومن بينها رؤساء من دول

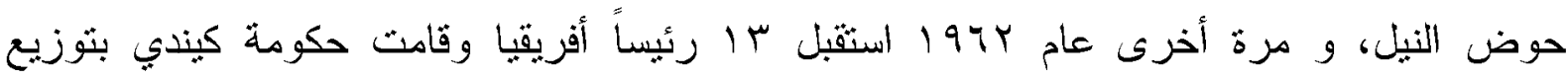
المساعدات الاقتصادية لبعض دول القارة من خلال خطط المنظمات الدولية، وفي عهر إدارة جونسون

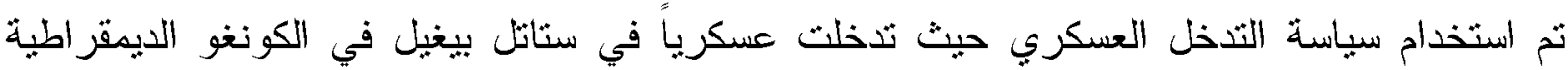


(زائر سابقاً) وأسقطت حكومة باتريس لومبا اليسارية ومساندة الحركة الإنفصالية التي يقودها تنتومبي.

وقد اهتد إدارة الرئبس "تبكسون" بتقديم المساعدات لدول حوض النيل وأفريقيا لمواجهة التغلغل

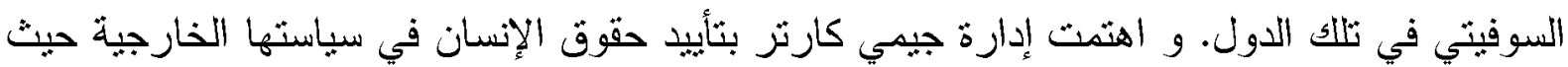

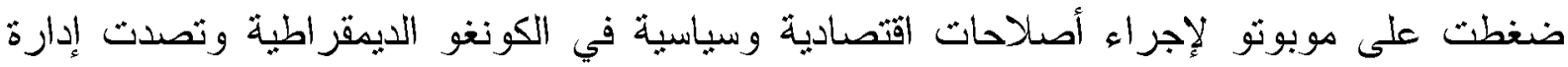

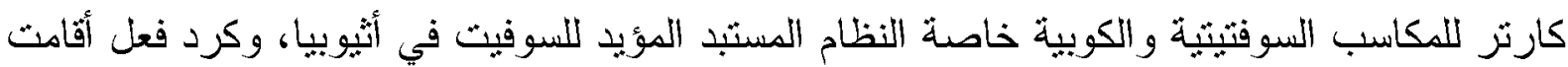

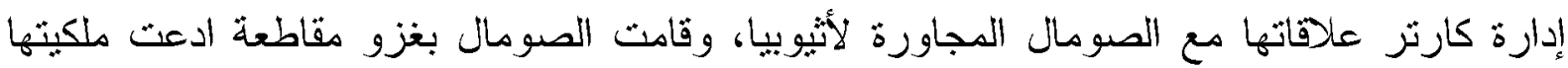

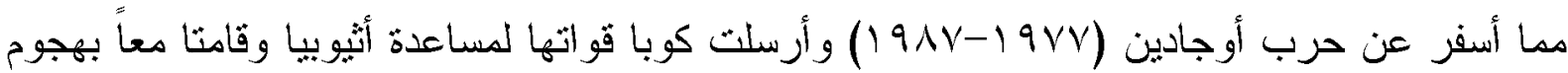

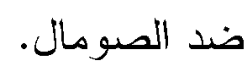

قدرت المساعدات الاقتصادية الأمريكية بحو الي مليوني دولار بنهاية السبعينيات في حين قدمت داث مساعدات لدول أفريقبا الأخرى بما بعادل آ ملايين دولار، وارتفع المبلغ إلى بليون دو لار عام 1910 (Reymond W., 1988, P39). منها ما بقرب من ، 10 مليون دو لار لدول حوض النيل

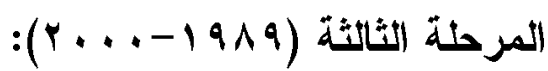

وفي فترة حكم "ريجان" والتي انتهت عام 19 19بأ انهيار الاتحاد السوفيتي ولم تكن أفريقيا على قائمة أولويات السياسة الخارجية الأمريكية، فقد كانت مجرد ساحة للمناورات ولم نكن المبدان الأول

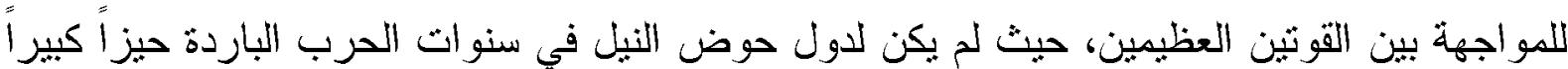

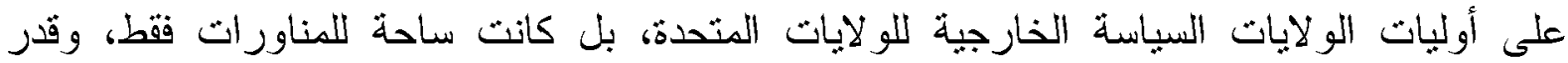

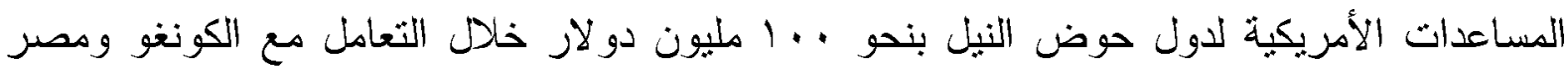

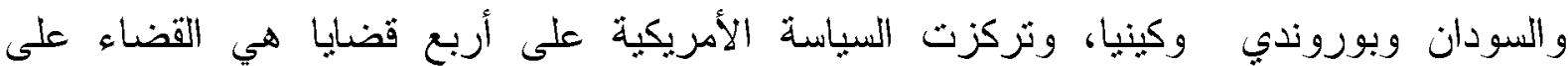
الثيوعية، الاهنمام بخطوط التجارة الدولية، والسبطرة على مناطق التعدين بالقارة مع الاهنمام بنشر

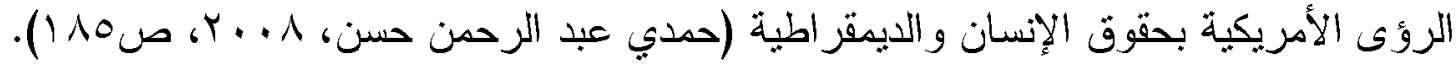
ץ- الفترة الثانية العلاقات الأمريكية بدول حوض النيل بعد الحرب الباردة: اهتم صانعو القرار بدول حوض النيل في ما بعد الحرب الباردة بعدد من العوامل والمتغيرات من أبرزها:

- ازدياد القيمة الاستراتيجية لدول حوض النيل لأسباب منها: الموقع المتميز والثروات الطبيعية وخطوط التجارة وهي مرنكزات استراتيجية تقوم عليها السياسة الأمريكية. 


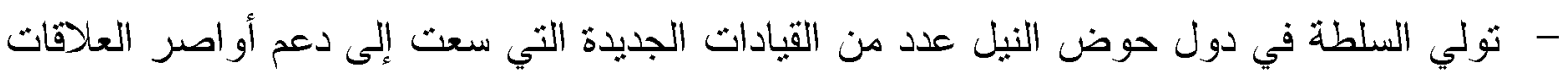

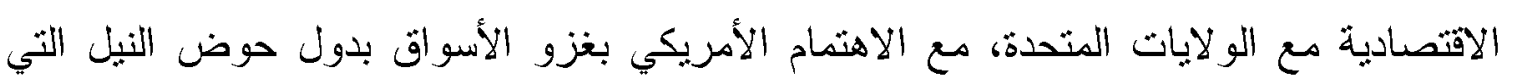
تضم ما يزيد عن •10 مليون نسمة آنذاك.

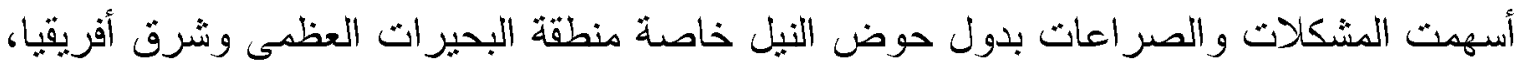

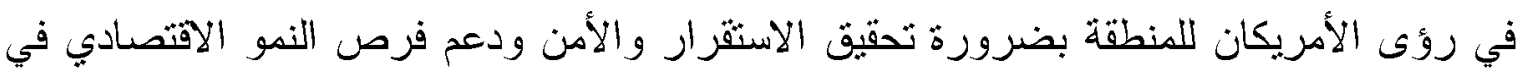
دول حوض النيل بما بخدم مصالحهم السياسية والاقتصادية.

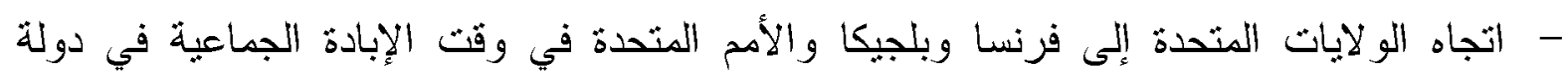

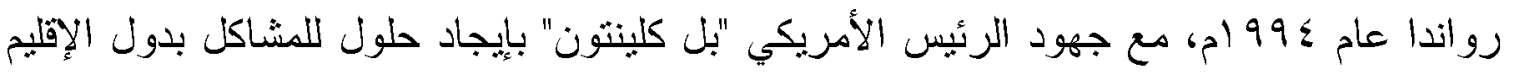

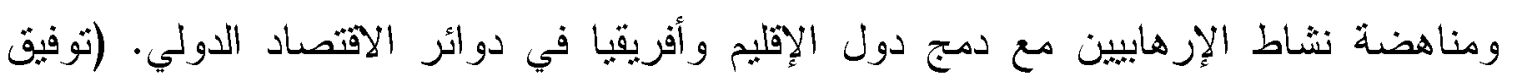

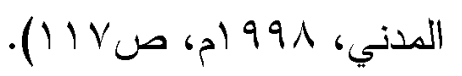

- انتهاج سياسة فرنسبة خاصة في اجنماعات القمة الفرنسبة - الفرانكوفونية التي أصبحت ضم فانم

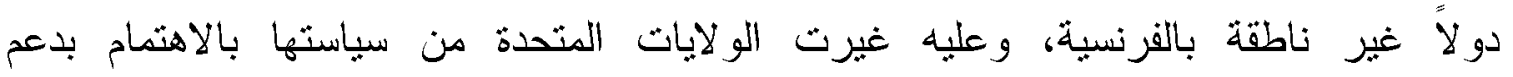

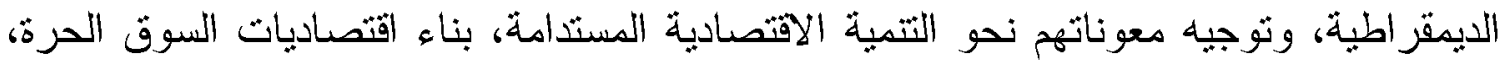

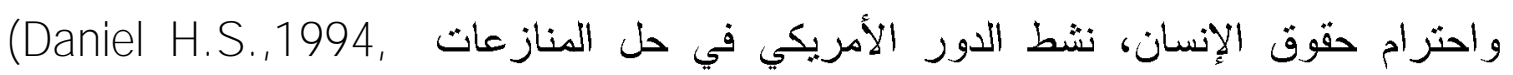

• التغير المكاني و نوع العلاقات الامريكية بدول حوض النيل خلا فترة كلينتون

- - بعد انتخاب "بيل كلينتون عام سب99 أقام بزيارة بعض الدول الأفريقية منها دول حوض النيل ولم يزر بورندي لما بها من صراع دامي بين قييلتي الهوتو والتوتسي وعقد الرئيس كلينتون اجنماعه

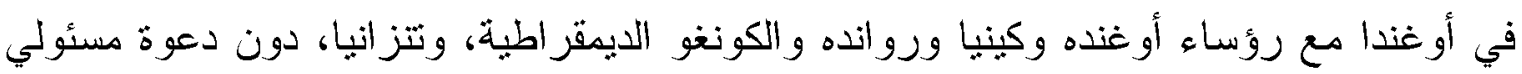

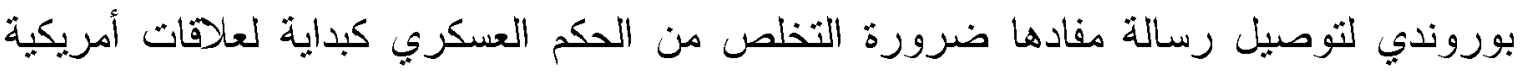
بوروندية مستقلة.

- - عند نولي "كلينتون" السلطة قام بتتفيذ إسهام قوات حفظ السلام الأممية خاصة بعد الفنشل في حل

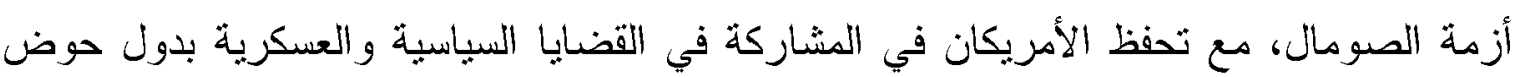

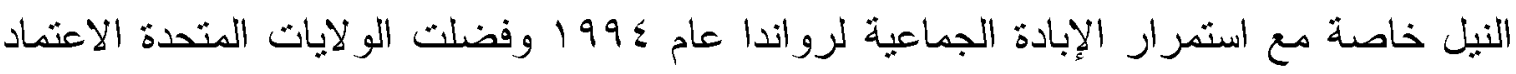

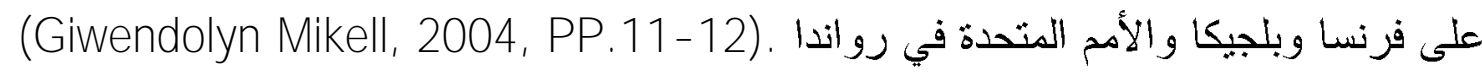

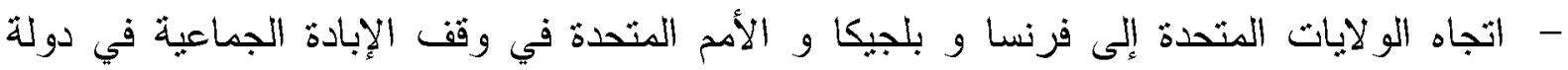

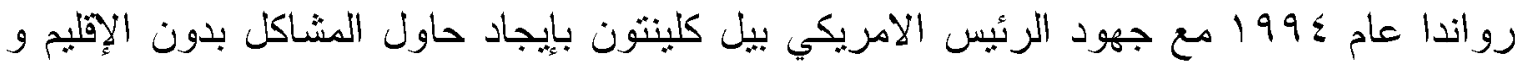


مناهضة نشاط الأرهابيين مع دمج دول الإقليم و إفريقيا في دوائر الإتصـاد الدولي (توفيق المدني، (1) (1) 1991

Leland Initiative أطلق كلينتون عدد من المبادرات لمساعدة أفريقيا من أهمها مبادرة ليليند -

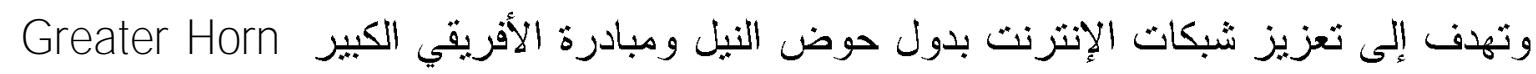
of Africa Initiative

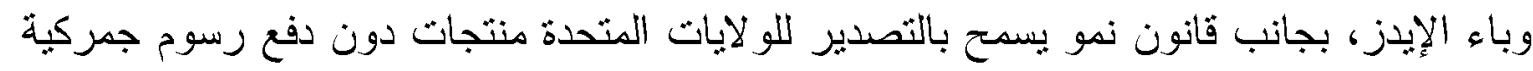

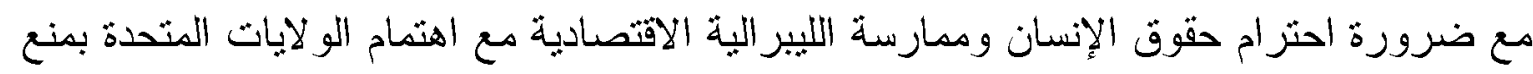

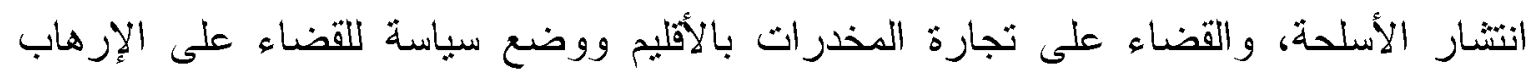
الدولي.

- قام كلينتون بزيارة أروشا بنتزانيا للمشاركة في حضور مراسم توقيع اتفاق السلام بين الفصائل

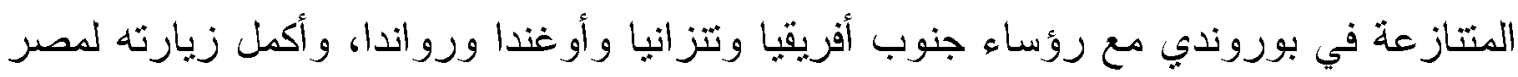

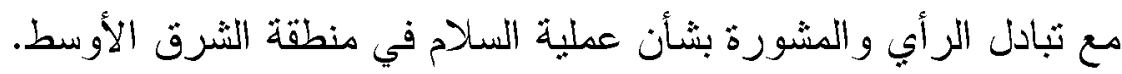

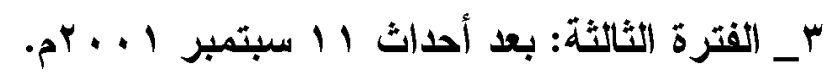

لاشكك أن هجمات || سبنمبر | +. rم شكلت قفزة نوعية في أنثكال وآليات الصراع الدولي، وإعادة تشكيل السياسات الخارجية للاول الكبرى وتبلورت استراتيجية الأمن القومي الأمريكي، حيث أعلنت الحرب على الإزهاب والإرهابيين من خلا لهل إنتاج الآتي:

1- التحول من سباسة الردع والتهديد إلى عصر سبادة القطب الواحد: r- كنع ظهور أية قوة دنافسة لها دور عالمي.

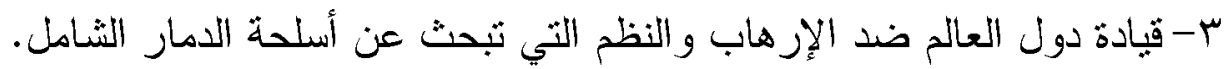

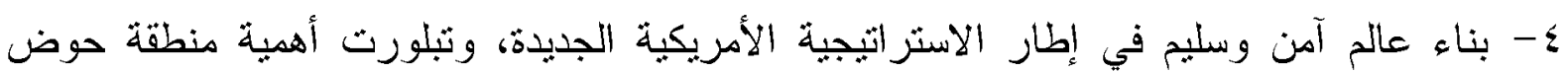

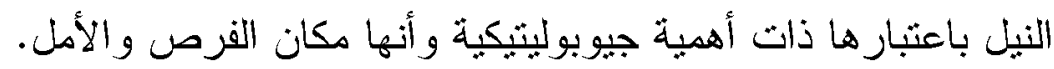

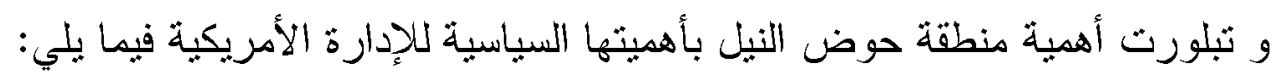

$$
\text { أولاً: الحرب على الإرهاب: }
$$

عقدت الولايات المتحدة اجتماع قومي بمبعوثي دول حوض النيل وبعض الدول الأفريقية في ؟ سبتمبر l +. rم وعرضت عليهم المطالب الآتية: 1- المشاركة الكاملة في التحالف الأمريكي الدولي للحرب ضد الإرهاب. ץ- تزويد وكالة الاستخبار ات الأمريكية بكافة المعلومات المطلوبة عن الإزهابيين. 
r- الاهتمام بأمن الحدود وفرض الرقابة على التحركات و المنافذ والحدود.

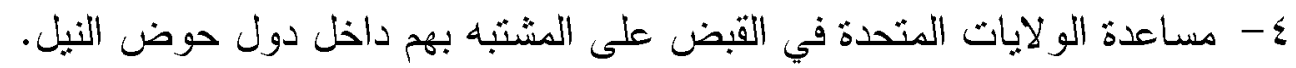

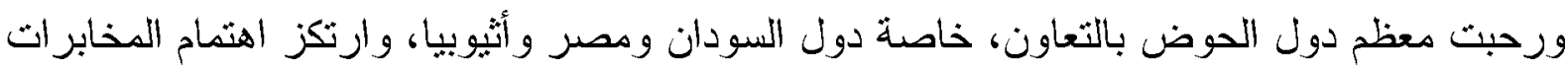

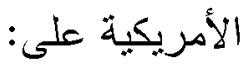

أ- منطقة القرن الأفريقي وشرق أفريقيا: وذلك لأهمينها الاستر اتيجية وتحكمها في المدخل الجنوبي

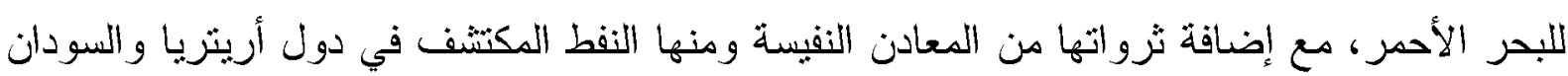

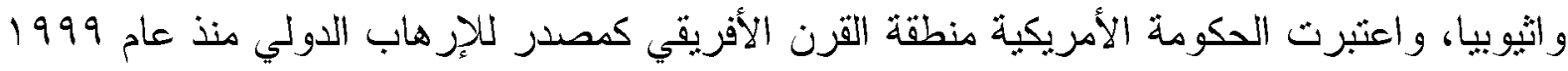

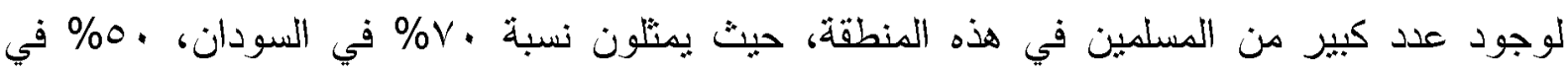

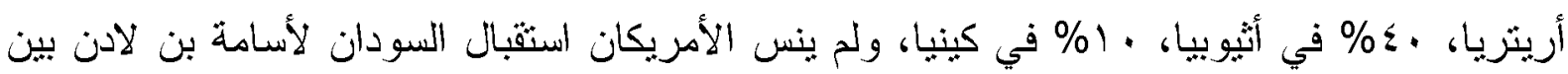

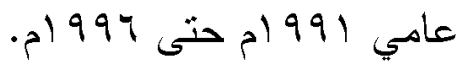
ونم طرح وإحباء مشروع القرن الأفريقي (مبادرة كلينتون 990 ام) ليضم إلى دول القرن الأفريقي

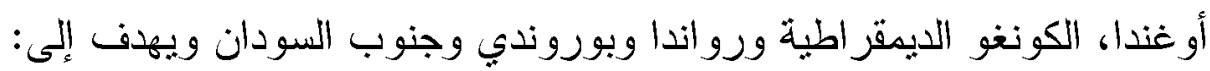

• إنشاء بنية أساسية لنشركات التعدين و النفط الأمريكية.

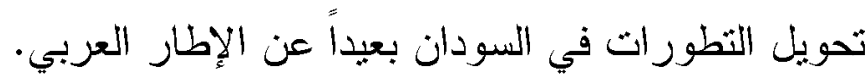
• خلق هوية مختلفة للمنطقة وتدعبم ومساندة حلفائها.

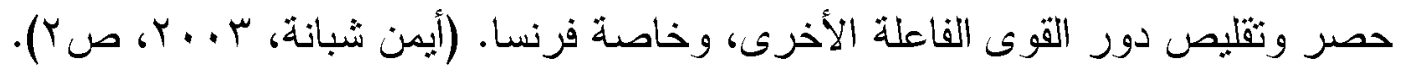

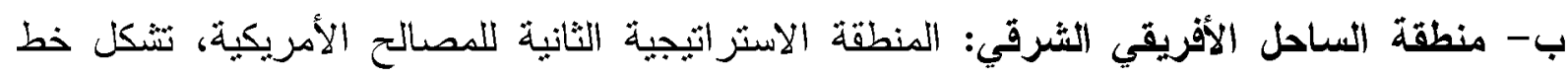

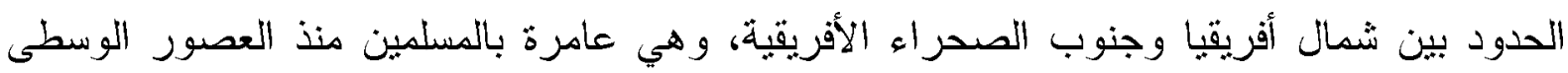
ومن بينها مصر كينيا وتنز انبا وارينزيا و أوغندا. (Sulayman . S., 2005, PP3-20). وتضم هذه المنطقة الجماعات الإرهابية الإسلامية ، وشهدت منطقة حوض النيل تفجير سفارثي

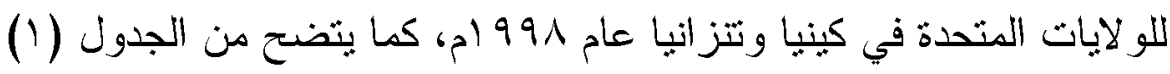
جدول (1) حجم اعداد الضحايا و القتلى و الجرحى في التفجيرات ضد السفارات الأمريكية ببعض دول الإقليم

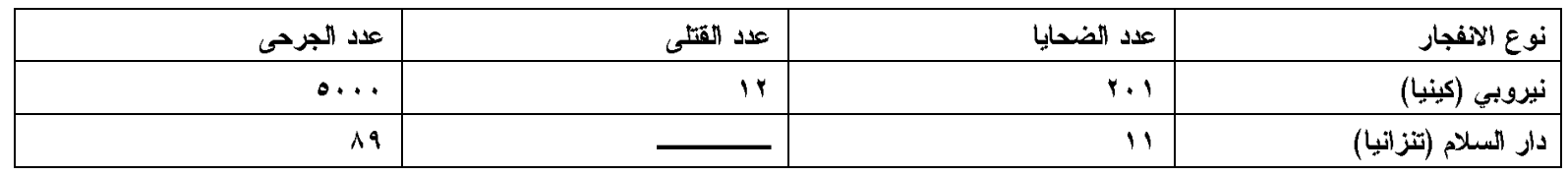

Source: 1- African Devalopment Report,2009

\section{2- African Strategic Report,2011.}


قام الرئيس كلينتون بثمير مصنع لإتثاج الأدوية في السودان اعثقاداً منه بأنه يقوم بتصنيع أسلحة كيميائية وأدانت إدارة كلينتون السودان بانئرن بالعدوان.

\section{ثانياً: المساعدات الاقتصادية:}

مع اكتثاف النفط وتدققه في بعض دول حوض النيل واتخذت مبادرة "جورج بوش" الأبن النفط

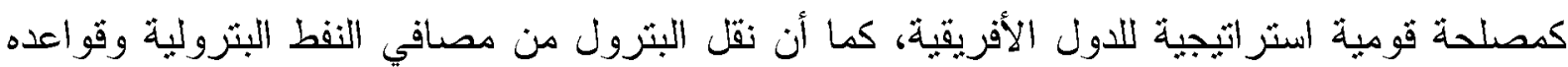
في الو لايات المنحدة الأمريكية يجنبها مخاطر النقل عبر قناة السويس والثران لثرق الأوسط.

وأعلن الرئيس "جورج بوش" عن إيجاد حساب نحدي الألفية The millennium challenge account

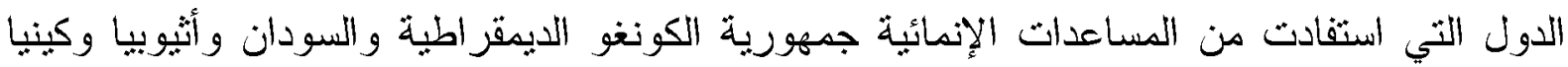

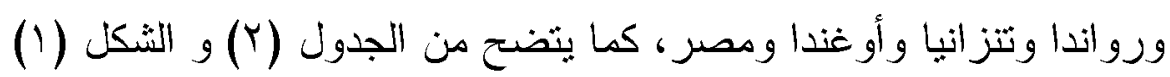

جدول (r ) المساعدات الأمريكية بغرض التنمية لبعض دول حوض الثيل بين عامي (1991 ـ

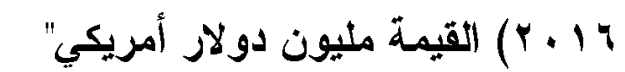

\begin{tabular}{|c|c|c|c|c|c|c|c|c|c|}
\hline الإجمالي & مصر & رو اندا & السودان & تنز انيا & أُو غندا & أريتريا & أَثيو بيا & كينيا & السنة \\
\hline 1 1r..9 & - & $\cdot . \Lambda$ & - & 19.8 & $\leq \Sigma . \wedge$ & 11.5 & $\leq 4.9$ & 19.0 & 1991 \\
\hline $109 . r$ & - & $1 \leq . \wedge$ & - & Yr & $\leq 9.1$ & $1 . r$ & $\leq Y . V$ & $r . .0$ & 1999 \\
\hline 1179 & $1 \ldots r$ & 17.1 & - & YT.A & $\leq 9$ & $\wedge . \wedge$ & rq.V & H.z & $r \ldots$ \\
\hline$\| \wedge \Lambda . V$ & $\ldots r r$ & $1 \leq . Y$ & 19.0 & YI. & $\leq 9.9$ & 1.1 & $\leq . .7$ & I. & $r . .1$ \\
\hline rYo9.V & $r \ldots r$ & 11.0 & 11.1 & $Y \leq . \Lambda$ & 09.1 & $1 . .9$ & $\leq r . r$ & 91.1 & $r \ldots r$ \\
\hline YVTE.Y & Yo... & YY.T & 11.9 & PV.A & 7 (N. & 10.0 & $0 . .5$ & $01 . r$ & $r \ldots r$ \\
\hline r & $r \ldots r$ & 19.4 & $71 . \Lambda$ & $r . . o$ & $7 \leq . Y$ & 7.8 & or & $\leq 7.9$ & $r . . \Sigma$ \\
\hline$r \leq 97 . r$ & YYIO & 11.0 & 11 & YI & $0 \leqslant . V$ & 7.5 & $0 \leq . V$ & $\leq \leq .1$ & $r . .0$ \\
\hline YHAE.E & 1110 & IY.A & 19 & $r . .9$ & $\leq 1.7$ & - & $7 . .0$ & $r \leq .7$ & $r . .7$ \\
\hline YYYI.A & $r \ldots r$ & 11.8 & $9 . . \leqslant$ & $r 9.9$ & $\leq Y . \Sigma$ & - & 01.7 & ro. 7 & $r \cdot . V$ \\
\hline Y & $10 \ldots$ & YV.V & 17. & $r \cdot v . q$ & $r+1 . \Lambda$ & 11.8 & Or.o & rr... r & $r+1$. \\
\hline$r . \leq 9.7$ & $\ldots 1$ & $19 \mathrm{~V}$ & .18. & $\Delta \wedge \Lambda$ & $\leq \wedge q$ & $r \leq . \wedge$ & - & $O \Lambda$. & $r+1 \leq$ \\
\hline$r . \leq 1.7$ & r. & $Y .0 . Y$ & $+. T+1$ & ors.o & $\leqslant r \wedge .0$ & rq.7 & - & THY.O & 9.17 \\
\hline
\end{tabular}

Source :J. Micheal Williams, Rheteric and Reality, US-African relation since 9/11; Research - Cituation, p 99_63 index html ، 2016. 


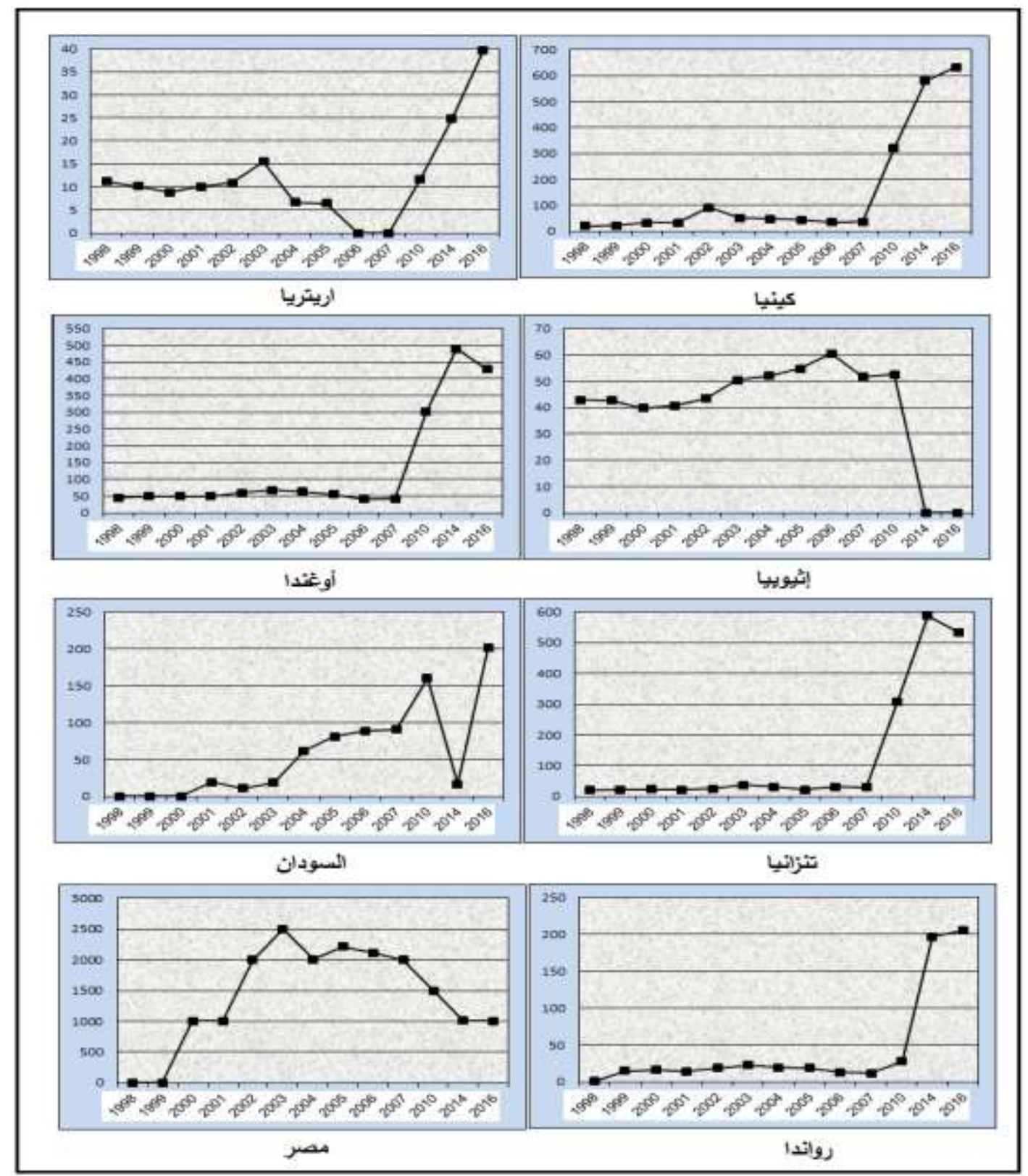

- نظراً لأهمية دول الإقليم للو لايات المتحدة الامريكية فقد شهدت زيادات مالية بغرض التتمية بها

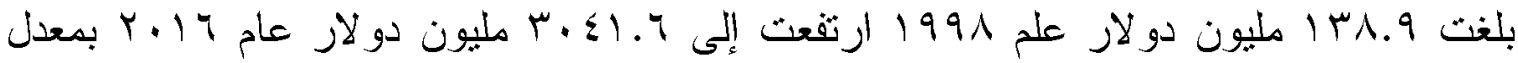

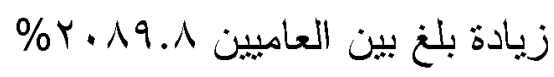

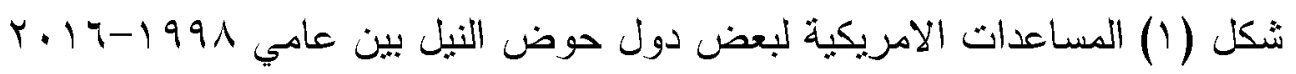

- حازت مصر على النصبب الأكبر من مساعداث التتمبة لدول حوض النيل بقيمة س. أبيار دولار

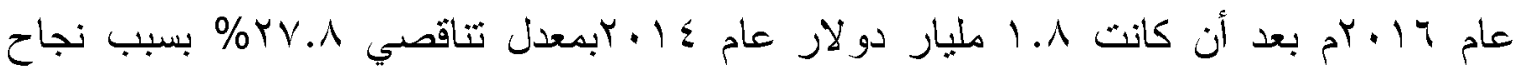
مصر في معدلات التتمية الخاصة بها، مما جعل الأمريكان يقللون قيمة معونتهم لمصر و إن شهدت زيادة عن عام . . . ب بلغت ا. . . \% بين العامين. 
- جاءت كينيا في المرثبة الثانية بعد مصر في حجم المساعدات الأمريكية بنحو ه.بrات مليون دو لار

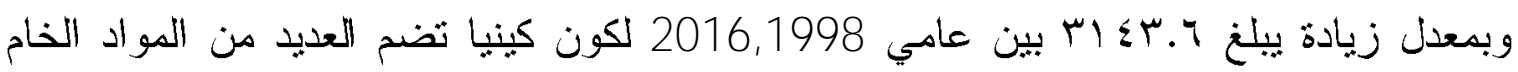

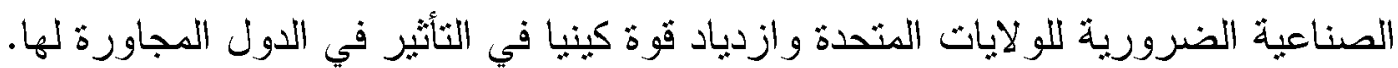
- احتلت ثنزانيا وأوغندا المرتبة الثالثة والرابعة في حجم المساعدات الأمريكية لوفرة المواد الخام

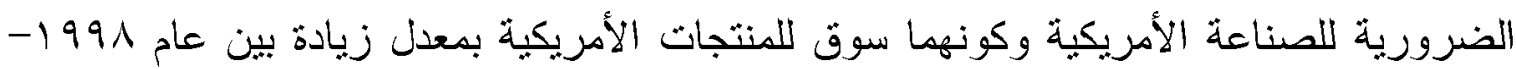

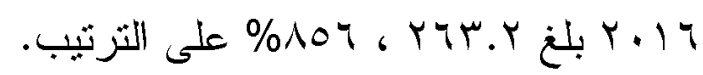
- ارتفعت مساعدات التتمية الأمريكية للسودان بمعدل زيادة بلغ ب؟بح \% رغم كون السودان دولة

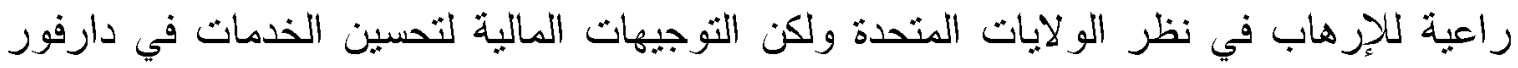

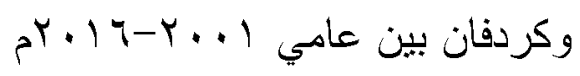

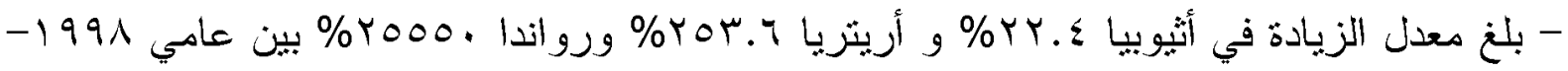
T1.r حجم مساعدات الولايات المتحدة لتلك الدول، ويمكن تفسير انخفاض حجم المساعدات الأمريكية لأثيوبيا لاتجاهها إلى الصين والاتحاد السوفيتي في علاقتها التجارية ومساعداتهما

\section{الاقتصادية.}

المحور الثاني : العوامل الجغرافية المؤثرة في العلاقات بين الولايات المتحدة و دول حوض النيل أسهمت عوامل جغرافية عدة في التنخل الأمريكي في منطقة حوض النيل منها ما تتمتع به من مميزات نسبية بحكم الموقع الجغرافي و الإستراتيجي و توافر الموارد الإستراتيجية من بثرول و غاز طييعي ذات الأهمبة للطافة الأمريكبة بجانب إثراف الإقليم على المر ات المائية الهامة.

\section{أولاً العوامل الطبيعية}

و تثمل الموقع الجغرافي والثروات الطبيعيه والمعادن والثروه الغابيه و العلاقات المكانية ومحاوله الو لايات المتحده الهيينه و السبطره على الموارد الطبيعبه لدول الاقليج وتشمل

$$
\text { 1- الموقع الجغر افي و العلاقات المكانيه : }
$$

تعد منطقه حوض النيل من اعظم اقليم العالم من حيث الاهميه الاستراتيجيه وذلك لما تمئله هذه المنطقه من موقع منميز يجعلها مع دوله الصومال وجيبوثي تسبطر على اهم الممرات المائيه الحيويه التي تربط بين الشرق والغرب باكثر الطرق بالأضافة إلى قربها من شبه الجزيره العربيه والخليج العربي الغنيين بالنفط فضلا عن كونها نمثل المدخلين الثرقي و الثمالي لافريقيا ، و إثر افها المباثُر 
على الملاحه الدوليه بين المحبط الهندي و البحرين الاحمر والمثوسط بجانب اهميثها في اطار الاسنر اتنجيه الدوليه للدول ذات النفوذ العالمي

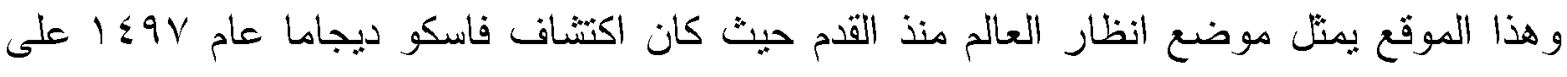
سواحل المحبط الهندي مما لفت انظار العالم الى الموقع المتمبز فقامت القوي الامبرياليه بعقد اتفاقات

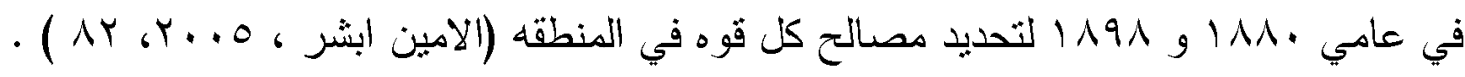
احتلت بريطانيا كل من كينيا والسودان ومصر، احتلت ايطاليا اثيوبيا واريتزيا لاهميه الموقع الاستراتيجي ظهر دور الاتحاد السوفيتي السابق حين اثار نار الفنته بين الصومال وجيبوتي واثيوبيا في السنبنات و السبعينات من القرن الماضي وظهر دوره في انحبازه لاثيو بيا في حرب تحرير أوجادين في فبراير $19 V V$ و انتهت بانتصار اثيوبيا، وبنهايه الاتحاد السوفيتي استحوذت الولايات المتحده على زمام المبادره من خلال استخدام الدعاوي الانسانيه او فض المنازعات واحيانا مبادرات نسويه لبعض المشكلات ولم يكن الدور الأمريكي واضح المعالم لانها كانت تتنظر لحين تصفيه الموقف للحصول على بدائل محدده واتخذت مسلك محاربه كل القوى الأسلاميه بإدعاء علاقتها بتتظيم القاعده و قامت بقصف مو اقع الجامعات الاسلامبه لاضعافها. قامت الولايات المتحده الامريكيه بإنثاء قاعده عسكريه قباله الجزء الثرقي من افريقبا لمراقبه الاوضاع ثم هناك الدور الاسرائبلي الدكمل للدور الامريكي باهتمادها بمنطقه البحر الاحمر وشرق افريقيا باعتباره منفسا نطل من خلاله للعالم للتخفيف العزلة الاقلبميه الني نعاني منها (السبد البشري

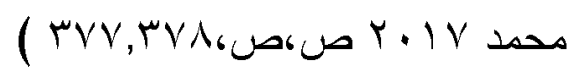

واهندت اسرائيل بإيجاز من الولايات المتحده بالبحر الاحمر من خلال اطماعها بالتوسع جنوبا و الاهنمام بشرق افريقيا واسيا للخروج من الحصار العربي عليها ولذلك وطدت علاقتها مع كينيا و اثيو بيا واريثريا كي تضمن حريه الملاحه والتجاره ومر اقبه تحركات الدول العربيه كالسودان و اليمن و السعوديه .

لا ننسى الدور الفرنسي في منطقه حوض النيل واحتفاظها بقاعده عسكرية وهناك دول اوروبيه منل ابطاليا و المانبا واسبانيا تسعى على فرض النفوذ و الهيمنه بمنطقه حوض النيل اضافه الى تطلع بعض الدول المنطقه للعب دورٍ مؤثرٍ في الافلمج و نخص منها اثثوبيا التي تستتد الى عقها المساحى 
و السكاني وتعاطف الدول الغربيه معها كونها نثثل المسيحيه في القاره الافريقيه ، وارينريا الثي تثطلع الى دور الزعامه استناداً اللى موقعها الاستز اتيجي وحماسها الثوري الذي يمثل قوه الدفع السباسي لها

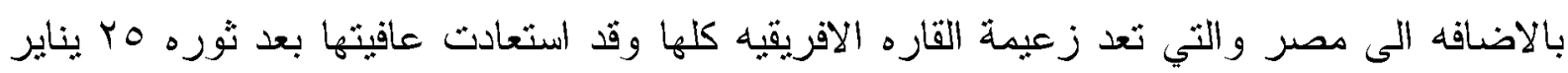

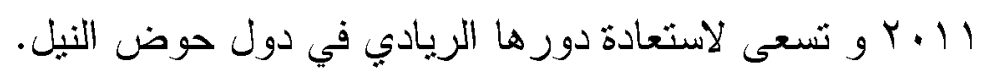

تلعب الولايات المنحده الامريكيه دورين رئيسين : اولهما محاصره السياستين المصريه السودانيه في المحيط الاقليمي واعاده رسم خريطه النوازن الاقليمي بمنطقه حوض النبل مع العمل على اعاده رسم الخريطه الجيوبولتيكية للسودان من خلال اتباع سياسه خارجيه ثهدف الى خلق سودان جديد موالي للولايات المتحده الامريكيه ويرتبط بالهصالح الامريكية و دعم الوجود الاسرائيلي في المنطقه وقد اهندت الولايات المتحده الامريكيه بقضايا المباه باعنبارها ورق ضغط و اعاده نزتيب القوه بين

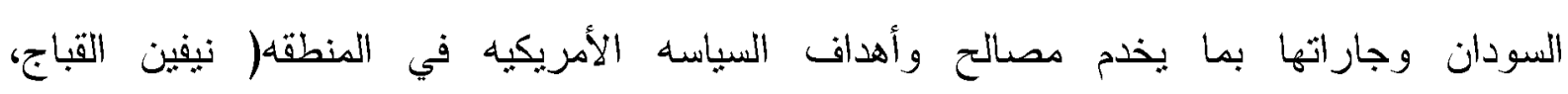

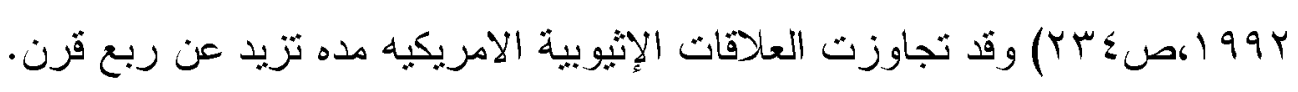

\section{اولا المناطق الاستر اتيجيه بدول اقليم حوض النيل}

تضم منطقه حوض النيل عدد إحدى عشر دوله يربطها ببعض نهر النيل والذي يبلغ طوله . . TIT كيلو مثر ويقطع نحو سب درجه عرض من به درجه جنوب الى اس متمالا و نطل بعض دول

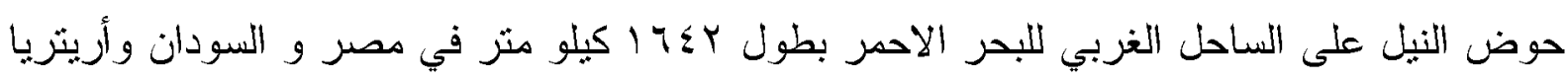
و نطل مصر على البحر المنوسط و نشرف كينبا و تنزانيا على المحيط الهندي فاكتسب هذا الموقع

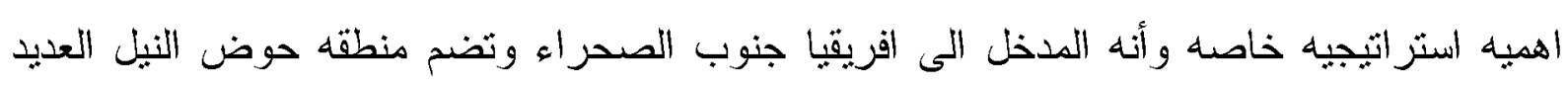
من المناطق الاسترانيجية هى: أ- - منطقه القرن الافريقي :

القرن الافريقي وذلك الراس النائي من البابس ناطحا للبحر ،على شكل قرن بشبه الماء شطرين

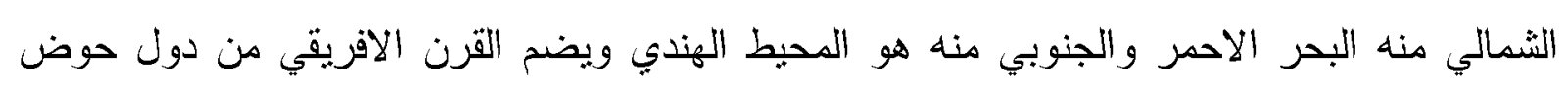

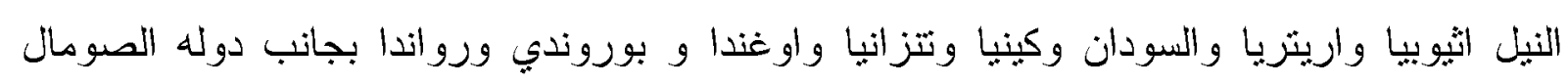

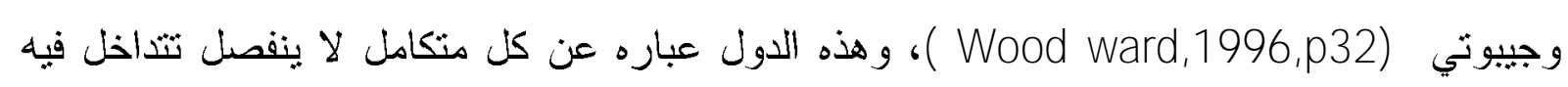

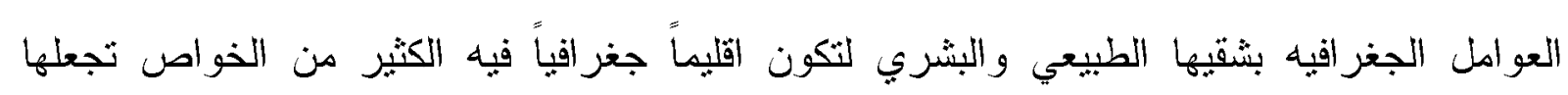


الاقرب لبعضها البعض و تثميز المنطقه بالامتدادات المكانبه وتداخل الاقليات بصوره كييره اضافه التداخل الثقافات بين السكان ونمط الحباه الاقتصاديه السائده بين هذه الدول مما نجم عنه نشابه مشكلات

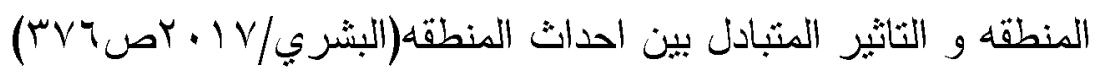
وتحرص الو لايات الدتحده الامريكيه الى التو اجد في المنطقه من خلال الاهتمام بالموقع الاستراتيجي

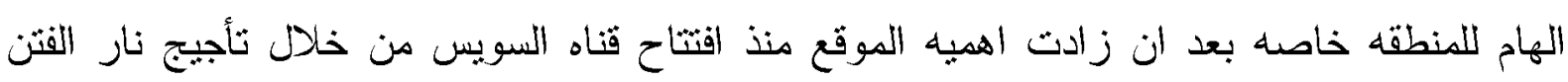
والحروب بين دول المنطقه خاصه بين القوميات المتناحره في اثيوبيا والصومال وكينبا اوبمساعده الانقلابات العسكريه وللقاعدة العسكريه الامريكبه في جيبوتي هى الاكبر في المنطقه وتضم ... .ـ فردا ما بين عسكري ومدني بالاضافه الى قواعد عسكرية سرية في كينيا وتضم قاعدتين مومباسا ونابلو كا البحريثان، في اثيوييا قاعده اربامينشي الجويه للاسنطلاعات ومهمنها الاسنطلاع و التجس. ب-البحر و الخلجان تشبطر منطقه حوض النيل على البحر الاحمر والجزء الثمالي الثرقي من البحر المتوسطو مضيق باب المندب الذي بربط المنطقه بشبه الجزيره العربيه وبالثالي تثمثل اهميه موقع تلك البحار و الخلجان بانها ثاعده انطلاقه جغر افيه استراتيجيه الى مناطق جغر افيه اخرى من العالم خاصده مناطق جنوب

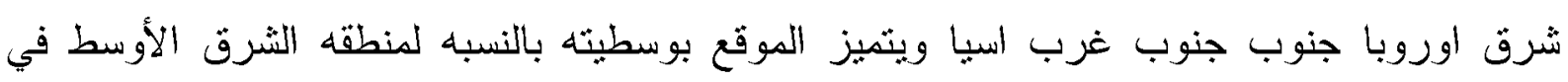

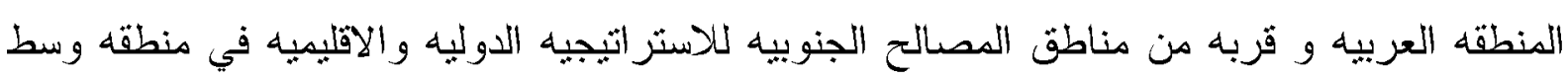
اسيا عبر بحر قزوين و منطقه جنوب و جنوب غرب اسيا عبر (المحيط الهندي) و منطقه الخليج و منطقه جنوب شرق اوروبا (عبر البحر المنوسط ). تحرص الو لايات المتحده على الحفاظ على قو اعدها العسكريه بمنطقه والوقوف امام طموحات ايران وثركيا والصين وروسيا في منطقه البحر الاحمر وتحرص أيضاً على حريه الملاحه في المنطقه التي لإني

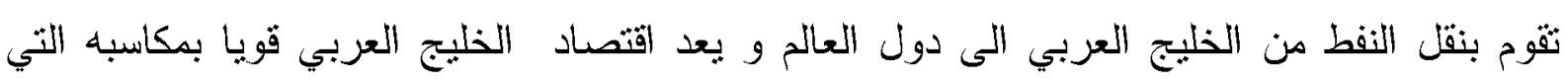
بلغت 1. نرليون دولار ويمثل المرثبه الثالثه عثر بين اكبر اقتصاديات العالم بلغ نصيب السعوديه §

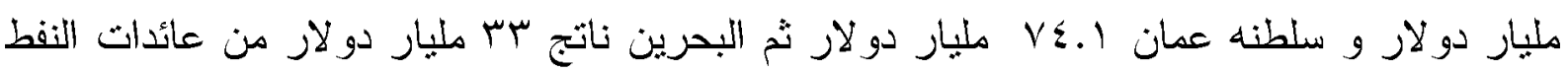

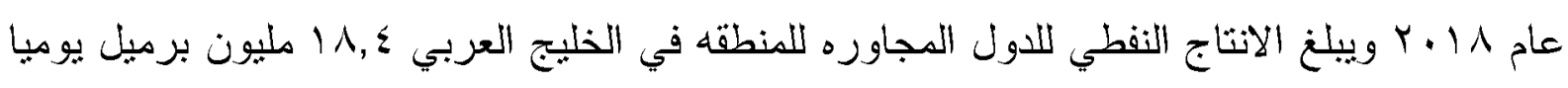

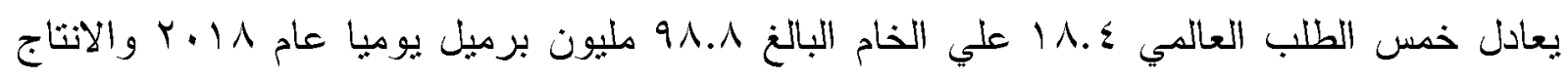


السعودي بعطينا 11\% من الطلب العالمي على النفط بانتاج بس.. 1 مليون وسז من . .1 برميل

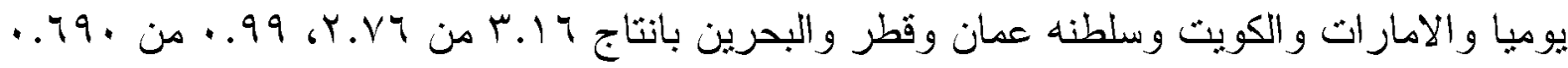

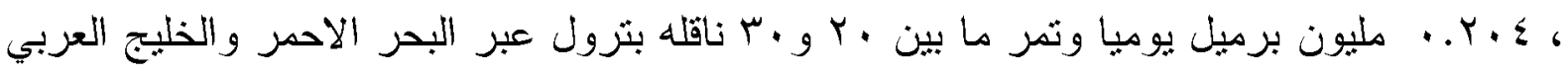

يومبا

ج- مضيق باب المندب

تمثل اهميثه في انه يصل البحر الاحمر وخليج عدن والمحبط الهندي و عرضه نحو Y كيلو مثر المسافه بين ضفتي المضيق في • ب كيلومثر من راس مانهالى في اسبا الى راس سيان على الساحل الافريقي وتنيكل الحركه التجاريه عبر المضيق نسبه ، (\% من الملاحة العالمية ويمر منه بوميا ؛ ملايين برميل من الخام الاسود يوميا( •r \% من النفط العالمي) يمنل ه. \% من حاملات النفط

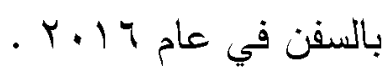
من بعد هجمات سبتمبر تفرض القوات البحريه الامريكيه هينتها بالمضيق لمحاربه القرصنه في المنطقه. د- قناه السويس عباره عن ممر مائي اصطناعي يصل بين البحرين الاحمر والمتوسط يثميز بصلاحيثه لمرور كافه

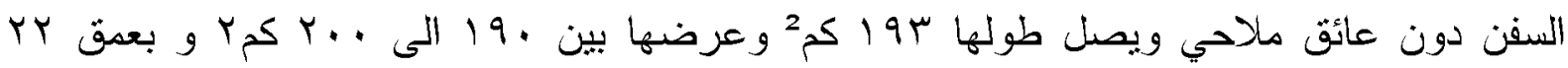

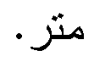

شكل الموقع الجغرافي للقناة بعدا استرانيجيا لمصر في قلب منطقه الثرق الاوسط وزاد من اهميتها الاستراتيجيه في منطقه تُبه الجزيره العربيه حثى مضيق باب المندب مما جعل مصر محط اطماع

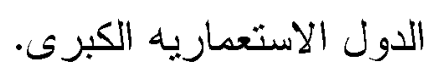

مع اهتمام مصر بزيادة سعه القناه ثم حفر قناه ملاحبه بطول بوكم² بغرض تشهيل عبور السفن باتجاهين و نحويل المنطقه من مجرد معبر مائى اللى معبر مائي لوجيستى عالمى لامداد و تموين النقل

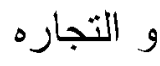


للقناة دور هام في مجال تصدير النفط الخام من الخليج العربي إلي الأسواق الأوروبية والولايات المتحدة الأمريكية مما أعطاها إستراتيجية وأهية حيوية للاقتصاد العالمي. يمر من قناة السويس • 1 \% من تجارة العالم و با \% من نجارة الولايات المتحدة الأمريكية ما يمانل §Y\% من تجارة الحاويات بالعالم ومايعادل ب o \% من التجارة بين الولايات المتحدة وآسيا. ولأهمية القناة عالميا ثبذل الولايات المتحدة جهودها من أجل الاستحواذ علي قناة السويس بصورة مباشرة أو غبر مبانشرة عبر تدخلها مع دول حوض النبل بغرض إحاطة مصر عسكريا أو من خلال مساعدثها الاقتصادية و العسكرية الثي تقمها لمصر.

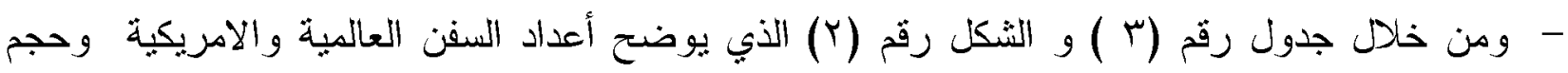

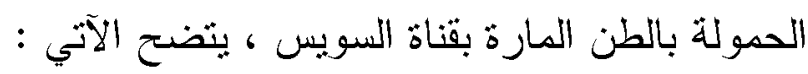
- بلغت جملة السفن الأمريكية المارة بقناة السويس 99 . 19 سفينة نمثل 7.

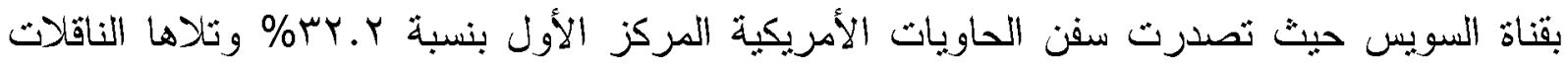

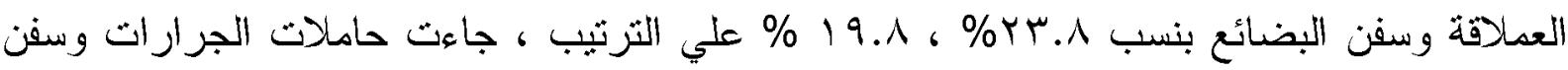

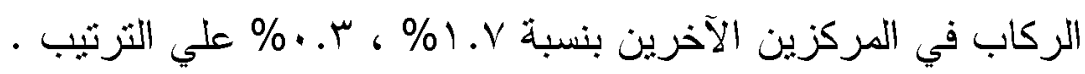

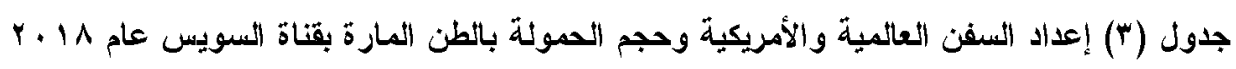

\begin{tabular}{|c|c|c|c|c|c|c|c|c|c|c|}
\hline \multicolumn{3}{|c|}{ حمولة الو لايات المتحدة } & \multicolumn{2}{|c|}{ الحمولة المارة العالمبة } & \multicolumn{3}{|c|}{ سفن الو لايات المنحدة } & \multicolumn{2}{|c|}{ انواع السفن } & \multirow{2}{*}{ النوع } \\
\hline $\begin{array}{r}\text { \% } \\
\text { العالم }\end{array}$ & $\%$ & ألف طن & $\begin{array}{r}\text { \% } \\
\text { العالم }\end{array}$ & ألَف طن & \% $\quad$ من & $\%$ & عدد & $\%$ & عدد & \\
\hline$r \wedge, 7$ & $1 \leqslant, \Lambda$ & $\wedge$ & 10,7 & $r \cdot, V$ & $\varepsilon, V$ & $r r, \Lambda$ & $19 Y 5$ & Y & $\leq Y V Y$ & ناقلات \\
\hline$\leq 4,9$ & 0,7 & $r$ & $\leq \cdot 1$ & $7 . \leqslant$. & $7, £$ & $r q, r$ & $r \cdot r$ & $r, \wedge$ & 799 & غفن طبيعي \\
\hline$\leq V, 0$ & 11,1 & 7 & 14.1 & 17. & $\leq 1,9$ & 19,1 & $17 . r$ & rI & rAY & سفن بضائع \\
\hline$r \Lambda, 0$ & $\cdot, 7$ & $\cdot, r$ & 1. & $1 . r$. & $r q, \varepsilon$ & 7,0 & ors & $v, r$ & irr. & البضائع \\
\hline$\leq \cdot, r$ & $r v, 1$ & $r$. & $r v .0$ & $\leqslant q, v$ & $\leq 0, \wedge$ & $r r, r$ & rTाr & $r_{1, \Sigma}$ & ov. 7 & الحاويات \\
\hline$\leq r . \Lambda$ & r... & $1 \leq$ & Y E.Y. & Tr.t & $\leq \leqslant, \leqslant$ & $i, v$. & $1 \leq \ldots$ & $1, v$. & Mo & حاملات \\
\hline
\end{tabular}




\begin{tabular}{|c|c|c|c|c|c|c|c|c|c|c|}
\hline$\leqslant 1 . r$ & r.o. & 1.9 & r. . . & $\leq .7$ & rT &.$r$ & rY & .00 & 97 & سفن ركاب \\
\hline$\leq$ & $\cdot v$. & . . & $\cdot . \wedge$. & 1 & $\leq r .9$ & $\leq . V$ & rN & $\leq, \wedge$ & $\wedge \uparrow \wedge$ & النسيار اتلات \\
\hline$r$. &. .7 &.$r$. & $\because v$. & 1 & ro.o & Y.V. & Tr & r.o. & Tr & سفن أخرى \\
\hline$\leq . .7$ & $1 \ldots$ & or. 9 & $1 \ldots$ & ITr.V & $\leq \Sigma .7$ & $1 \ldots$ & 1.99 & $1 \ldots$ & $|\Lambda| V \leq$ & المجموع \\
\hline
\end{tabular}

Source : 1- American chamber of commerce in Egypt , 2018.

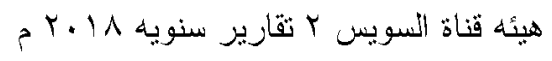

- شاركت الولايات المتحدة بنحو ج ... وبمألف طن من إجمالي الحمولات المارة بقناة السويس والتي تخطت ب. 1 مليار طن ،

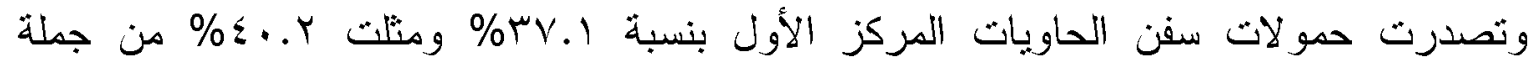
الحمولات المارة بالقناة وتلاها حاملات الجرارات و الناقلات العملاقة بنسب بr\% ، 1.؛ 1\%

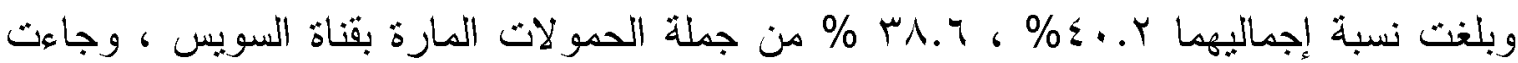

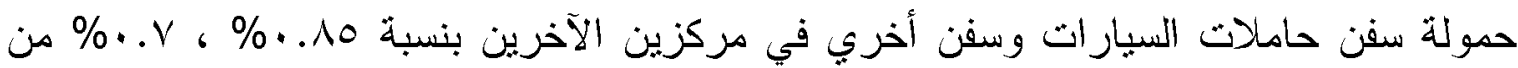
جملة الو لايات المتحدة ، وأن شارك بنسبة ، ؛\% ، . ب\% من جملة الحمو لات لنفس السفن بالعالم

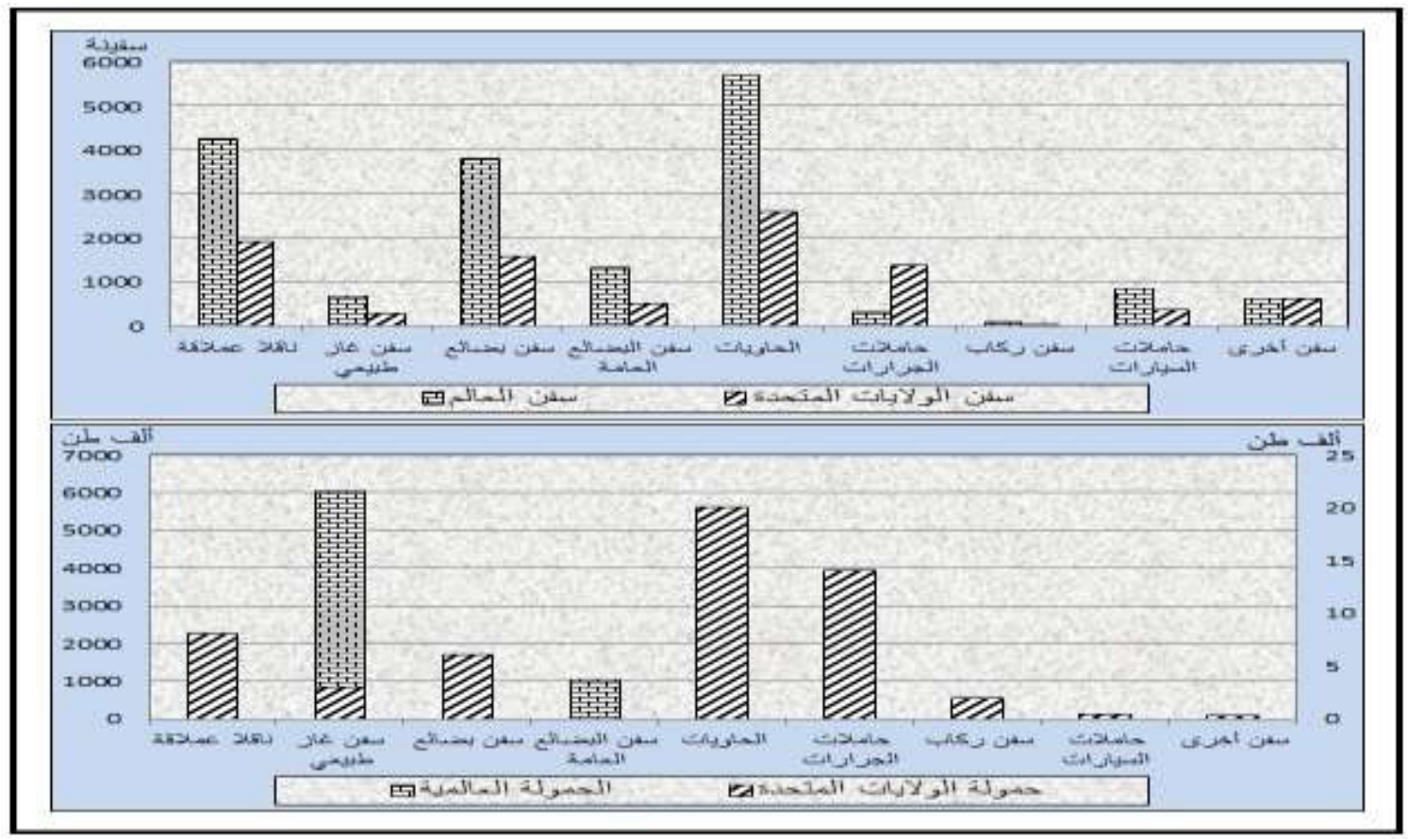

شكل (Y) اعداد السفن العالمبه و الامريكيه و حجم الحموله بالطن الماره بقتاة السويس عام 1 | . Y 


$$
\text { r- الثروات الطبيعيه }
$$

دخلت المنطقه قائمه الأولويات الأمريكيه من زوايا الأمن القومي الأمريكي المنعلق بثرواتها طييعيه من بترول ومعادن وثروة غايية وفيما يلي استعراض الثروات الطبيعيه في دول حوض النيل.

أ_ البترول : يثركز النفط في منطقه غرب افريقيا في نيجيريا وغينيا الاستو ائيه وهناك العديد من الثركات الأمريكيه الثي تمثلك اكبر عدد من الرخص المنداوله للتنقيب عن النفط يرتفع الاتتاج

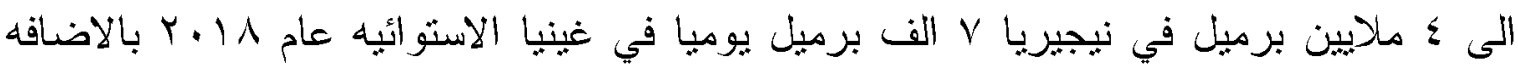
الى انتاج الجابون 10 الف برميل .

أما في منطقه حوض النيل في يثزكز انتاج البثرول في الكونغو الديمقراطيه وجنوب السودان و السودان ومصر • في السنوات الاخيره اهتمت الولايات المثحده الامريكيه بمصادر النفط الافريقي كبديل عن الثرق الأوسط حبث ثوفر افريقيا خمس حاجه الولايات المتحده من النفط من المتوقع ان

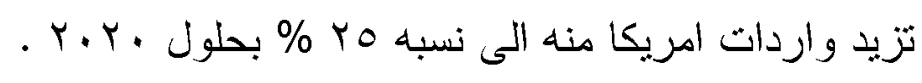

وتزايد احتياجات اللايات المتحده الامريكيه من النفط خلال السنوات الخدس المقبله سيثرتفع

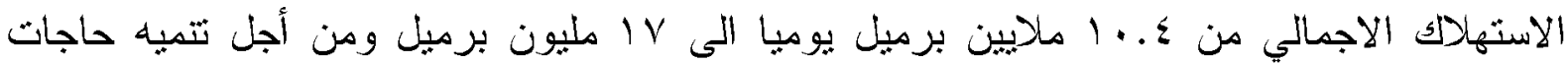
البلاد النفطيه ، نصح ثقرير الاداره الامريكيه ان تزكز على زياده الواردات من حوض ثزوين ومن تهن أفريقيا ودول حوض النيل و أمريكا اللاتينيه.

وفي سبيل الحصول على البترول من حوض النيل قاتث الولايات المنحده الامريكيه بدعم مفاوضات

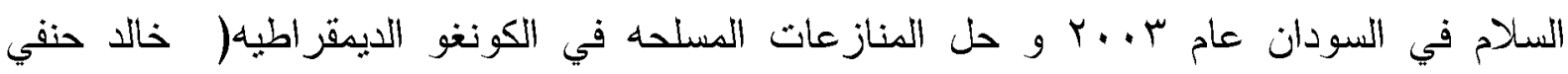
. (r. r...06

وفقا لثركه الطاقه البريطانيه العالمبه مثلت افريقيا بدول حوض النيل ع. ـ (\% من انتاج النفط العالمي

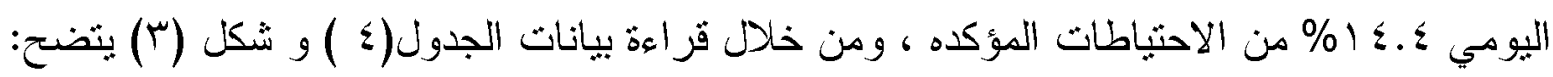

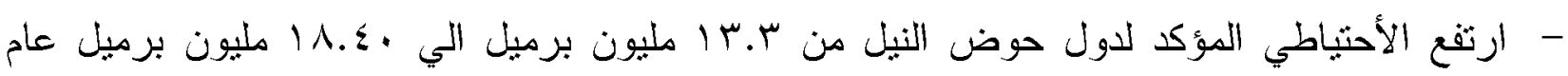

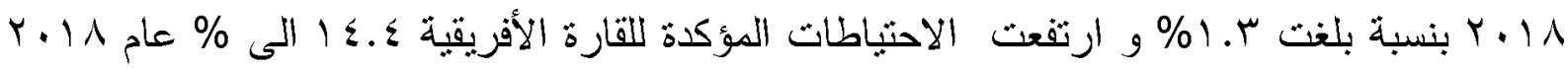

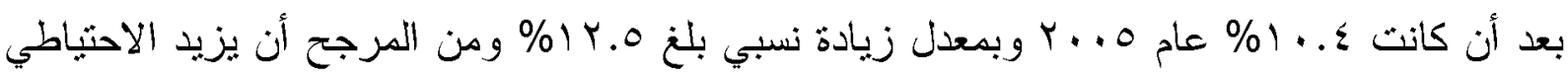


في السنوات القادمة مع استقرار الأمور في القارة الافريقية ، ووجود شركات البثرول العالمية ل اللاسنكشات.

- ما زال الثرق الاوسط في المقدمة بالنسبة للاحتباطي المؤكد للبترول بنسبة فاقت نصف العالم

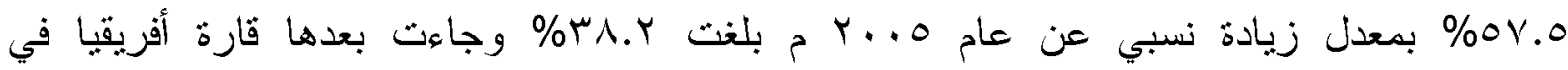

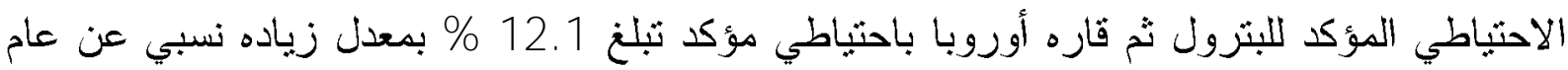

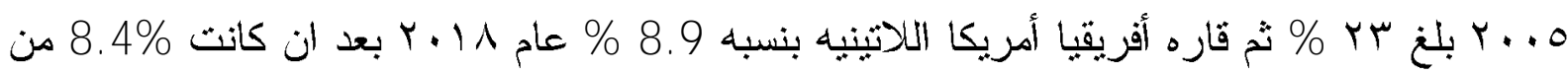

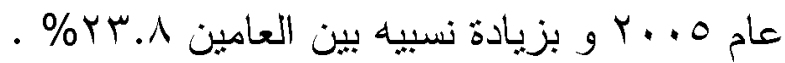

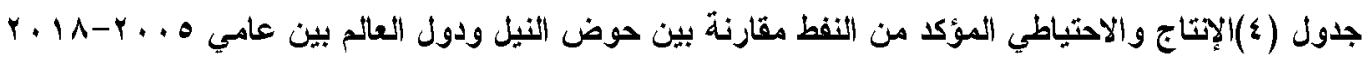

\begin{tabular}{|c|c|c|c|c|c|c|c|c|c|c|}
\hline \multicolumn{5}{|c|}{ الإنتاج اليومي " ألف برميل" } & \multicolumn{6}{|c|}{ الأحتياطيات المؤكدة " مليون برميل" } \\
\hline النسبي & $\%$ & $r \cdot 1 \Lambda$ & $\%$ & $r \ldots o$ & النسبي & $\%$ & $r .1 \Lambda$ & $\%$ & r..o & 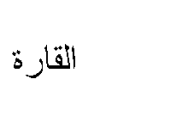 \\
\hline $1 . . \leqslant-$ & $1 . . r$. & $\Lambda . r \cdot r$ & kr.l. & $9 . Y 7 \leqslant$ & $T \leq . r$ & 1 r. & $1 \wedge \leqslant$ & $9 . r$ & $11 \mathrm{r}$ & اففريقيا \\
\hline $1 \leq Y . \wedge$ & $1 . r$ & $1 \ldots$ & $1 \ldots$ & 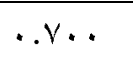 & rA.r & $1 . r$ & i^. $\Sigma$ & 1.1 & ir.r & حوض النيل \\
\hline 0.7 & Yo.r & $r \cdot .7 .7$ & ห५.५ & Y. $\leqslant O V$ & $1 . . \varepsilon$ & ov.o & 1). & 71.1 & 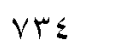 & الشرق الأوسط \\
\hline 18.7 & $11 \ldots$ & 1.910 & $1 . r$ & $V .9 Y \wedge$ & $\mid v .1$ & Y. $\leqslant$ & $\leq 1$ & r. $\varepsilon$ & $\leq 1$ & اسيا \\
\hline$\leq .0$ & $\Lambda . \varepsilon$ & 17.111 & TY.A. & iv.oNr & rr & $\mid r .1$ & $\mid v i$ & 11.7 & 149 & أو أوربا \\
\hline$\therefore v$. & $\Lambda . \varepsilon$ & T.N1Y & $\Lambda . \wedge$. & $7 . V 7 \varepsilon$ & rr.A & 1.9 & Ko & ^. \{ & 1.1 & امريكا الآثتينية \\
\hline rr.o. & rt.t & $1 \wedge .9 . r$ & $1 \wedge . \leq$. & $1 \leq .10$ & $I \leq . V$ & r.r & or & 0.1 & 71 & امريكا الشمالية \\
\hline 0.9 & $1 \ldots$ & $\wedge ! . \leq 1$ & $1 \ldots$ & $\vee \neg . \wedge \Sigma$ & IV.Y & $1 \ldots$ & $1 \leq . \wedge . \leqslant$ & $1 \ldots$ & $M \cdot I . r$ & العالم ب الم \\
\hline
\end{tabular}

Source:- Bp Global "Statistical Review of world energy , J une , 2005.

-International energy statistics , 2018. 


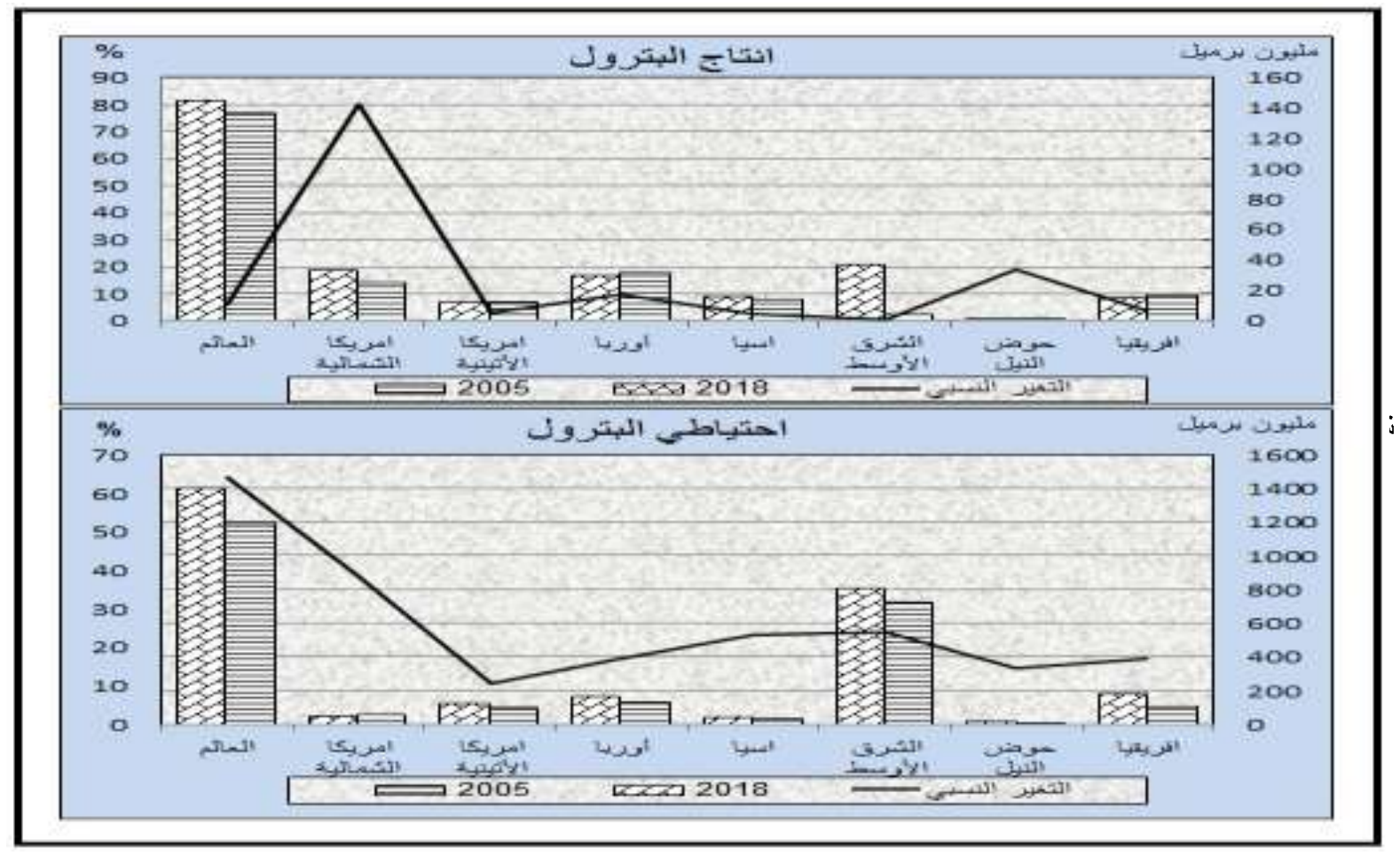

أنخفض الاحتباطي المؤكد من البثرول في امريكا الثماليه من 1.ـ\% الى ؟.ب\% بمعدل نقصان

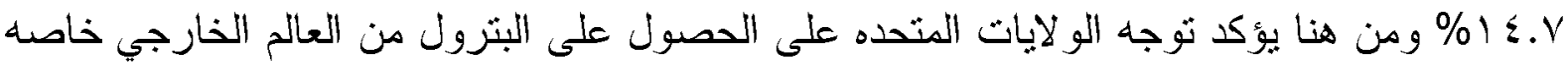
| افريقبا و الثنرق الاوسط

الولايات المتحده لديها احتياطي من النفط الخام يقدر بالنسبه ؟\% من الاحتباطي العالمي ونستورد

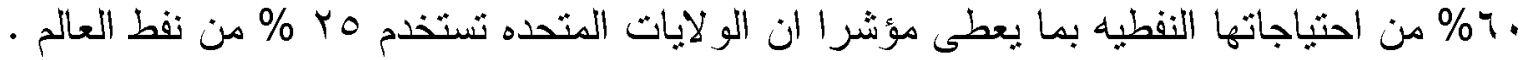

\section{- - استبراد الولايات المتحده من البترول} من قراءة الجدول(0) و الثنكل(r) تتضح الحقائق الاتيه : - جاءت افريقيا في المرتبه الثانبه من واردات الولايات المندده الامريكيه بنسبه ا._r\% بعد قاره

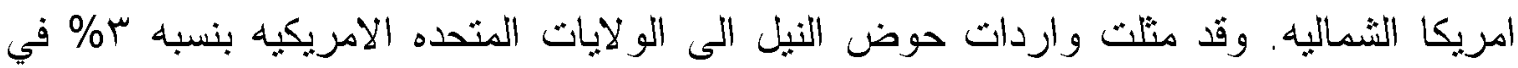

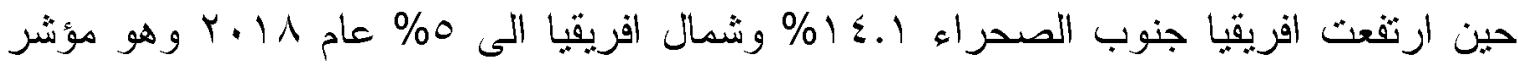
جيد يعطي الامل لنشركات النفط العالمبه بالاتجاه الى دول القارة للبحث عن اكتثافات جديده من

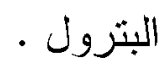
- - ارتفعت صـادرات حوض النيل من البترول الى الولايات المتحده الامريكيه 100: الف الف

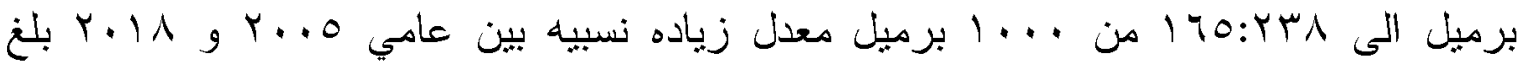


r.r\% ومن هنا يتضح اهمبه النواجد الامريكي في المنطقه حيث انها مبشره بالمزيد من

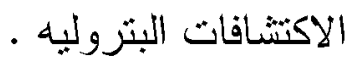

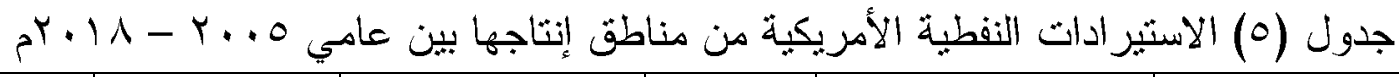

\begin{tabular}{|c|c|c|c|c|c|}
\hline نسبة التغيير & $\%$ & $r .11$ & $\%$ & الإنتاج (ألف برميل) & المنطقة \\
\hline 11.9 & 0.1 & YA..Iץ. & 。 & Yo... $\leqslant 1$. & شمال أفريقيا \\
\hline..$\%$ & r... & 170.441 & $r$ & $100 . \leqslant \wedge 1$ & دول حوض النبل \\
\hline-.11 & 1 | & A....14r & $1 \leq .1$ & VY...1A. & دول جنوب الصحراء \\
\hline-.11 & r. P.O & $1 . r \leqslant 0.0 Y T$ & Y. & Wrq.VA & الجملة \\
\hline 17.9 & Y.Y & Irrele. & Y. & $1 . \leqslant \leq \leqslant$. & آسبا \\
\hline $1 . .1$ & ir & 17011. & 11.1 & $9 . .174$ & أوربا \\
\hline $11 . r$ & $r \ldots v$ & $-1.10 \ldots$. & 19.9 & 1..10..rt & أمريكا اللاهينية \\
\hline Y.६ & 10.9 & AVG.IVT & 17.1 & NONIAY & الثرق الأوسط \\
\hline ఛ.. & ห... & 1 I\&Aץ. & $r v . r$ & 1. & أمريكا الثمائية \\
\hline 1.9 & 1.9 & $0.05 \% .914$ & 1... & $0 . . \wedge 9.404$ & الإجمالي \\
\hline
\end{tabular}

Source :1- Energy Information Administration, "U.S Importers origin, 2006,2018.

1- اعتمدت الولايات المنحده على استيراد النفط من الثرق الاوسط 0.9 1\% امريكا اللاتينيه

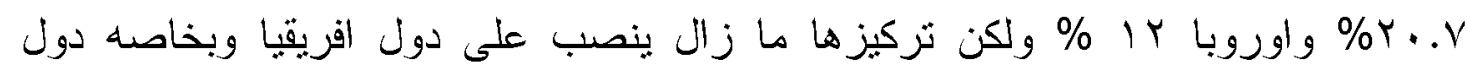

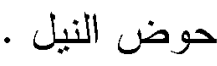

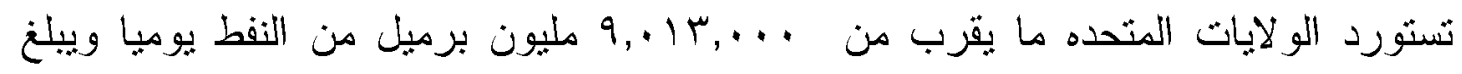

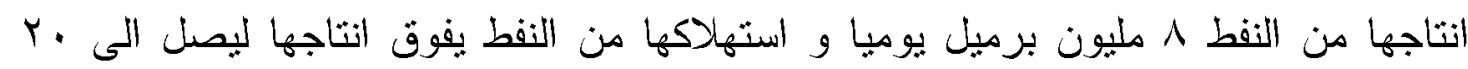
مليون برميل فمن المؤكد ان الولايات المتحده في حاجة إلى المزيد إلى النفط العالمي .

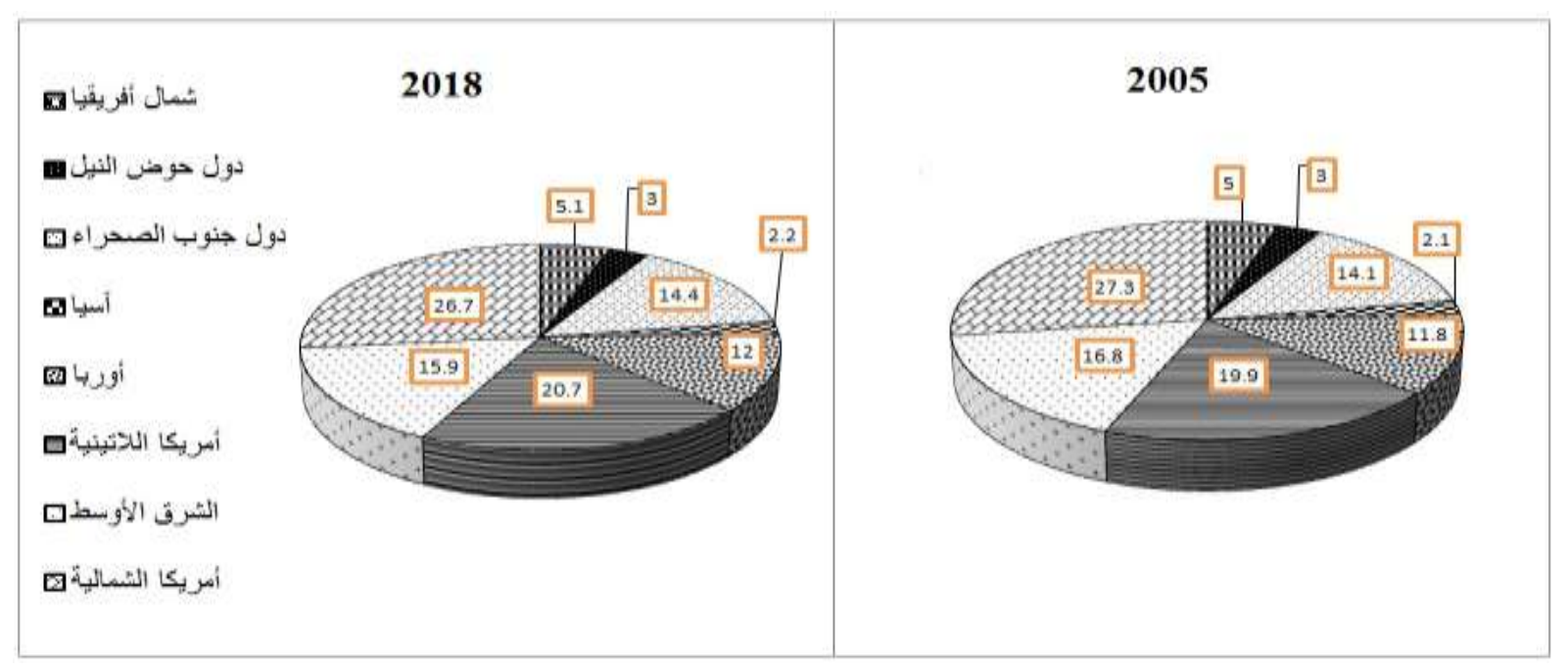

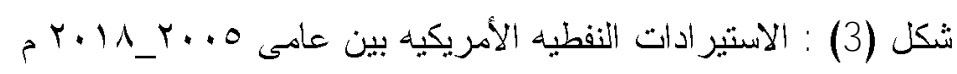




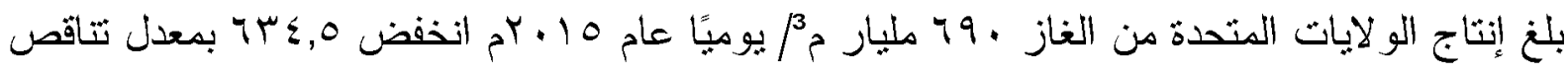

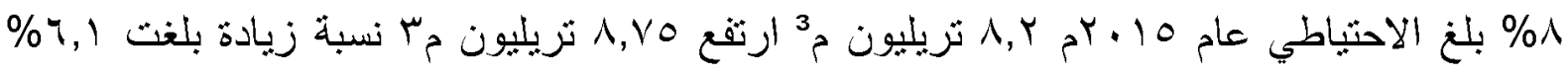

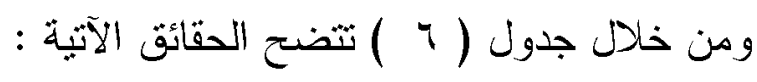

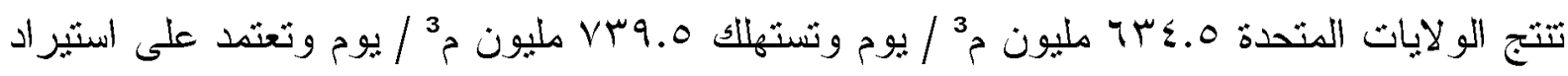

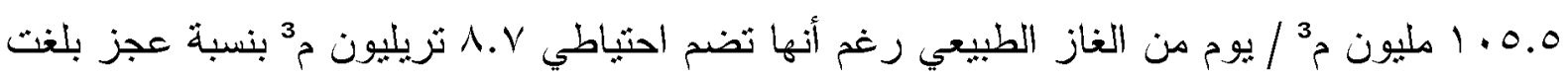

تحرص الو لايات المتحده على استيراد الغاز من دول العالم خاصه كندا في قاره امريكا الثماليه أو من

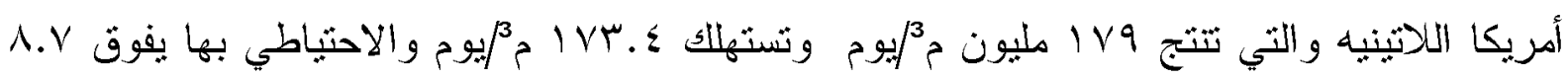

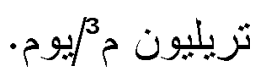

جدول (T) معدلات طلب و إنتاج الغاز الطبيعي عام Y Y. Y في العالم مقارنة بدول حوض النيل.

\begin{tabular}{|c|c|c|c|c|}
\hline تريئيون مثبياطي & مليون / مجئ مجز & مليون مَّ/ الاستهلك & مليون مب الإنتاج & المنطقة \\
\hline$\Lambda . \vee$ & 1.0 & VTq,o & $\nabla r \leqslant, 0$ & اللولايات المتحدة \\
\hline $1 \cdot, 9$ & $\wedge, \vee$ & $9 \leqslant Y, \wedge$ & 901,0 & أمريكا الشمالية \\
\hline$r r$ & $\{\wedge, 9$ & $11 \cdot 8, r$ & $1 . \Delta v, \varepsilon$ & أوربا \\
\hline$\vee \wedge, \wedge$ & $1 Y T, \varepsilon$ & orq,o & १०१, १ & الشرق الاوسط \\
\hline$\uparrow, \wedge$ & $v$. & $\Delta \%$ & $\leq 9$. & حوض النيل \\
\hline$i r, \Lambda$ & AT, r. & $1 \leqslant 1, \wedge$ & TYO & أفريقيا \\
\hline $19, r$ & $19 r$ & Vฯq, & $7 \cdot v, 0$ & اسبا \\
\hline 194.8 & $1 \cdot v$ & $\{r q$ & $\{1 \wedge \leqslant . \wedge$ & الإجمالي \\
\hline
\end{tabular}

Source:- Statistical review of world enyrgy, $67^{\text {th }}$ edition, J une,2018. 


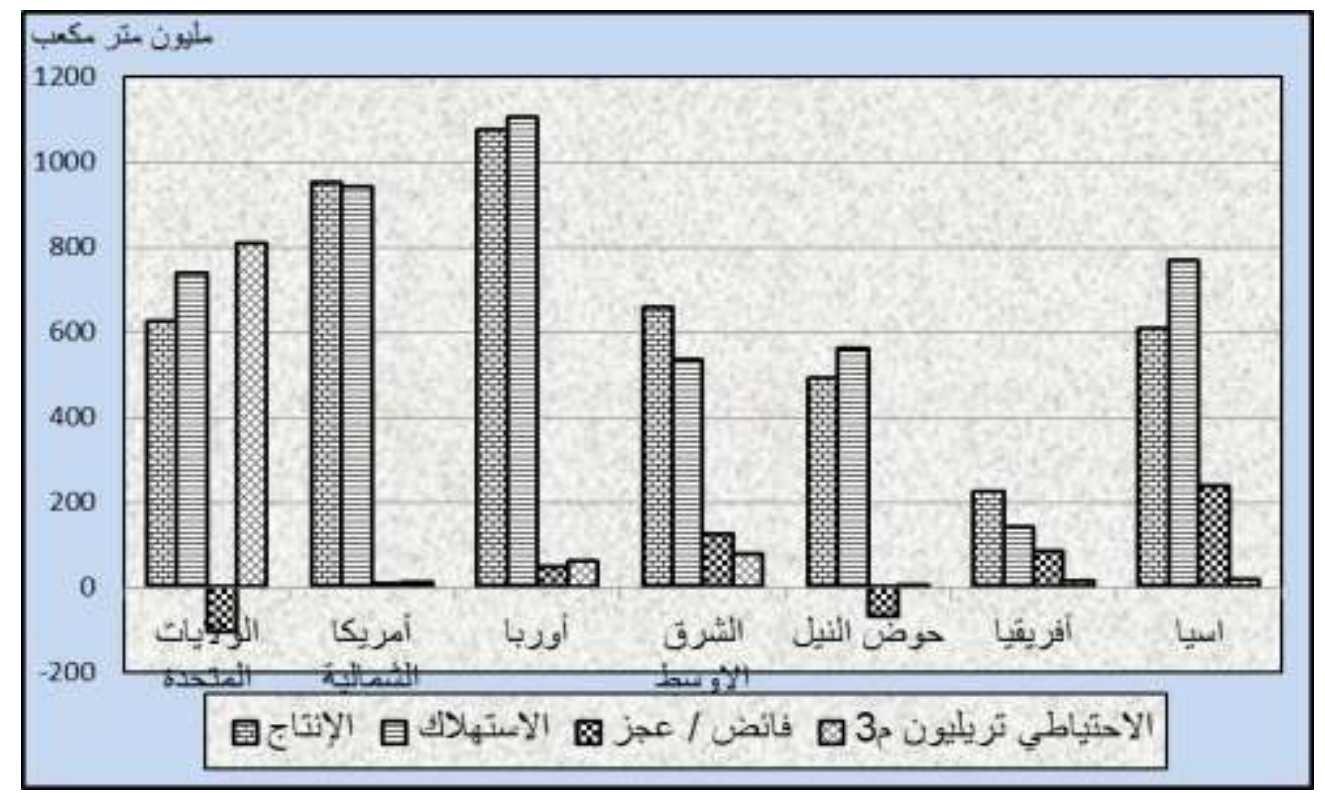

شكل (؛) معدلات طلب و إنتاج الغاز الطبيعي عام Y. Y ب في العالم مقارنة بدول حوض النيل.

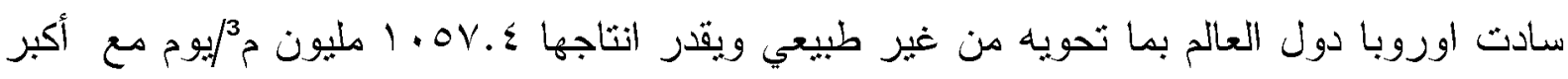
احتباطي با تريليون م²/يوم.

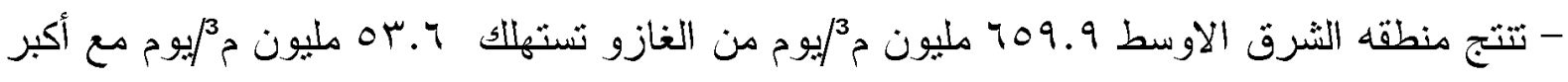

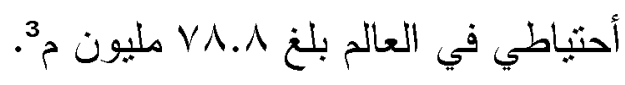

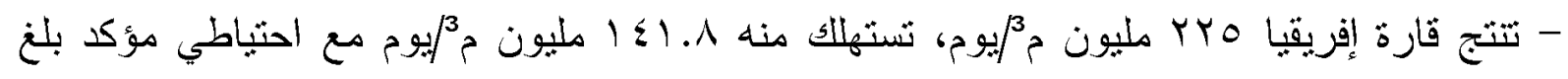

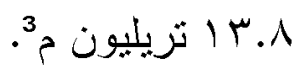

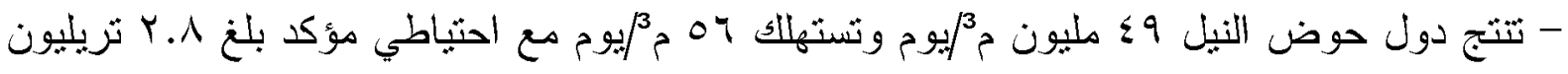

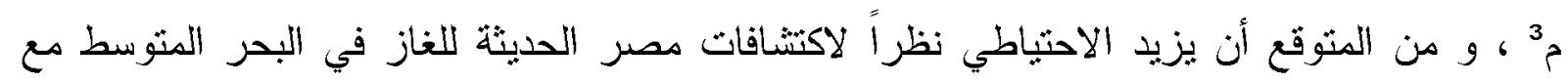
الاكتشافات الحديثة في جنوب السودانو تنز انيا.

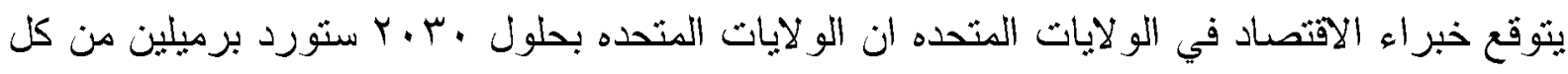

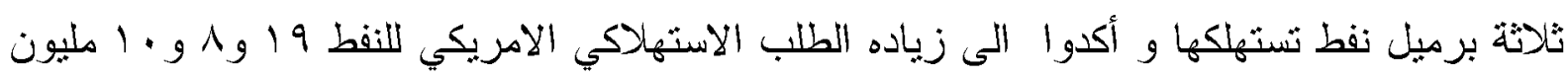

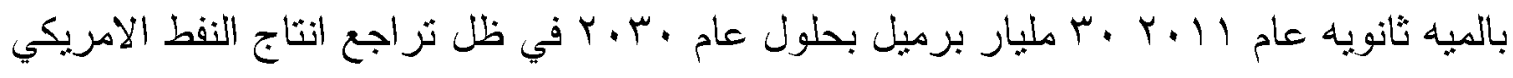
تعمل الولايات المتحده على حمايه مصادر الانتاج النفطي في القاره الأفريقيه نظراً لما تعانية دول

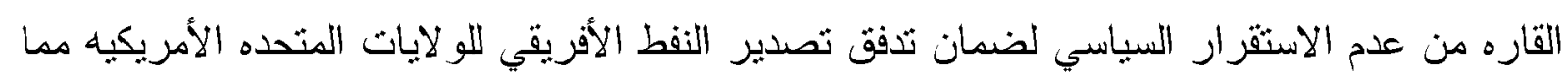


يساعد على التقليل من الاعتماد على نفط الثُرق الاوسط عبر سياسه نتوع الواردات من الطاقه حيث تعد منطقة حوض النيل و افريقيا عنصر اساسي في المنطقه و تثرصد المنافسين لها في القاره

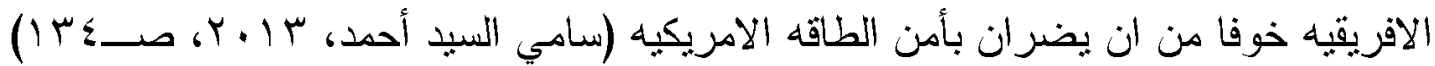

$$
\text { - المعادن }
$$

لا شكك أن ثن افر الإثتاج المعدني في قاره افريقيا ودول حوض النيل أسهم في الهيمنة الامريكيه على الهى تلك الدول من أجل الحصول على المعادن خاصد الني تعد موارد خام للصناعة الامريكية.

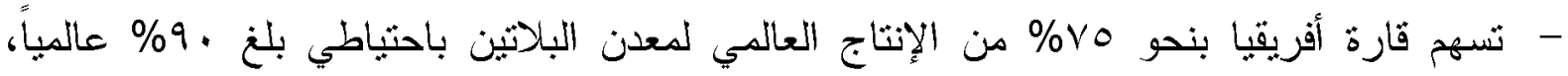

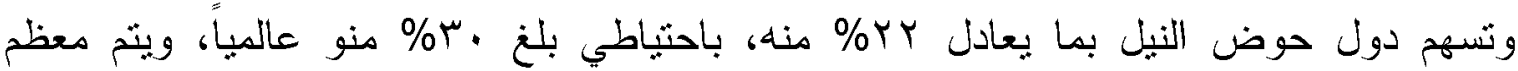

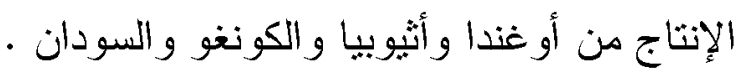

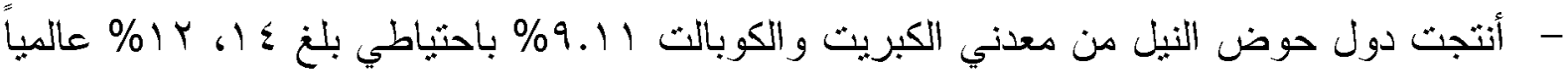
ويثركز الإنتاج في السودان وأوغندا و الكونغو الديموقر اطية.

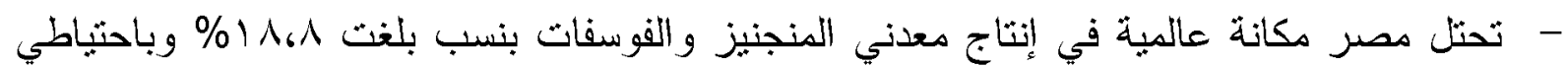

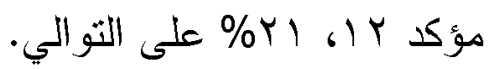

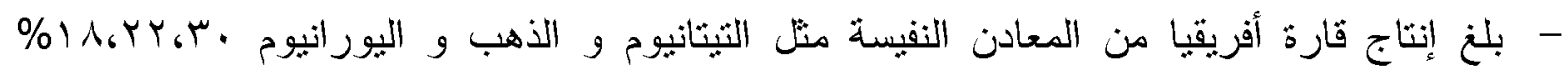

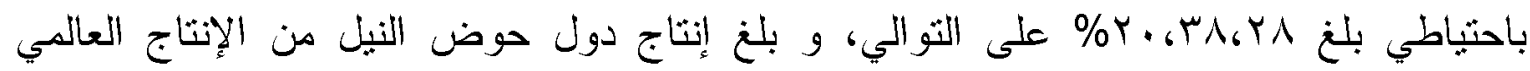

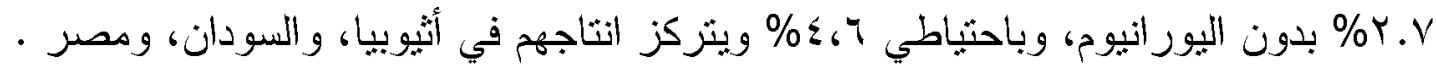

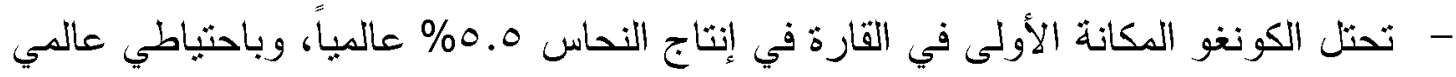

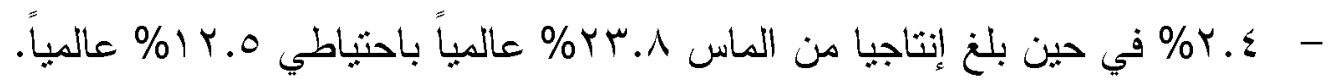

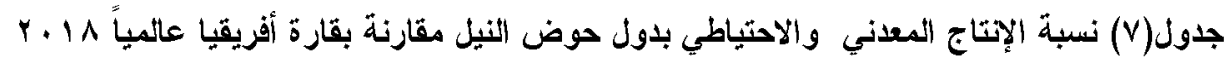

\begin{tabular}{|c|c|c|c|c|c|}
\hline أهم الثول المنتجة & النيل احتباطي حوض & الأفريقى الاحتباطي & النيل & \% إفريقيا & المعدن \\
\hline أو غندا، أثثو بيا، الكونغو & $r$ & 9. & rr & vo & الثبلاثين \\
\hline السودان & $1 \leqslant$ & $\pi$ & 11 & $0 \leqslant$ & الكبريت \\
\hline أو غندا، الكونغو الديمقراطية & ir & $\leq 0$ & 9 & $\leq 1$ & الكوبالت \\
\hline مصر | مصر & $1 \leqslant$ & 01 & $\wedge$ & $r r$ & المنجنيز \\
\hline مصر & r) & $1 \leq$ & 11 & $\leq 9$ & الفوسفات \\
\hline أَثْبوبيا & 1 & ru & $r$ & r. & التيتانيوم \\
\hline أَثيو بيا، السو دان، مصر & $\varepsilon$ & $r_{\Lambda}$ & r & rr & الذهب \\
\hline كينيا & $\cdots \varepsilon$ & $i n$ & r & 1. & الفلسبار \\
\hline كينيا & 1 & 11 & - & rV & البروكسبت \\
\hline
\end{tabular}




\begin{tabular}{|c|c|c|c|c|c|}
\hline الكونغو الكيمقراطية & Y. $E$ & r.s & 0.0 & 0.0 & 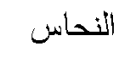 \\
\hline الكونغو الكيمقر اطية & IY.O & 7. & rr.A & or & 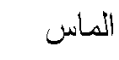 \\
\hline السودان ،مصر ، كينيا، رو اندا & $1 \leq .0$ & $\circ$. & ir & $\leq$ & الميكا - الميا \\
\hline الكونغو الايمقراطية & r৭.1 & ᄉ. & 19.0 & 70 & الميثاليوم \\
\hline
\end{tabular}

.$r \cdot$ IAUS. Department of the interior, Mineral commidty, summaries - ISource

2- r. I Ainstitute for natural resources Africa -UNU/INRA

لاثك أن وجود ثلك المعادن في حوض النيل بدول القارة، خاصة اليورانيوم والذهب جميعها نخضع

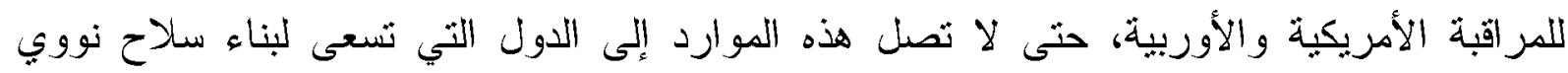

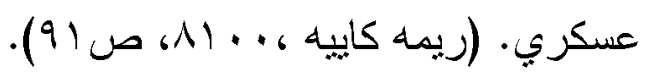

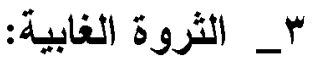

تسهم دول حوض النيل بما يزيد عن r با من الإنتاج الغابي في أفريقيا و نعد الغابات مصدر هام للحصول على الأخثاب الصلبة، خاصة وأن معظم غابات دول حوض النيل من الغابات الاسنو ائبة و المدارية، فتحرص الولايات المتحدة على استيراد الأخشاب من معظم دول حوض النيل، بجانب

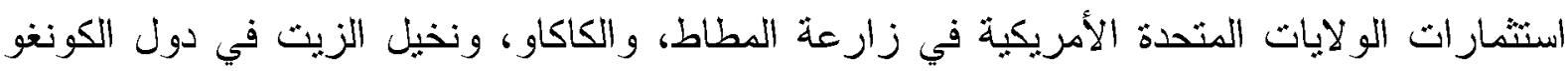
وأو غندا ورو انده ويتضح من دارسة الجدول ( ^ ) و شكل حجم الغابات في دول حوض النهات النيل .

جدول (^) توزيع الغابات في دول حوض النيل عام ^ا بـ (مليون فدان)

\begin{tabular}{|c|c|c|c|c|}
\hline \% للا يتم تصديره & \% من مساحة الدولة & $\%$ & المساحة (قان) & الدولة \\
\hline 11 & $r . .1$ & $1 . \varepsilon$ & $0 . r \ldots$ & أو غندا \\
\hline iv & Ir.t & $\therefore \varepsilon$ & $1 . v \ldots$ & رواندا \\
\hline$r$. & 8 & .1 & $\cdots 0$. & بوروندي \\
\hline$r 4$ & rv. & $\leq 5.9$ & IV... & السودان \\
\hline$\{1$ & rv.r & M.r & V.. ... & تنزانيا \\
\hline$\varepsilon r$ & or.r & 11.1 & : .9. & الكونغو \\
\hline 11 & r.1 & .1 & $\ldots r$. & كينيا \\
\hline$r$ & rV.r & $11 . r$ & $\varepsilon Y . \&$ & جنوب السودان \\
\hline- & r.r &.$r$ & $\because v \ldots$ & أريتريا \\
\hline 11 & r.: &.$r$ & $1 . r \ldots$ & أثثيوييا \\
\hline- & - & $1 \ldots$ & rvo.v.. & المجموع \\
\hline
\end{tabular}

Y.। As.worldbank.org, open data, Source: http:blog 


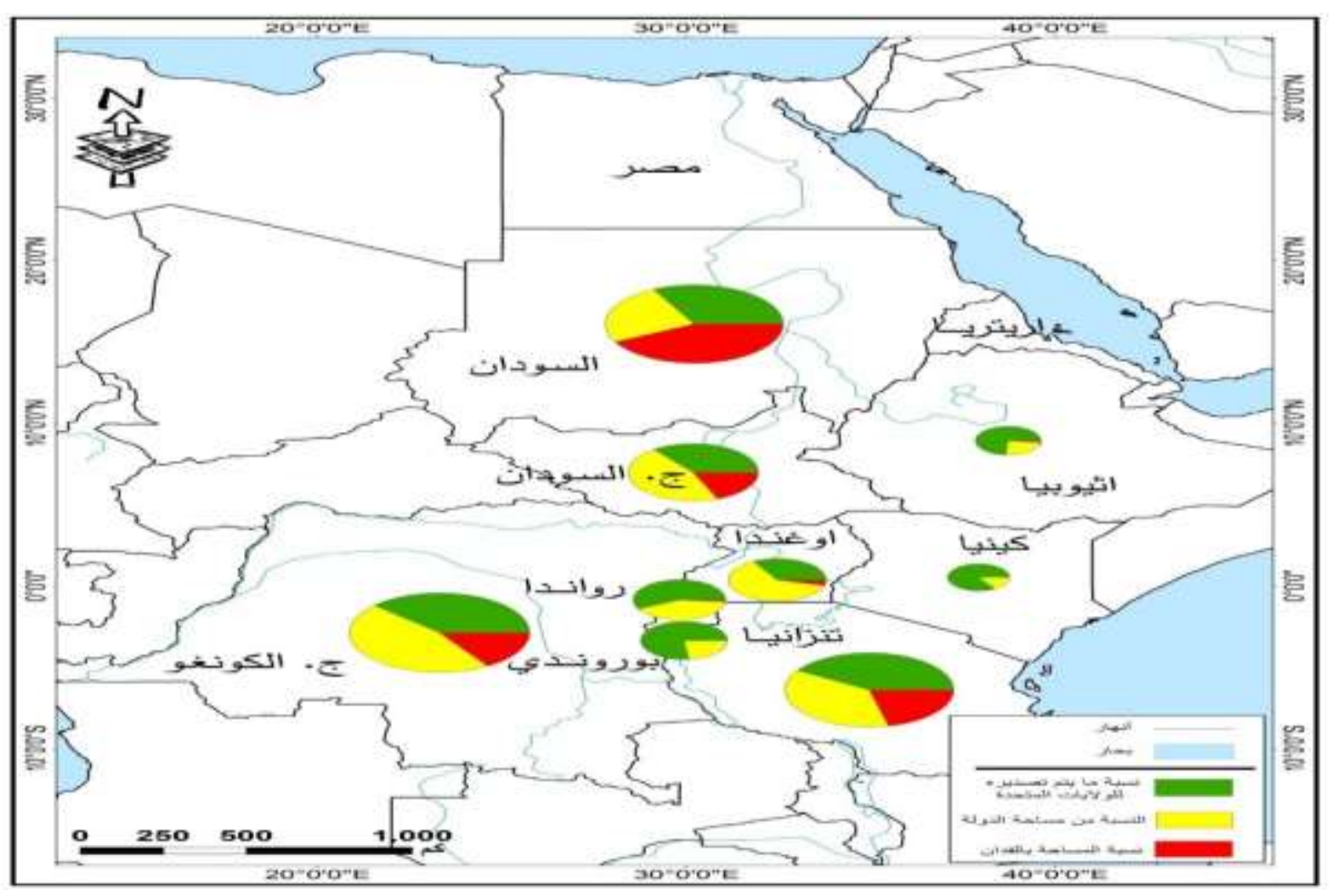

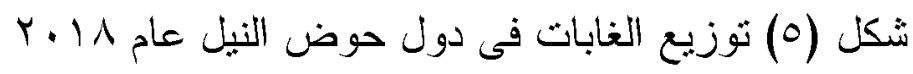

ثانياً العو امل البشرية وتثمل معدل السكان و معدل الأمية و البطالة، و الدور الأمريكي في استخدام المياه في دول الإقليم و إستثمارنها للهيمنة على دول الإقليم و حركة النجارة بين الو لايات المنحدة و دول حوض النيل. السكان والأمية والبطالة

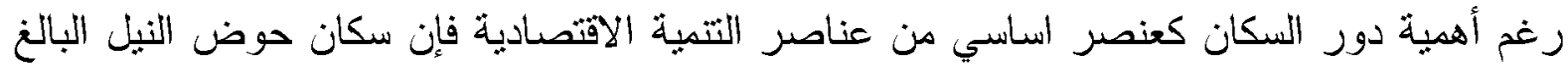

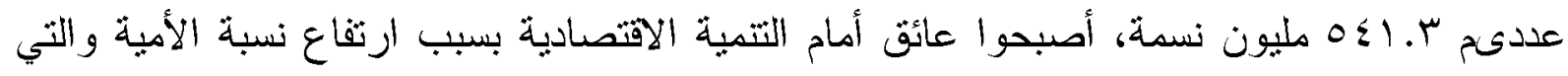

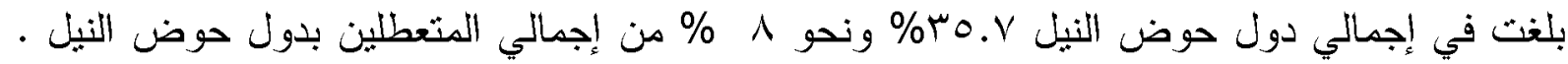

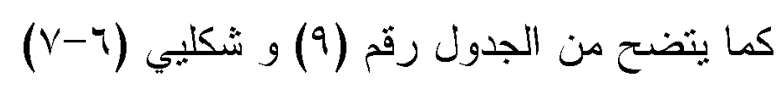
أن ما تعانيه دول حوض النيل من انتشار الأمية ناتج من قصور في دول حوض النيل وعدم توفير

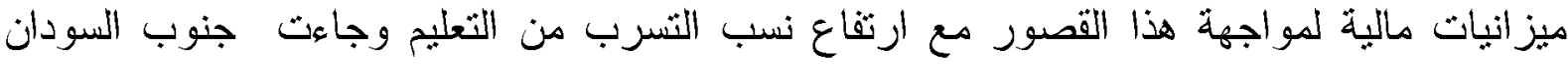

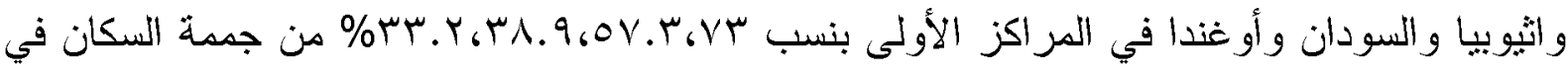

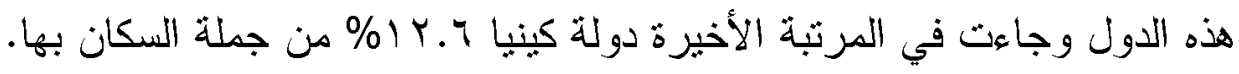




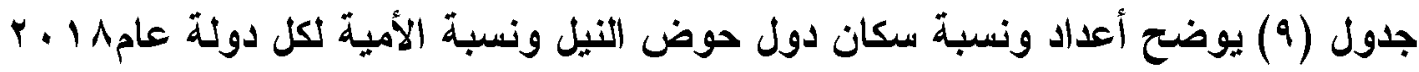

\begin{tabular}{|c|c|c|c|c|c|}
\hline لمبنة البطالة & الأمية & 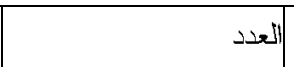 & $\%$ & 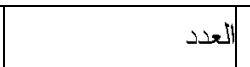 & |لثولة \\
\hline 1.7 & Mr.A & r.v & Ү.। & II vorva & | بوروندي \\
\hline$\varepsilon$ & rr.r & Yr.l & 17.2 & $\Lambda \leq .7 \Lambda .91$ & الكونغو الكيمقراطية \\
\hline A.V & r. & 1.1 & 1 & 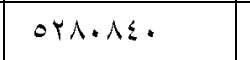 & | أريتريا \\
\hline 0.1 & or.r & GY.T & YI.r & $1.9 r Y \leq 009$ & أثيوييا \\
\hline 9.ะ & K. .7 & 4.0. & 1. & 01 rrar.1. & كينيا \\
\hline r. & $r \lambda .9$ & r... & r. & 1rmi.rq & رو اندا \\
\hline IY.A & $r \lambda .9$ & $17 . r$. & A.Y & S1A. 10rr & | السود دان \\
\hline$Y \leq . V$ & vr & $\wedge$ & ५.। & OYTIATS人 & لجنوب اللسودان \\
\hline r. & Y.A & ir.1 & 11 & STrYTITq & تن ازنيا \\
\hline r.v & Tr..r & $1 \leq .1$. & A.r & $9 \lambda \leqslant Y T 090$ & | أو غندا \\
\hline A.r & YA & $r \leqslant .0$. & $19 . r$ & $9 \lambda \leq Y r+090$ & | مصر | مصر | \\
\hline$\wedge$ & rov & IAY.A. & $\ldots$ & $011 T \wedge \leqslant \leqslant 1 \%$ & الإجمالي \\
\hline
\end{tabular}

\section{source}

- Y. IAH.B.6 $|Y-1|$ Reference Bureau, Op. Cit, PP Population

$-r$.Department of Economic and social affair, $1 \wedge$

ارتفعت نسبة البطالة في دول حوض النيل لتصل أقصاها في دولتي جنوب السودان والسودان

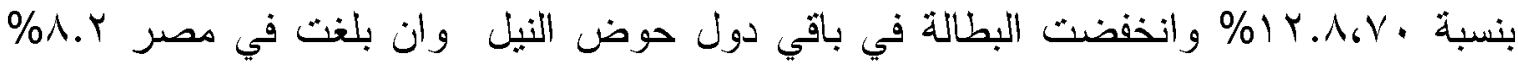

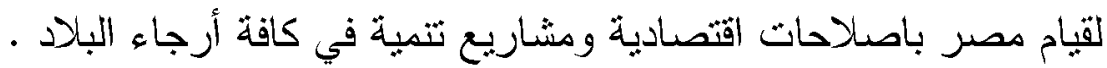

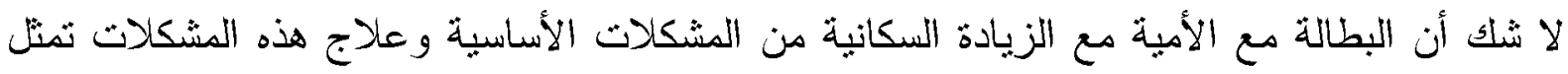

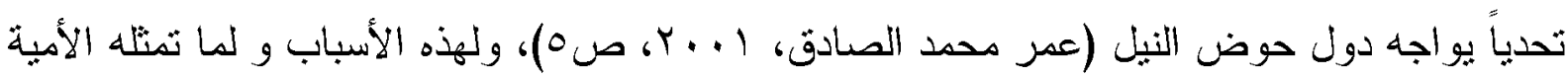
و البطالة من مشكلات في دول الحوض، سهل من مهمة الولايات المتحدة الهيمنة والتدخل في الثؤون

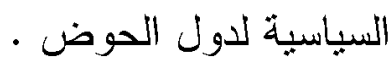




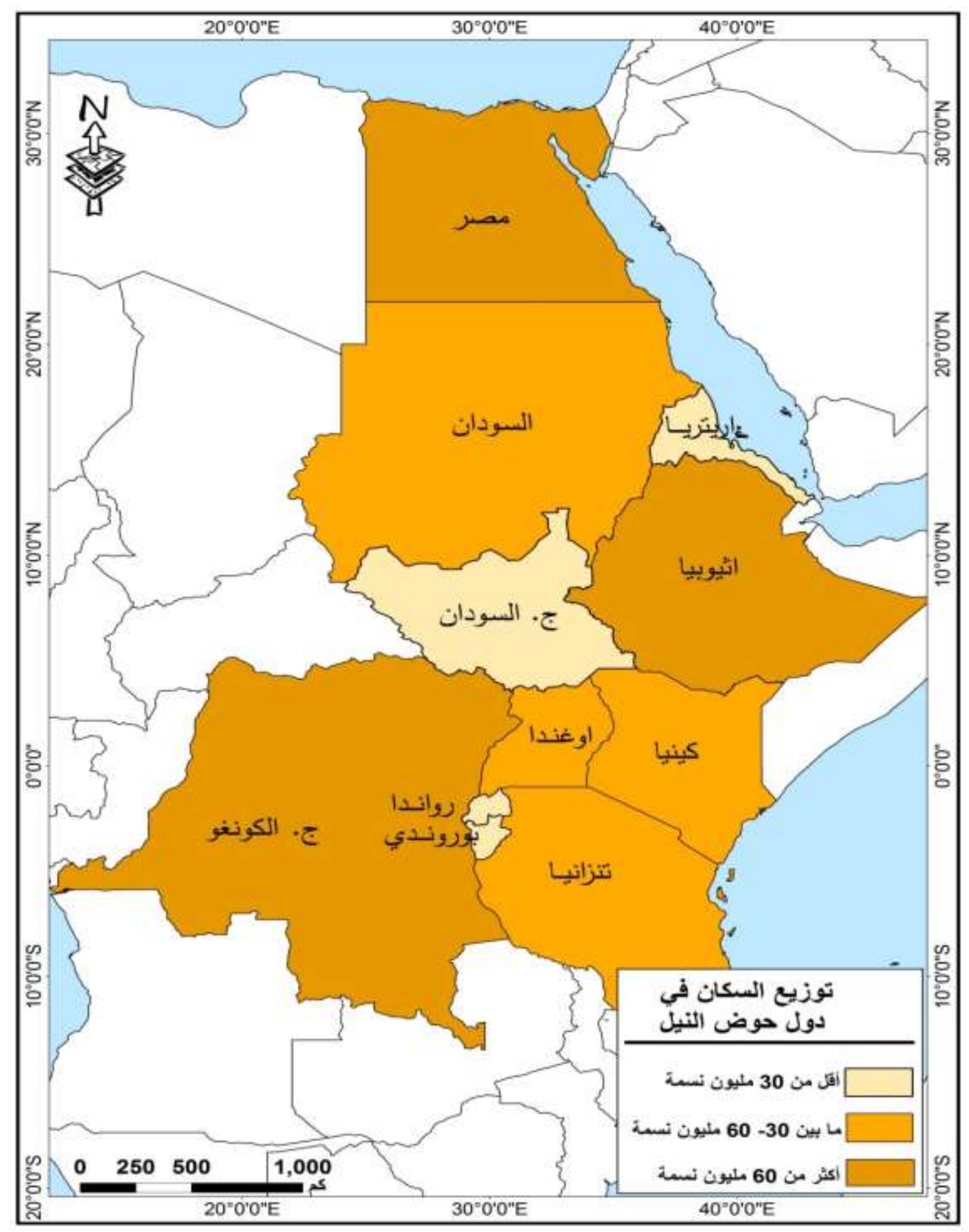

شكل (آ) توزيع سكان دول حوض النيل 


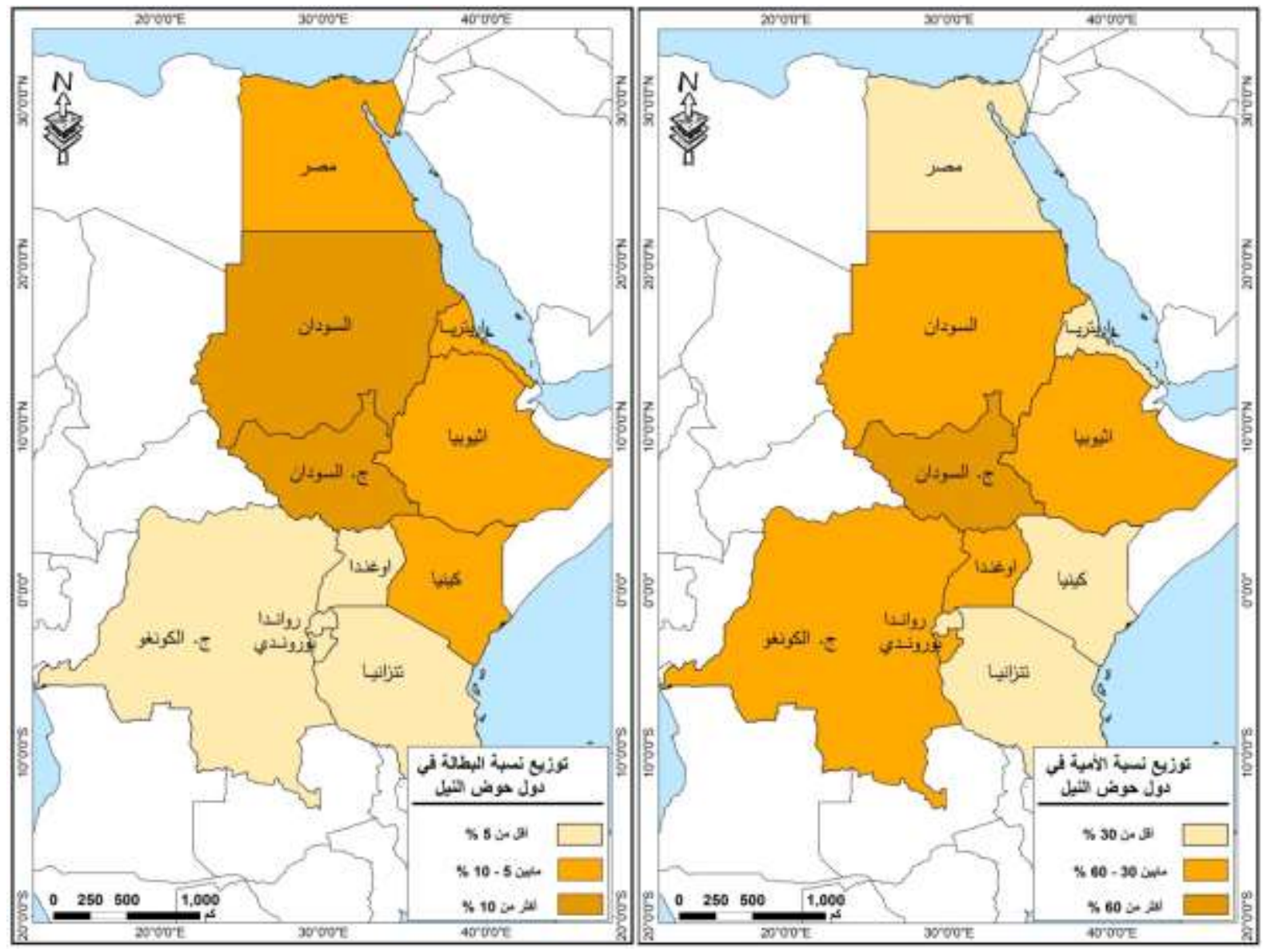

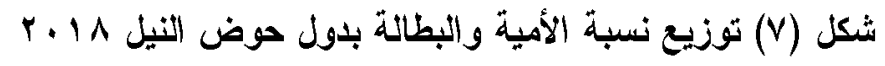

1- - استخدامات المياه

أقدمت خمس دول من دول المنابع النيلية في ه. مايو • •. ب بالتوقيع بشكل منفرد على الاتفاقية الإطارية، عنتيبي، بإيعاز من الولايات المتحدة دون الأخذ في الاعثبار اعثراض دولتي المصب (مصر والسودان)، مع النحرك الأثيوبي المكثث لإنثاء عدد من السدود الجديدة على نهر

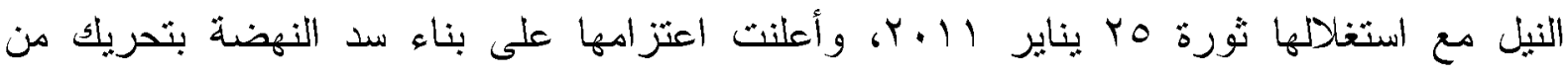
الو لايات المتحدة و واسر ائيل، وتسعى الولايات المتحدة في تحقيق مصالحها من خلال نكريس هيمنتيا الجيوسنراتيجية وتمكين حلفائها (إثيوبيا واسرائيل) من تحقيق مكاسب سياسية واستراتيجية على ملى حساب المصالح الحيوية والأمن المائي لمصر بصفة خاصة من خلا توظيف الدول النيلية غير العربية لاستعمالها كأداة للضغط على مصر والسودان باعنبارهما دولثان منحالفتان ضد إسرائيل وينضح من خلال الجدول ( · ( ) و بشكل (1) الذي ينضح منهما . 
- تعد مصر من أفقز دول الحوض من المياه حيث بلغ نصيب مصر من مباه نهز النيله00 مليار م

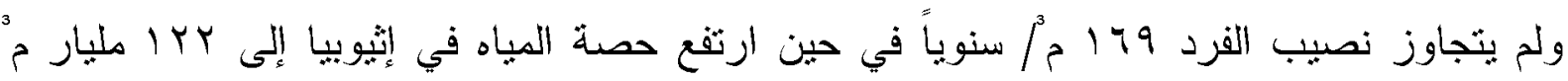
سنوياً لغزارة الأمطار الموسمية بها وكونها منبع لرافد النيل الأزرق ورو الفين الفئ أخرى.

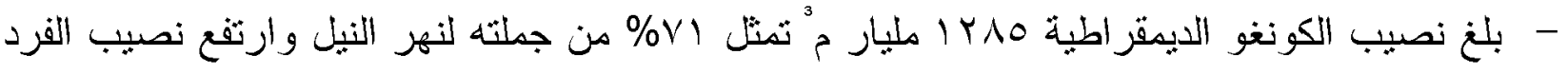

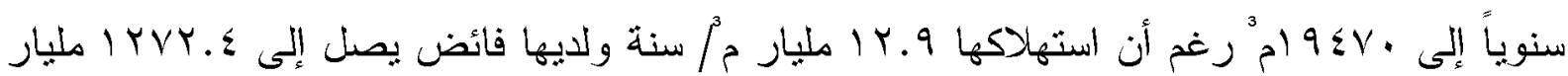
ra

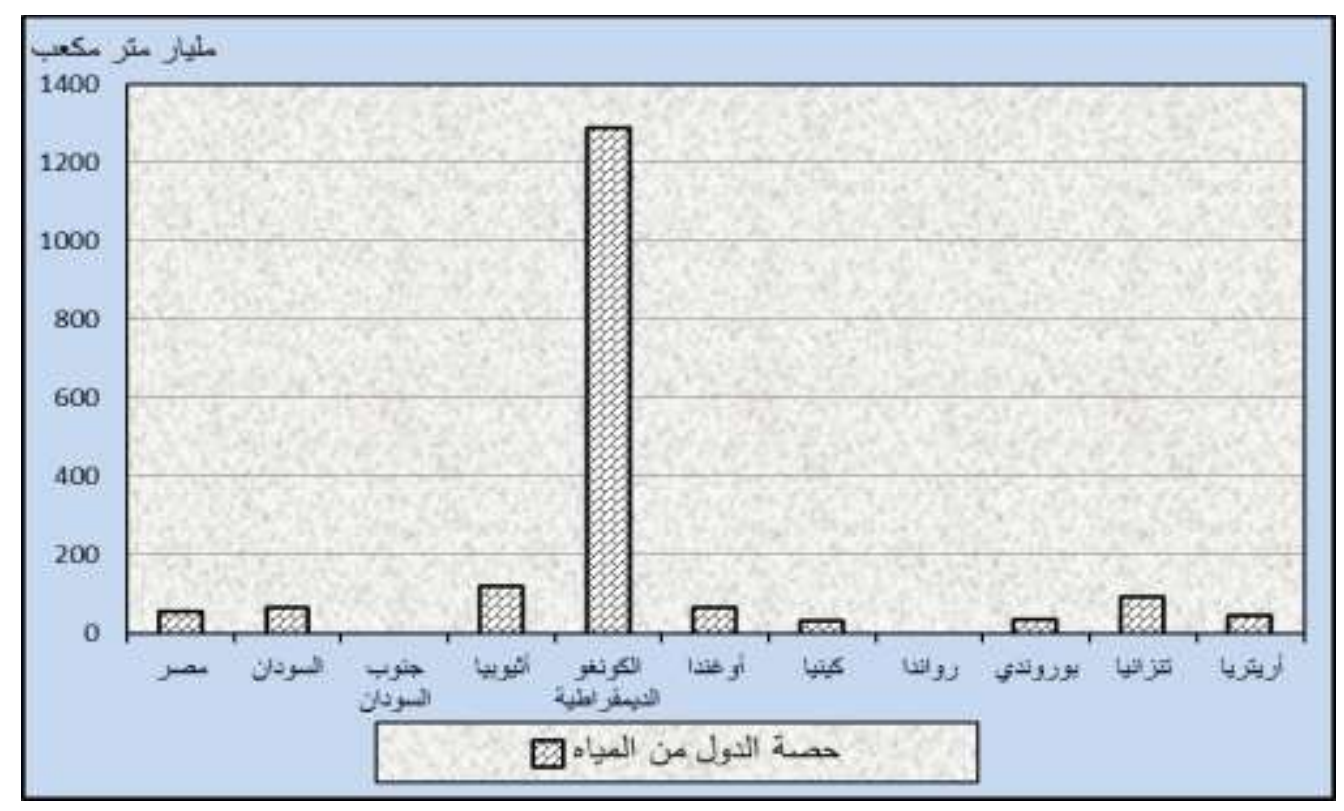

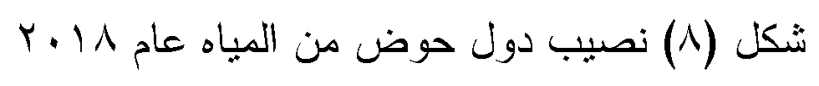

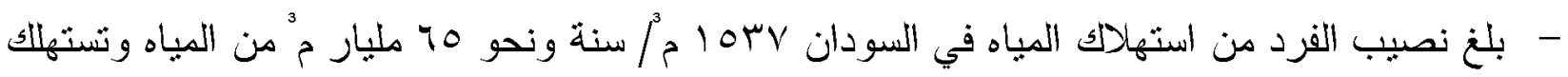

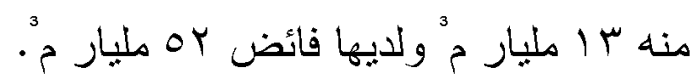

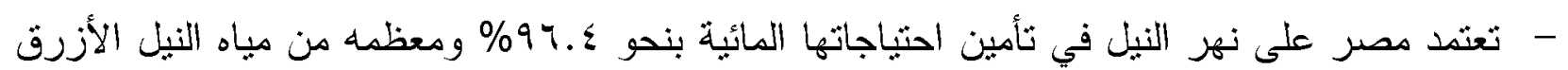
و تستغل الو لايات المتحدة هذه الورقة للضغط على مصر مع ثوصياتها بالتتسيق بين إسرائيل واثيوبيا

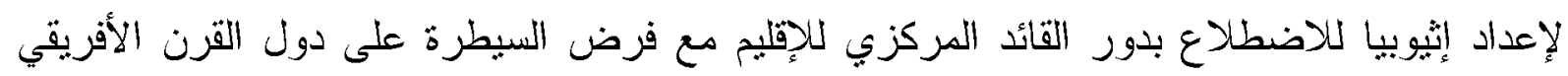

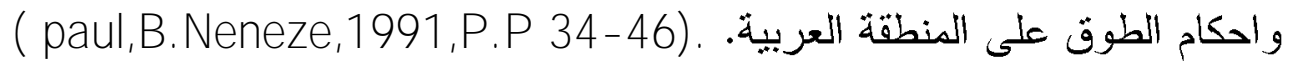

تعد منطقة حوض النيل سوقاً للمنتجات الأمريكية أكبر من أهمينها كمدر للمواد الخام، وعلى الرغم من قلة نسبة الصادارت إليها، وبلغت 1 1\% من إجمالي صادارت الولايات المتحدة إلى أفريقيا جنوب 
الصحراء، في حين ثبلغ نسبة الواردات الأمريكية من المنطقة ما يزيد عن ؟.0\% من إجمالي

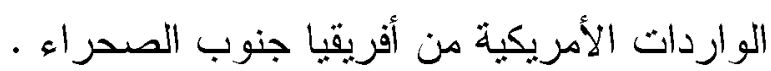

اهنم الرئيس الأمريكي كلينتون بزيادة العلاقات التجارية عام 991 ام خلا قبامه بجولة في أفريقيا زار فيها أوغندا ورواندا، والتقى في "عنتيبي" بمعظم رؤساء دول حوض النيل واهتمت الزيارة بالجوانب الاقتصادية بالعلاقات الأمريكية الأفريقية، ومن خلال الزيارة تثرر إلغاء بعض الديون المستحقة على بعض دول حوض النيل، وتخصص مبلغ ·ـمليون دولار لبرنامج تتمبة التجارة

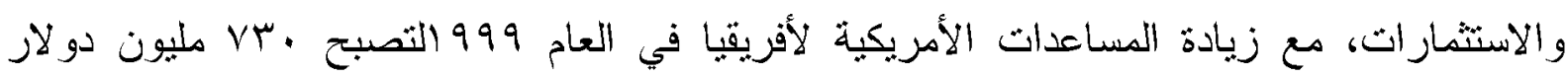
زادت الصاد ارت والواردات الأمريكية، كما يتضح من د ارسة الجدول ( 11 )و شكل (9 ) ومنها يثنين

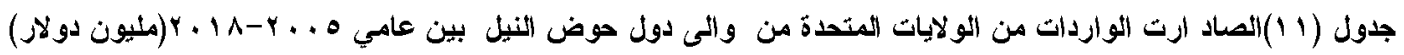

\begin{tabular}{|c|c|c|c|c|}
\hline \multicolumn{2}{|c|}{$r+1 \lambda$} & \multicolumn{2}{|c|}{$r \ldots o$} & \multirow[t]{2}{*}{ اللدولة } \\
\hline الثو الردات & الصاد ارت & الكو اردات & الصاد ارت & \\
\hline 10 & $1 \leq .0$ & $\varepsilon . \varepsilon$ & V.o & بوزروندي \\
\hline$\wedge$ & $\wedge$ & $1 . r$ & 1.1 & أريتزيا \\
\hline$\leqslant \leqslant 0$ & 177 & 71.1 & $01 \leqslant .0$ & أنثيو بيا \\
\hline ryo & $7 \leq \leq$ & $r \leq \lambda$ & rY.r.r & كينيا \\
\hline $7 \mathrm{~V}$ & ro & $7 . r$ & $1 \cdot . V$ & رو اندا \\
\hline 17 & 90 & 14.7 & $1 . r . r$ & النسودان \\
\hline va & rrA & r.V & 97.2 & تن ازنيا \\
\hline 79 & $\wedge 1$ & 297.2 & TY.O & أو غندا \\
\hline IYN & $11 \mathrm{~V}$ & 117 & 111 & الكونغو اللديمق ارطية \\
\hline 1.217 & 0.1 & 1.7 & r.v.. & مصر \\
\hline ra. 1 & $V \leqslant \Lambda \Lambda .0$ & YฯA.lo & 2999.7. & الإجمالي \\
\hline
\end{tabular}

Source: saharan Africa-Trade in sub U.S 2005- $r+1 \wedge$

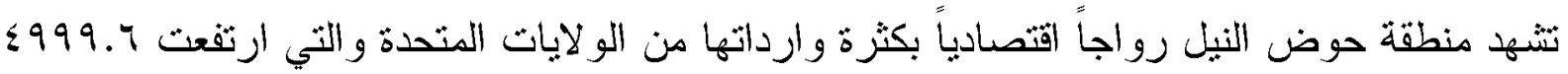

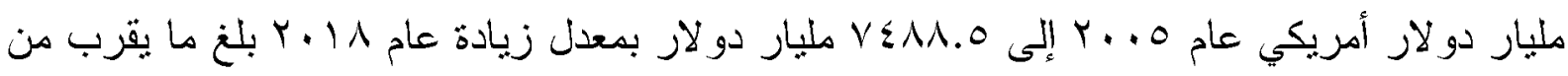




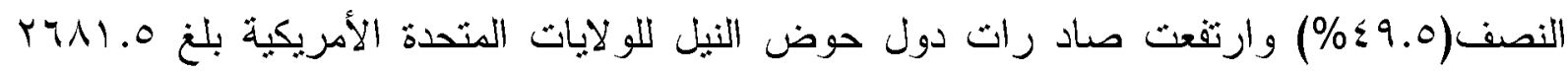

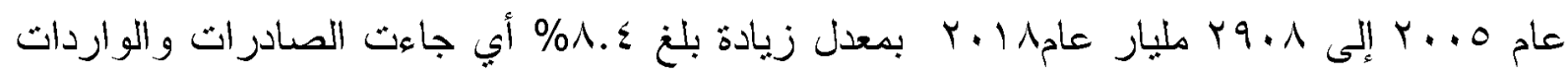

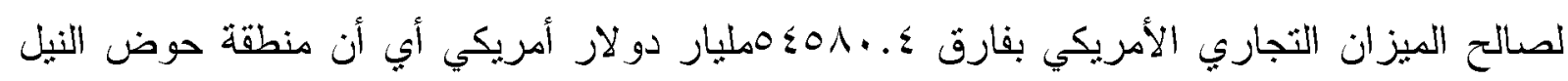
منطقة خصبة لنسويق البضائع الأمريكية و استبراد المواد الخام اللازمة للصناعات الأمريكية .

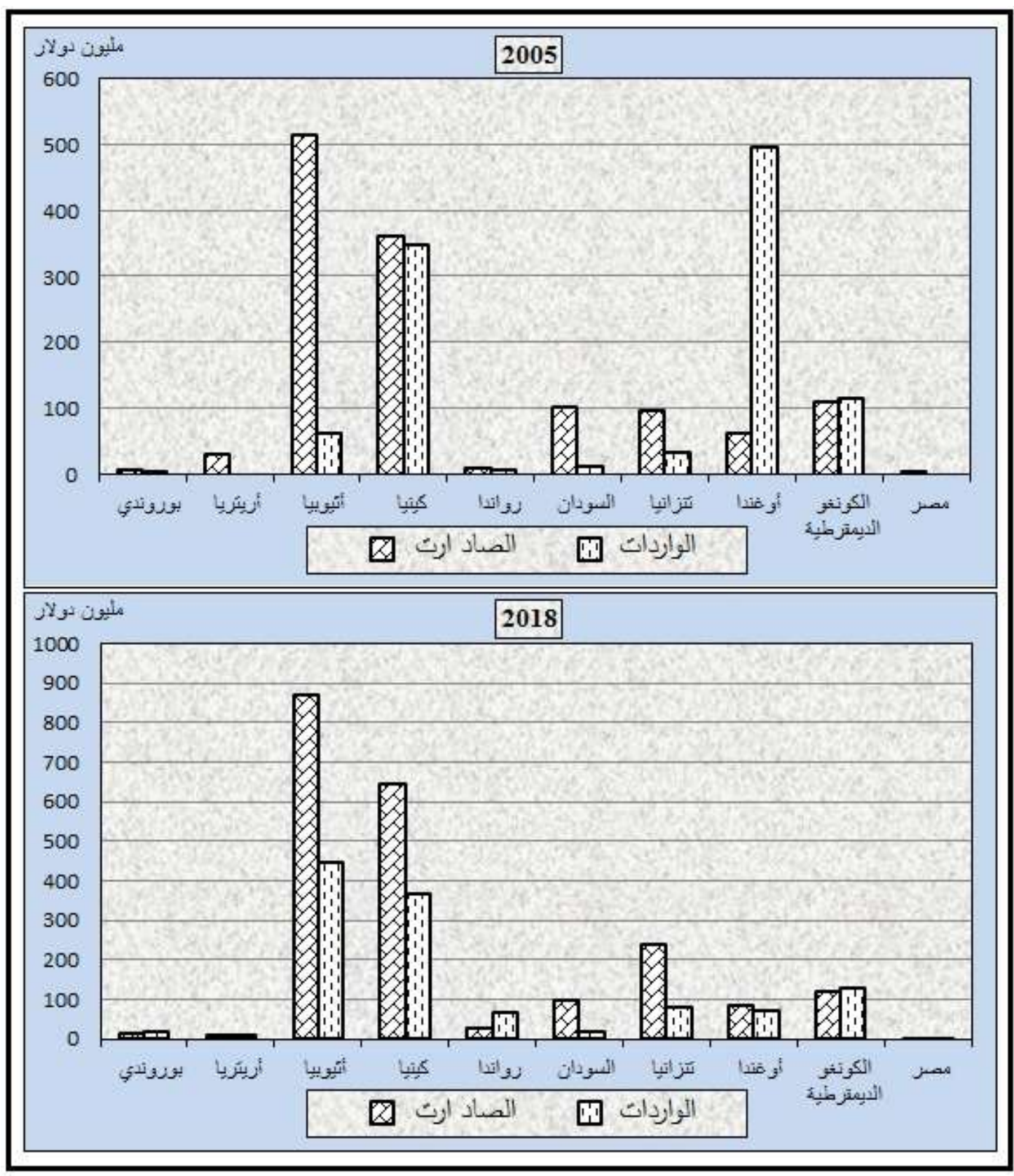

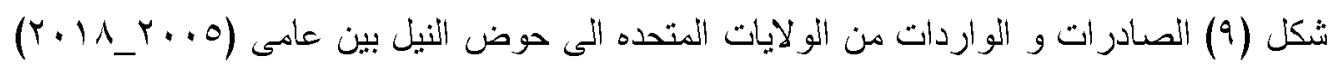


من أهم الصادرات الأمريكية لدول حوض النبل محركات السبارت، البذور الرئيسية والحبوب منتجات الفحم و الطائر ات و آلات البناء ومعدات الاتصال و الكيمباء الصناعية، ومعظم واردات الو لايات المتحدة من النفط و المعادن و المنسوجات و الكاكاو و الغاز الطبيعى.

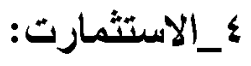

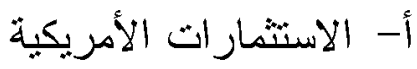

أن حجم الاستثمار الأمريكي المباشر في أفريقيا وصل ارتفاعه من 1.0 مليار عام Y.... إلى 17

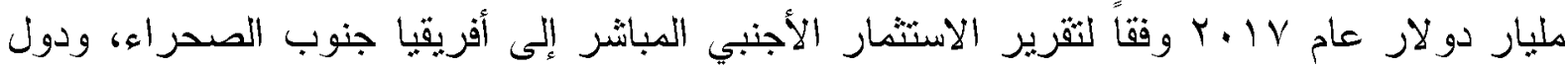

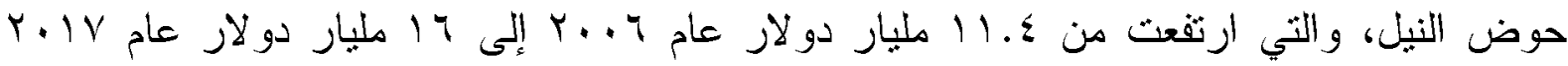
بنسبة زيادة قدرها س. ،ـ٪ بين العامين، معظم الاستثمارات موجهه لقطاعي النفط و الغاز وفي مجال

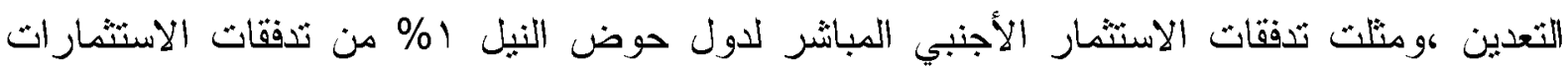

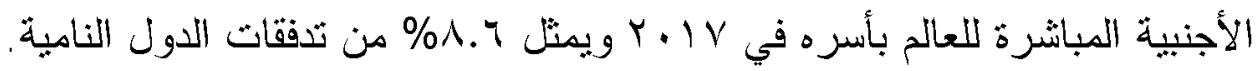

(World Investment, Report,2017,p.14)

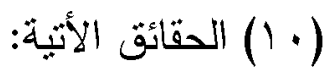

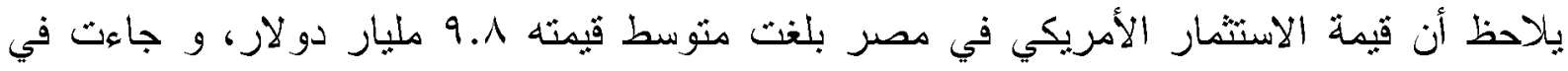

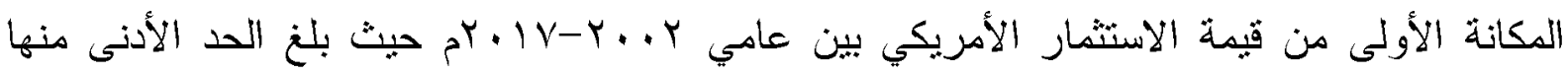
ع.

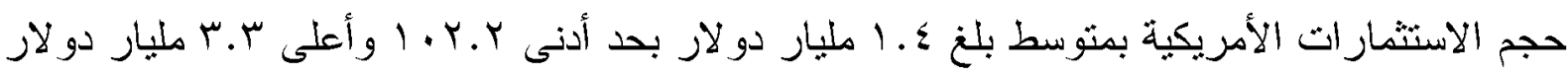

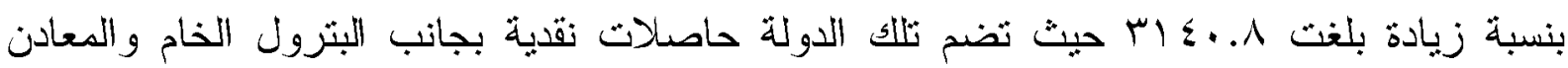

- احتلت تنزانبا المركز الثالث في دول حوض النيل في الاسنثما ارت الأجنيية ،بمنوسط هYY.

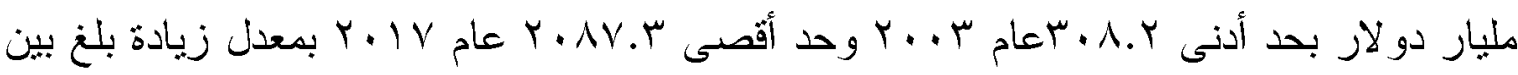
العامين rov.r\% بمكن تفسبر ذلك بغناها بالمو اد الخام الزارعية و التعدينية .

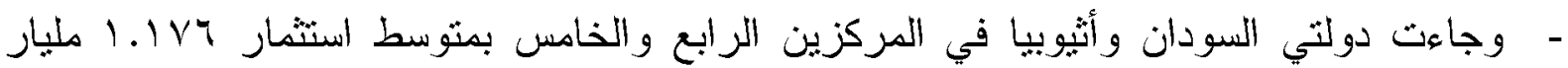

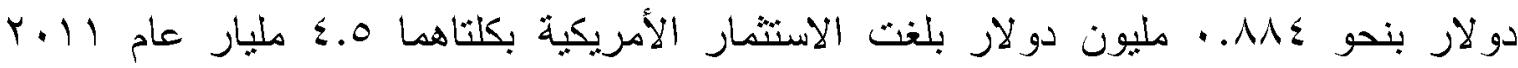


ويمكن تفسير ذلك إلى اعثبار الولايات المتحدة للسودان بأنها من الدول الراعية للإزهاب الدولي،

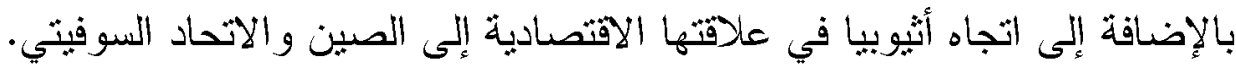

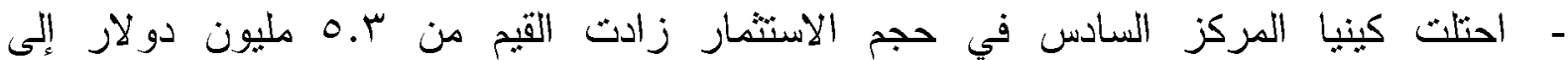

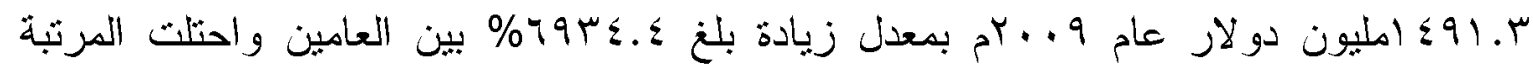

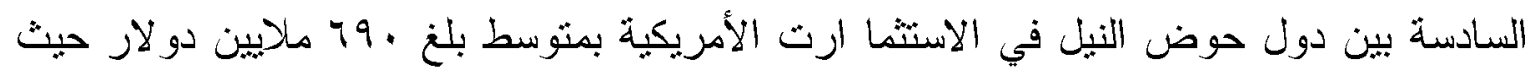

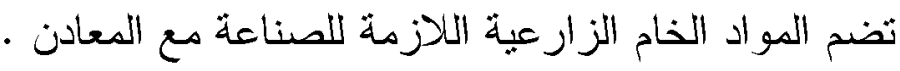

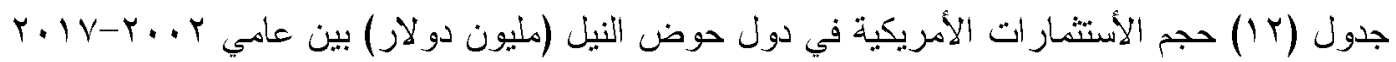

\begin{tabular}{|c|c|c|c|c|c|c|c|c|c|c|c|}
\hline الجملة & السودان & تنز انيا & أُو غندا & رواندا & أُثيوبيا & يا & الكونغو & يا & بوروندي & دصر & السنة \\
\hline $10 \leq V . Y$. & - & rAV.T & IA.T & 1.0 & roo & YY.A & $1 \wedge V . T$ & YV.T & $\ldots r$ & $7 \leq 7.9$ & $r \ldots r$ \\
\hline Yos $.9 \leq$ & - & $r . r . \tau$ & $\leqslant \Lambda$ & V.V & $0 \leq 0.1$ & $r \leq .1$ & $\leq .9$ & $\leq 7.9$ & $\ldots \leq$ & YlOV.E & $r \ldots \leq$ \\
\hline $79 \leq 9.0 \leq$ & - & 940.0 & vo.7 & $V .97$ & r7o.1 & $1 . \varepsilon$ & YצY. & Y..Y & .01 & orro.t & r... \\
\hline WVYYG.Y & $170 \% .1$ & THATr & 09.2 & I.Y.r & $1.1 .0 \leq$ & rq & IVYT.A & $\leq \wedge \Lambda$ & .0 & $110 V \Lambda .1$ & $r \ldots \lambda$ \\
\hline $10 \ldots$..YO & $r .7 r \cdot V$ & Mir.r & Va.r & ro..o & 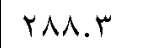 & 91 & rrar.r & 1198.7 & .ro & $7 Y \wedge 0.7$ & $r+1$. \\
\hline MIrrq.79 & $M T \leq . r$ & 1YYq. & rᄉ. & 119.11 & $7 \times 7.0$ & rq & 1717.9 & $1 \leq 0 . .0$ &..$V A$ & $7 r .0$ & $r .11$ \\
\hline $1 \leq \Lambda \Lambda 1 . \wedge 7$ & IVTA.E & $17 . \leq .7$ & $7 \pi .1$ & 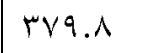 & YIGY.V & $\leq 9 . r$ & $17 V Y$ & $719 . V$ & $\leqslant Y . .7$ & Toro.r & $r .10$ \\
\hline 10190.07 & $1 \vee 9 \wedge .1$ & $19 V 4.7$ & A1.Y & $\leq .1 .7$ & T.人1.Y & $\leq 9.1$ & IVAY.O & VY. & V.rY & $V \ldots 1 . r$ & $r .17$ \\
\hline $17.4 . .7$. & 1791 & $19 . \leq .7$ & Y. r & $\leqslant 11 . v$ & Tr.1.T & or.o & $1 \wedge \varepsilon . . T$ & sr. & $\wedge$ & $V \cdot I Y . Y$ & $r+1 \mathrm{r}$ \\
\hline A.MV.YE & 1184 & Kro.9 & TY.V & IAV.Y & $M \Lambda \leq .9$ & $\leq$ rol & $1 \leq .0$ & 79. & 0.1 & $9 \Lambda \leq 0 . r$ & المتو سط \\
\hline $1 \leq \lambda r . V V$ & rol.r & $r \cdot \Lambda . r$ & rv. & 1.0. & 1.1 .0 & $1 . \varepsilon$ & I.Y.Y & Y.Y & $\ldots r$ & TrV.E & حد أُدنى \\
\hline $17 . r . .7$ & YMII & $r \cdot A V \cdot r$ & 11. & $\leqslant 0 \wedge .9$ & TY.1.T & 91 & HTIY.l & $1 . \leq 9 \wedge . r$ & $\leq V . .7$ & $110 \mathrm{~V}$.1 & حد \\
\hline $9 \wedge . . \Sigma$ & $\leq 0.9$ & OVV.T & 194. & $r . \leq 01$ & qY^.A & $77 \ldots$ & $r ! \leq \ldots$ & $79 r \leq . \leq$ & 99.9 & $\leq \vee \vee V . \Sigma$ & التغير \\
\hline
\end{tabular}


Source- www://fao.org/fastat( accessed8/3/2021)

- Y. Y VCommission for Africa UNECA United Nation, Economic.

African Sruliscal yeara book $\left.\left(r_{+}\right) \leq-r_{+}\right) \cdot$.Addis Ababa

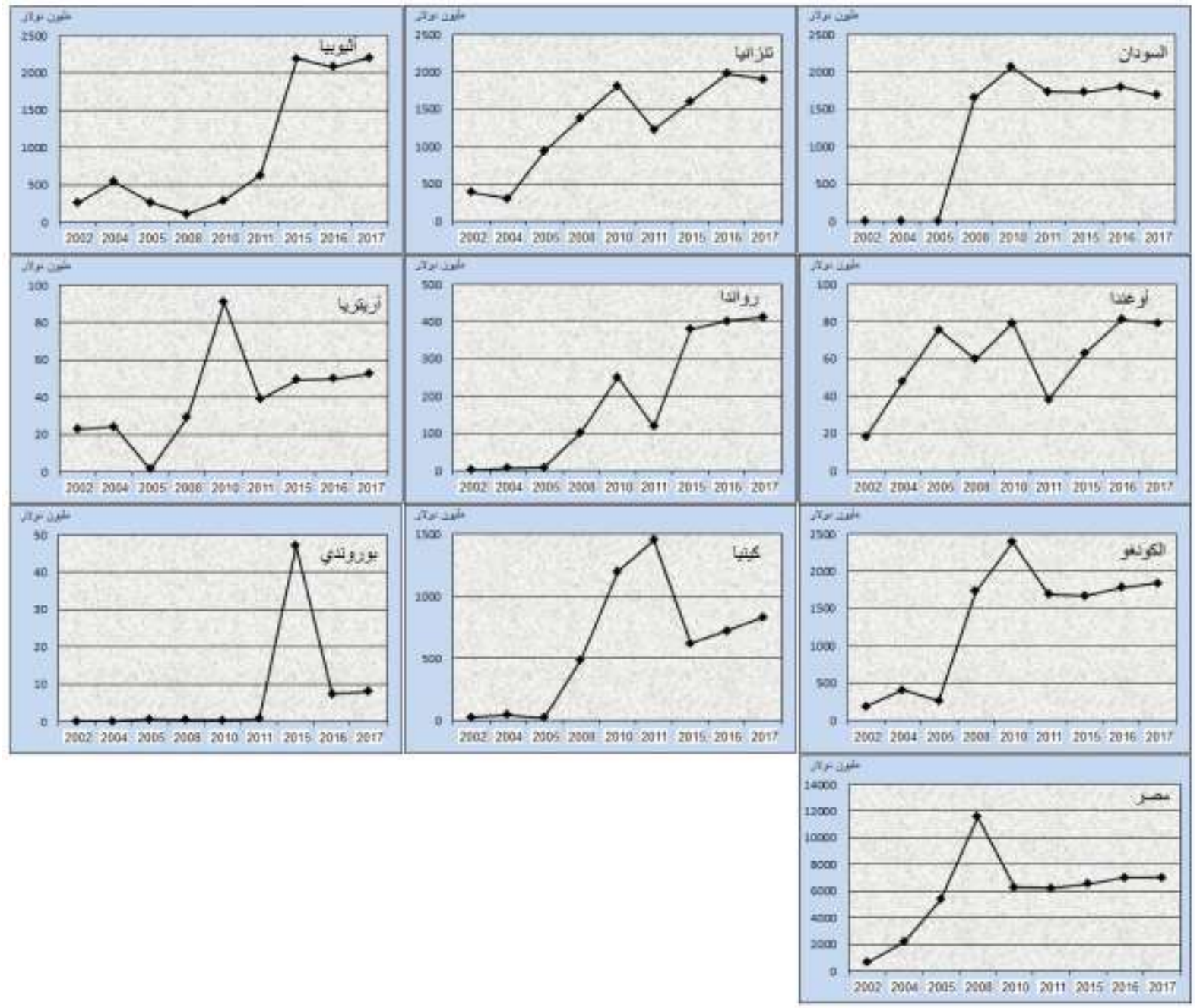

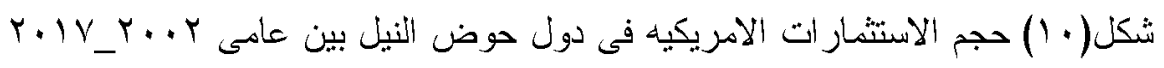

- شهدت دول رو اندا وأو غندا وأريثريا وبوروندي ثراجع في الاستثمار ات الأمريكية بمتوسط بلغ

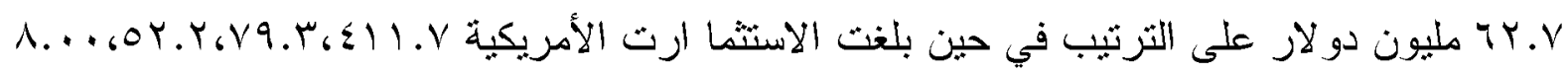
مليون دولار ويمكن تفسير تراجع الاستثا ارت في ثلك الدول إلى ما تعانيه من مشكلاث سباسية داخلية.

ب-الاستثمار ات الأمريكية مقارنة بالاجنبيه : تشهم من العديد من الدول باسثثار اتها فى دول الإقليم مع الاستثمارات الأمريكية كما يثضح من من خلال جدول ( r ) نلاحظ أن حجم الاستثـار ات الأجنيية في دول حوض النيل بلغ سبر.وج مليار 


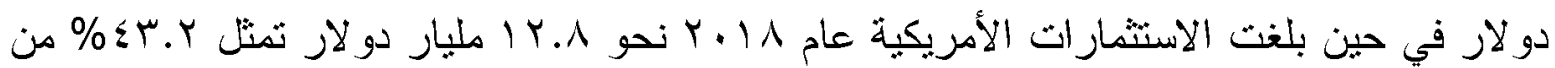
حجم الاستثمار ات في دول حوض النيل. - احتلت مصر المرتبة الأولى من حجم الاستثما ارت الأمريكية (9.4r\%) بدول الحوض وجاءت في

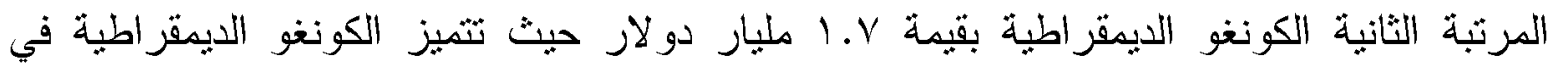

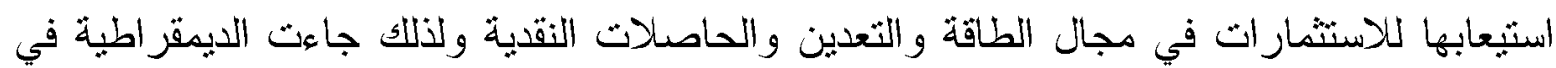

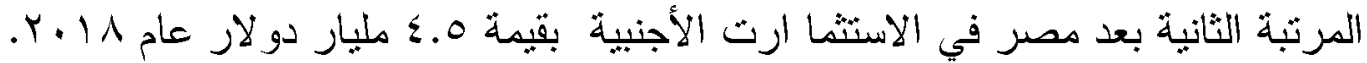

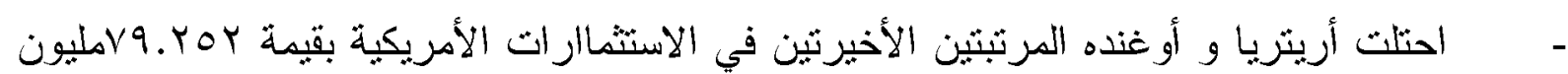

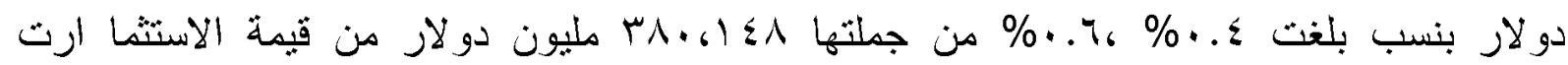

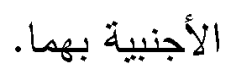

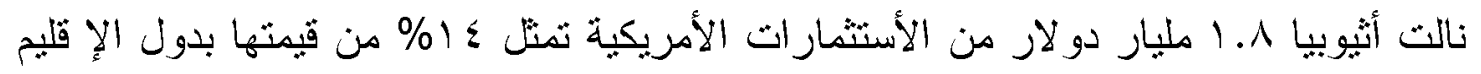
وحصلت V. البار دو لار من الأستثمار ات الأجنيية خاصة من الصين واسر ائيل وتركيا. جاءت ثتزانبا و السودان فى المركزين الرابع والخامس فى الأستثمارات الأمريكيه بقيمة V.1 ، ا.1 نقريبا مليار دولار أمريكى ونالا معا ج.1،9.1 مليار دولار في الأستثارات الأجنيبة خاصة فى البحث عن المعادن فى نتزانبا والبنرول فى السودان إلى جانب الأستثمارات فى الزراعه في كلا البلدين.

جنول (r') حجم الاستثا ارت الأمريكية والأجنية في دول حوض النيل

\begin{tabular}{|c|c|c|c|c|c|c|}
\hline \multirow[t]{2}{*}{ الجملة } & \multicolumn{2}{|c|}{ الاستثمار الأجنبي } & \multicolumn{2}{|c|}{ من الاستثمار الأمريكى } & \multirow{2}{*}{ بالمليون } & \multirow[t]{2}{*}{ اللدولة } \\
\hline & $\%$ & مليون & \%من جمله الأستثـار ات & $\%$ & & \\
\hline $17 .$. & $04 . Y$ & $9 .$. & $\varepsilon r . \wedge$ & $0 . \varepsilon$ & v.. & بوروندي \\
\hline THt. & VY.Y & $\{0$. & YY.A & $1 \% \cdot \varepsilon$ & IVT..T & الكونغو الديمقراطية \\
\hline r... &..$\wedge \varepsilon$ & $1 \leq 1$ & Y & $\cdot \varepsilon$ & or & أريتريا \\
\hline rool.r & $\leq 9.4$ & ivo. & $0 . . v$ & $\because 1 \leq$ & $1 \lambda .1 . r$ & أنثيوييا \\
\hline 1900 & 09.1 & 1100 & $\leq . .9$ & $Y . Y$ & A.. & كينيا \\
\hline $901 . V$ & $07 . V$ & $0 \leqslant$. & $\varepsilon r . r$ & r.r & .211 & رو اندا \\
\hline
\end{tabular}




\begin{tabular}{|c|c|c|c|c|c|c|}
\hline rov. & 00.0 & 191. & $\leq \leqslant .0$ & KY.r & 109 & اللسودان \\
\hline THE.T & $\{1.9$ & 174. & 01.1 & $M . Y$ & $1 V \cdot \leq .4$ & تتز انيا \\
\hline$\{09 . Y$ & AY.A & ra. & IV.Y & .4 & VQ.Y & أوغندا \\
\hline $19 \vee 1 . r$ & «2.r & rav. & $00 . \mathrm{V}$ & rᄉ. 9 & O.V.Y. & هصر \\
\hline raArr & 94.1 & 17904 & $\varepsilon r . r$ & 1... & IYAV. & الإجماني \\
\hline
\end{tabular}

Source: United Nations Economic commission for Africa(UNECA)Africa statistical yearbook Addis Ababa (2018) 


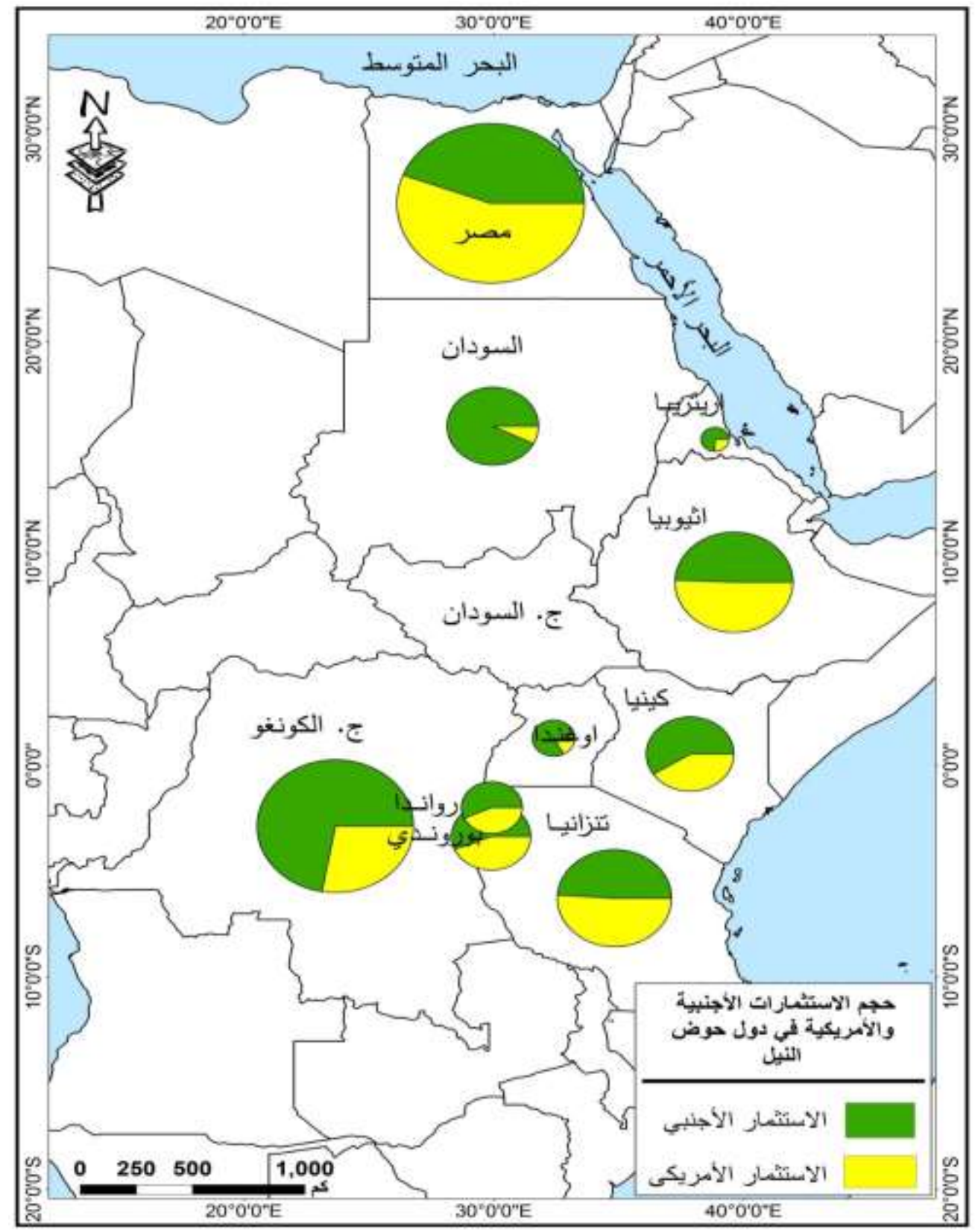

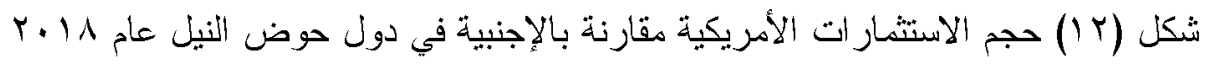

$$
\text { ه- أتجارة الخارجية لاول حوض النيل: }
$$

بتضح من خلال د راسة الجدول (ع ()) و الثُكل اليياني أن دول حوض النيل قد بلغت صادراتها

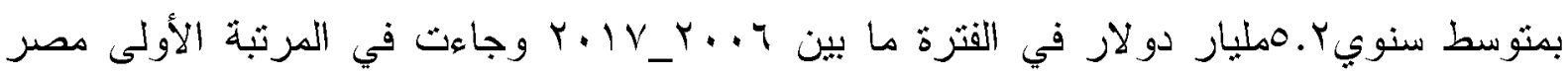
بمنوسط سنوي بلخ ع.بrمليار دو لار تمثل ع.9 ؛ \% ومن خلال الجدول بيضح: 
- - مأن دول مصر وكينيا والسودان والكونغو الديمقراطية ثمثل المركزين الأول والثاني إلى

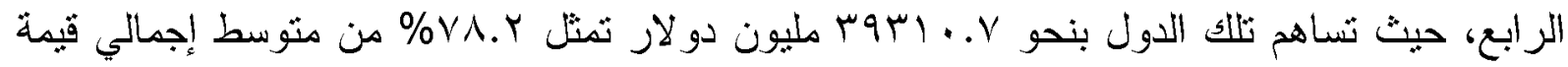

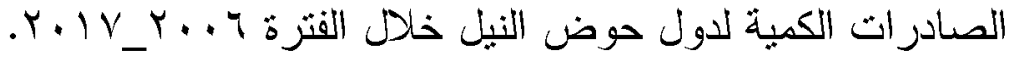

تذبلت رواندا وأريتريا وبوروندي قائمة حوض النيل من حبث مساهنهم في الصادرات الكلية بمنوسط سنوي بلغ ه.بامليون دولار تمثل V. \% من منوسط مساهمتهم في الصادرات الكلية لهذه الدول

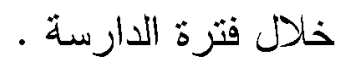

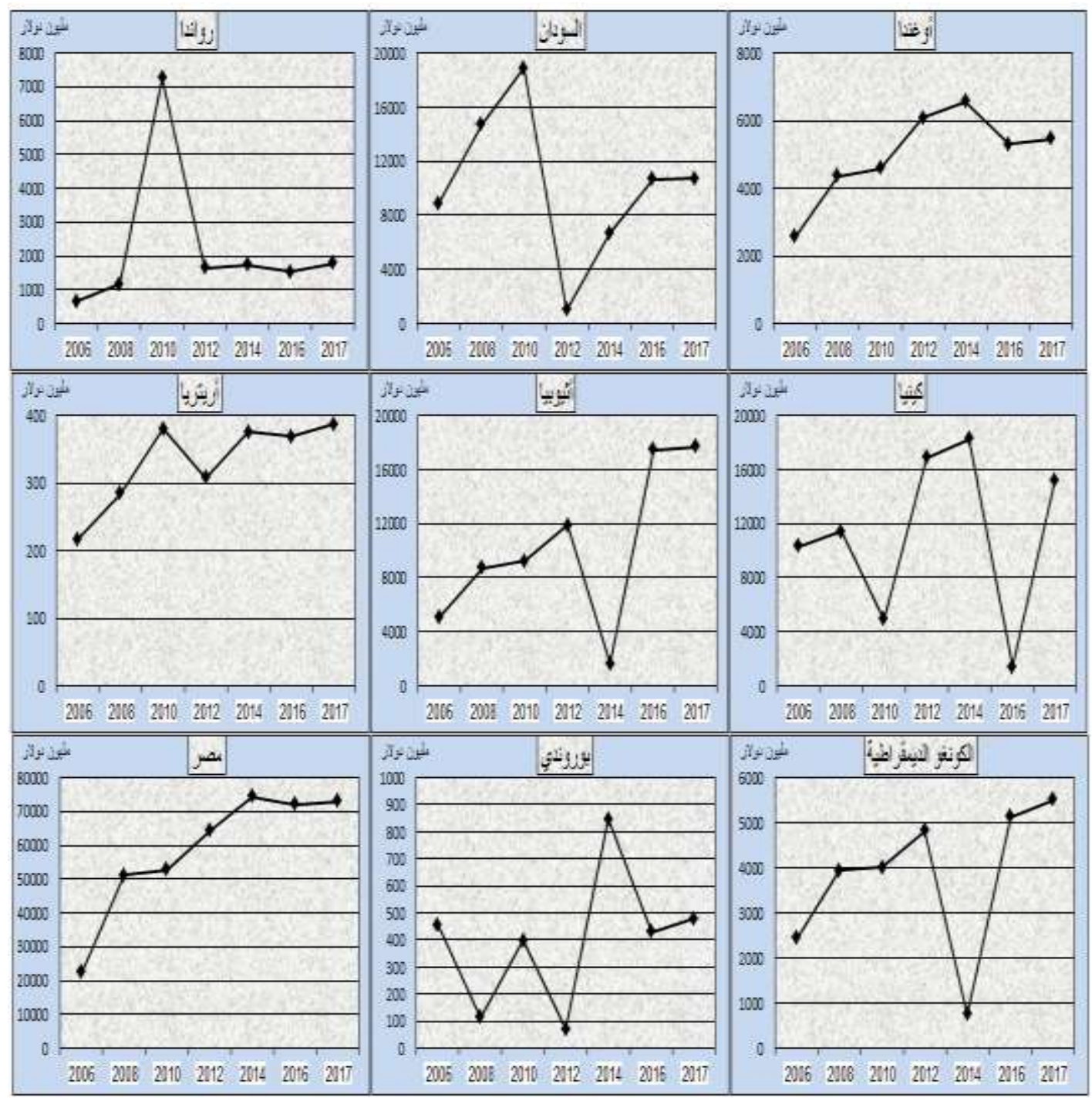

$$
\text { ب- بالواردات }
$$

واختلف الوضع بالنسبة لقيمة الواردات الكلية لدول حوض النيل كما يتضح من الجدول جدول نطور

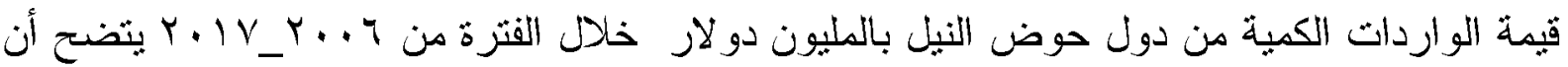


دولة مصر وكينيا و أثيو بيا والسودان و الكونغو الديمقراطية في مقدمة دول حوض النبل من حيث قيمة

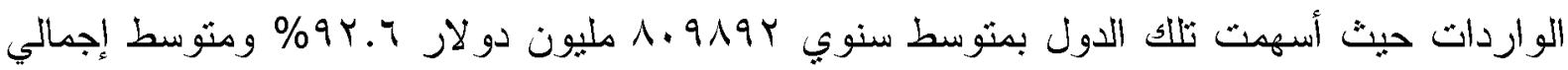

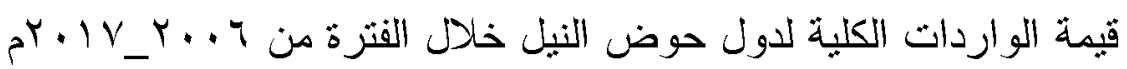

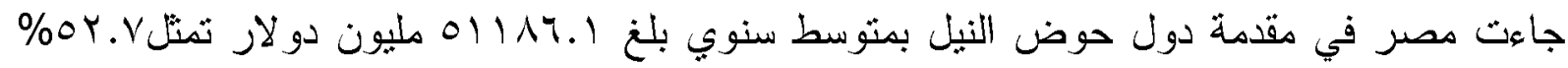
من المتوسط العام وتلاها دولة كينبا ثم أثنيوبيا و السودان و الكونغو الديمقر اطية بنسب ه. ب1 ، 11. 11 ،

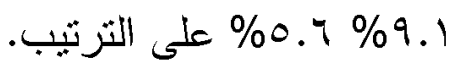

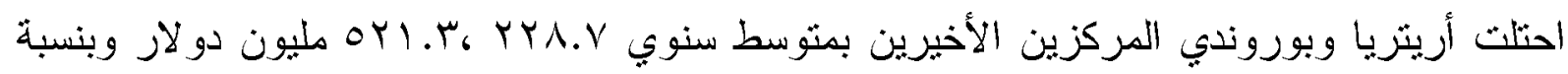

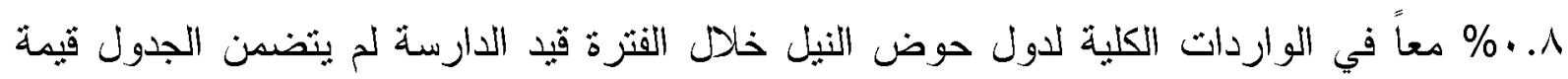
واردات تنزانيا، حيث لم نزد في التقرير ،وجنوب السودان الني تمر بمشاكل سياسية داخلية .

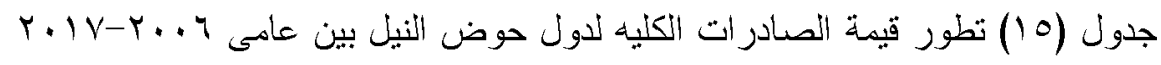

\begin{tabular}{|c|c|c|c|c|c|c|c|c|c|c|c|}
\hline الإجمالي & أو غند & تنز ان & نالسودا & رو اند & كينيا & أثثيو بيا & يأريتر & الكيمق الكونغو اط & بوروند & هصر & الكسنة \\
\hline EVฯVT.E & roov & - & $\Lambda \wedge \Lambda$. & 7.01 & $1+r+1$ & 01.0 & YIV & $r \leq 0$. & $\leqslant 00$ & $Y Y \leq 1 \cdot .9$ & $r \ldots r$ \\
\hline 71701 & ryva & - & $A \leq 7$. & 719 & IYAV. & OVAV & 178 & rATV & $7+\varepsilon$ & Y9970 & $Y \ldots r$ \\
\hline $971 \leq 9$ & $\varepsilon r q V$ & - & $1 \leq V 17$ & $11 \mathrm{VT}$ & NITAV & 149 & YAO & $r q \leq Y$ & $11 \leq$ & DITVY & $Y \ldots \lambda$ \\
\hline AY.01 & $2 r .7$ & - & No9Y & IYOV & $|Y \cdot Y|$ & VAvo & rar & $r \cdot V r$ & $r \leq r$ & $E \leqslant T r T$ & $r . .9$ \\
\hline 99475 & $\leqslant 0 \wedge$. & - & 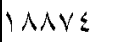 & YYOO & $\{91 \leqslant$ & $9 Y Y q$ & rᄉ. & 2.10 & ra1 & OYV $\leqslant A$ & $r+1$. \\
\hline $1.7 \wedge V Y$ & 01 Yo & - & $90 \leqslant 7$ & 1 rog & $17 \leqslant .7$ & AVYo & $2 \lambda$. & 0499 & A०ᄉ & $0 \lambda 9 T \leq$ & $r .11$ \\
\hline 1.7989 & $7 \cdot \lambda \Lambda$ & - & $99 \mathrm{~V}$ & 1704 & $17 \wedge 1$. & IIAVO & $r \cdot A$ & $\varepsilon \lambda Y O$ & v. & $T E Y \wedge T$ & $r+1 Y$ \\
\hline $1 Y \leq \leqslant V V$ & 7110 & - & 5770 & IVAr & iATrV & 11491 & $\leqslant 0 \Lambda$ & MINo & 911 & VTOTH & $r+i r$ \\
\hline MYKE. H & ToVt & - & $77 \leqslant 1$ & no. & IArrV & 1781 & rvo & $V \leq \lambda$ & $\Lambda \leq 4$ & $v \leqslant$ rov & $r+1 \leq$ \\
\hline $1 T \leq V .9$ & OANH & - & $1 \cdot \leq \leq 1$ & IVYq & $1 \leq 00$. & |VTOI & rvv & $1 \leq r \wedge r$ & 7.5 & virol & $r .10$ \\
\hline $1 Y Y \backslash 9$. & orgs & - & 1.704 & IOr & $1 \leq 1 \mathrm{~V}$ & $1 V \leq 74$ & ruA & $01 T \lambda$ & $\leqslant Y q$ & VYY.Y & $r .17$ \\
\hline$M+r q r$ & $0 \leq V T$ & - & $1+v \leq 1$ & IVV & $104 .$. & $1 v v+1$ & rAv & $001 Y$ & $\leqslant \wedge$. & $V T+11$ & $r+i v$ \\
\hline $\begin{array}{l}\text { IYS } \\
\leq\end{array}$ & $\leq \leq \nearrow \vee . Y$ & - & ANO. & ITAE & $r$ & $11 \leq 0 Y$. & YYA.V & OHYA.Y & OYI.T & $\begin{array}{l}01114 . \\
1\end{array}$ & طالمتوسد \\
\hline & $\xi$ & - & 9.1 & 1.5 & $1 r .0$ & 11.1 & $\cdot r$ & 0. . &. .0 & OY.V & $\%$ \\
\hline
\end{tabular}

Source:http://comstat.comesa.int 


\section{ج- - التجارة الخارجية لدول حوض النيل:}

وبالنظر إلى حجم التجارة الخارجية لدول حوض النيل بالمليون دولاز خاصة مع الولايات المنحدة الأمريكية، يتضح لنا دور دول حوض النيل في الميزان النجاري للولايات المنحدة الأمريكية و العالم

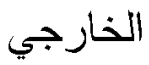

\begin{tabular}{|c|c|c|c|c|c|c|c|c|c|c|c|c|}
\hline \multicolumn{6}{|c|}{ العالم الخارجي "مليون دو لار " } & \multicolumn{6}{|c|}{ الو لايات المتحدة الأمريكية "مليون دولار" } & \multirow[t]{2}{*}{ 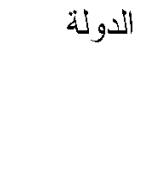 } \\
\hline$\%$ & الجملة & $\%$ & 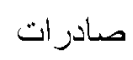 & $\%$ & و واردات & $\%$ & 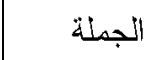 & $\%$ & 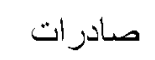 & $\%$ & و اردات & \\
\hline $1 \ldots$ & $1 . r .$. & - $1 . V$ & $0 \wedge \leqslant 0$ & $\leq r . r$ & $\leq \leqslant 00$ & $1 \cdots$ & Arol & $7 . .0$ & 0.01 & r9.0 & re & 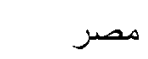 \\
\hline $1 \ldots$ & 777 & $\leq V .1$ & 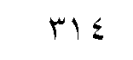 & or.9 & ror & $1 \ldots$ & rT. & $71 . \varepsilon$ & $9 \leq .0$ & rᄉ. & 9.1 & بوروندي \\
\hline $1 \ldots$ & $9 \vee \ldots$ & $\leqslant 9.0$ & $\leq \wedge$. & 0.0 & $\leq 9$. & $1 \ldots$ & 70. & ir & $\vee \wedge$ & $\wedge \wedge$ & orr & الكيمقر النغو \\
\hline $1 \ldots$ & $\leq \vee 7$ & ra.r & iAv & $7 . . V$ & r^q & $1 \cdots$ & lov.r & 10 & N.r & 10 & $1 \leq 9$ & أُرينزيا \\
\hline l.. & $191 \mathrm{r}$ & $\leq \Lambda$ & 901 & or & 1.41 & $1 \ldots$ & invo & 79.1 & $1 r .1$ & $r . r$ & $07 V$ & أثثيو بيا \\
\hline l.. & $r 111$ & rv. 9 & $\wedge \ldots$ & $7 r .11$ & 1511 & $1 \ldots$ & $1 . . v .1$ & r.. & ryo.1 & |r.A & $T \leq r$ & كينيا \\
\hline l.. & rror & $0 . .9$ & livs & $\leq 9.1$ & 1.1 .0 & $1 \ldots$ & $v_{0} . \varepsilon$ & r..A & YO.Y & 7.Y & $\leq 0 . Y$ & رو اندا \\
\hline $1 \ldots$ & 1748 & Or.r & AAV & $\leq 7.1$ & $\vee \wedge$. & $1 \ldots$ & 1.r & Vr. 9 & $09 . r$ & YV.l & rr & السو دان \\
\hline l.. & $11 \ldots$ & $\leqslant 9.1$ & ra7. & $0 . .1$ & $r .1 \leq$ & $1 \ldots$ & $\leq 4 \pi$ & H.V & Trt & rA.r & $|M|$ & تنز انيا \\
\hline l.. & $\leq \Lambda \mid \Lambda$ & $r . .1$ & rAry & 79.9 & $1.9 \wedge r$ & $1 \ldots$ & 171.7 & 01.9 & $\leq \wedge .1$ & $\leq \Lambda .1$ & 11.1 & أو غندا \\
\hline l.. & - & - & - & - & - & $1 \ldots$ & IIV.r & A.. & $1 \wedge . \wedge$ & $1 \wedge . \wedge$ & rr & ج السودان \\
\hline l.. & $\leq \ldots V Y$ & $01 . V$ & r.VTV & $\leq \Lambda . Y$ & $19 r \leq 0$ & $1 \ldots$ & $1 Y 97 \leq .0$ & ov.r & $V \leq r \leq .1$ & $\leq Y . V$ & $00 \leq \ldots \leq$ & الجملة \\
\hline
\end{tabular}

Source: $Y$. IAFioreign frade: U.S. Top trading partners, cansus bureau,

r. 1 Ahttp://constant.comesa

$$
\text { ينضح من د ارسة الجدول ( } 19 \text { ) و الثكل(11 )ما يلى : }
$$

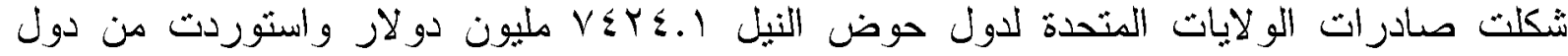
حوض النيل بما بعادل ع..،ـمهليون دولار وشكل الميزان التجاري لصادرات وواردات الولايات 


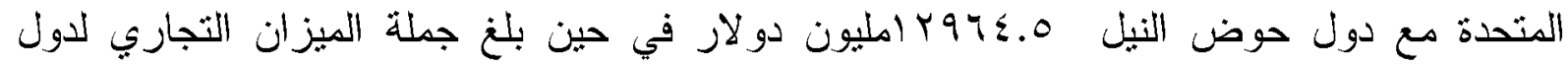

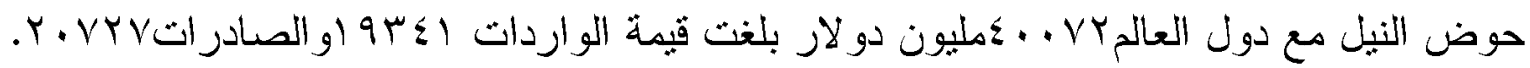

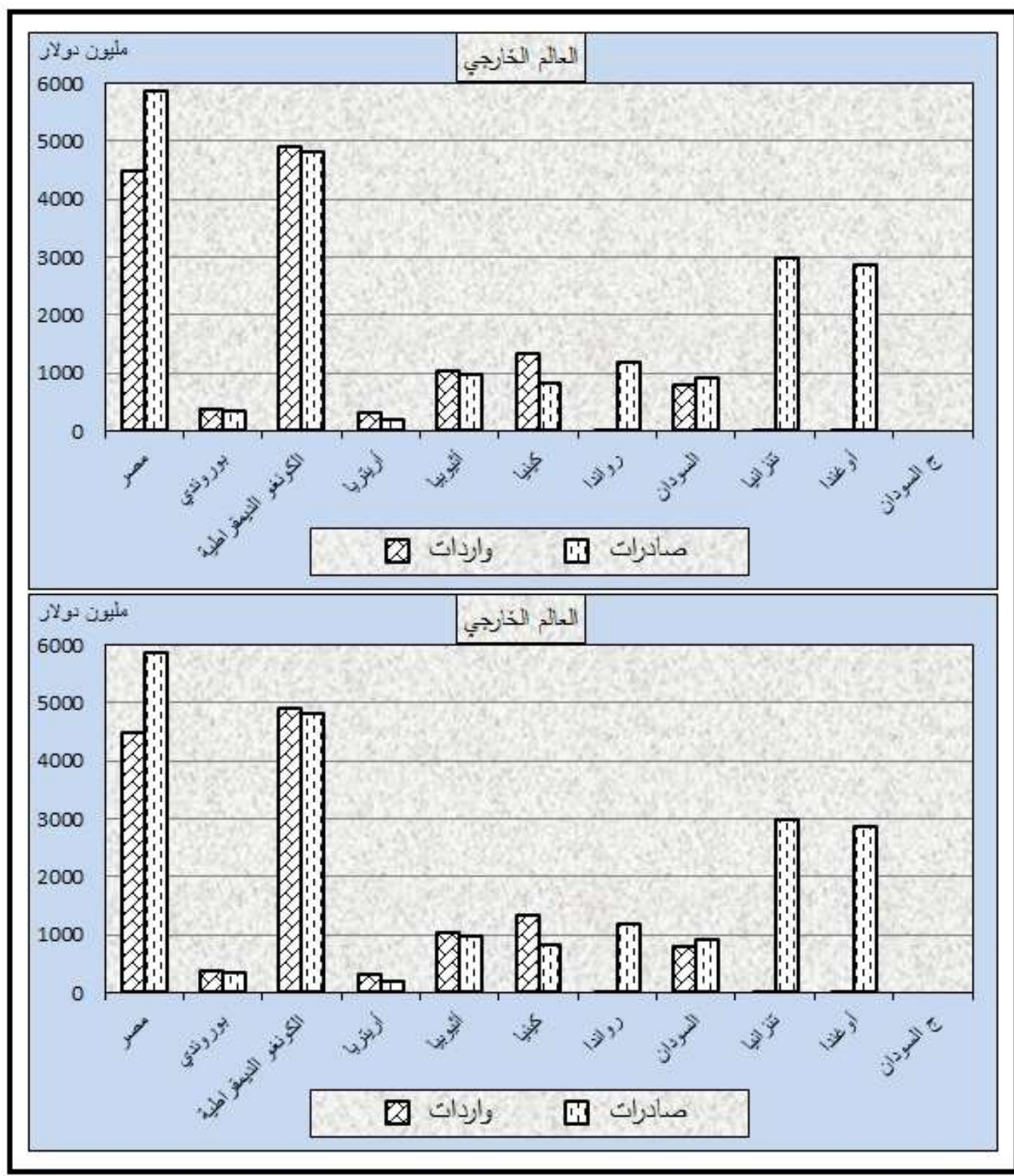

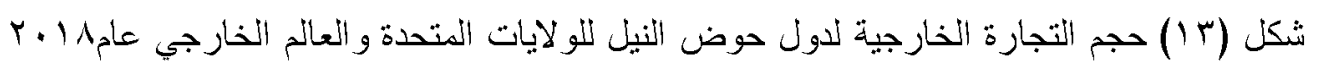

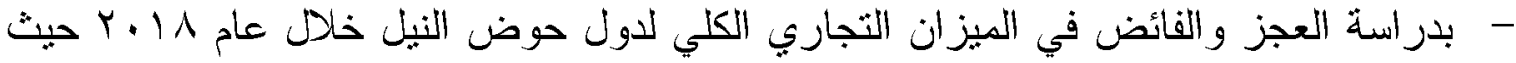
حققت كل دول حوض النيل عجزا في ميزانها التجاري الكلي واختلف الوضع بالنسبة للكونغو

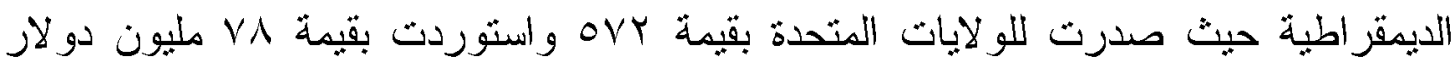

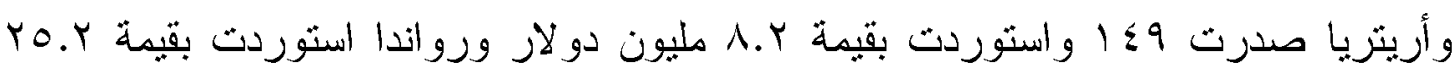

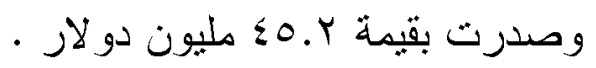




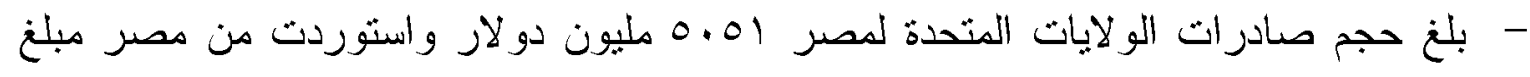

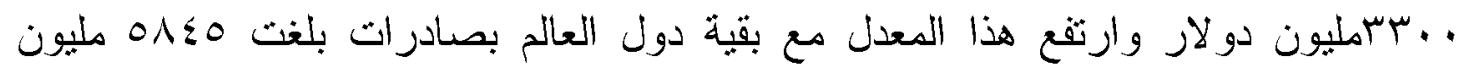

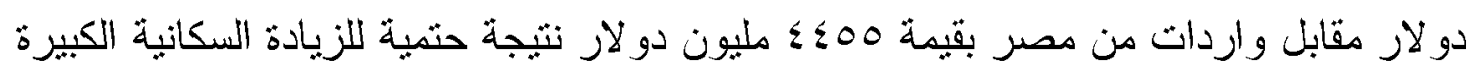

$$
\text { في مصر الني تلتهم كل جهود التتمية داخل البلاد . }
$$

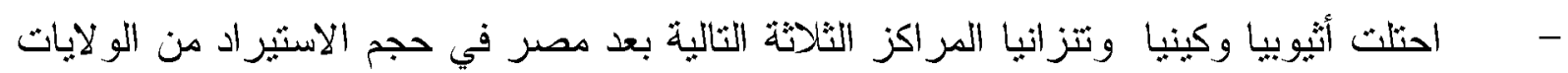

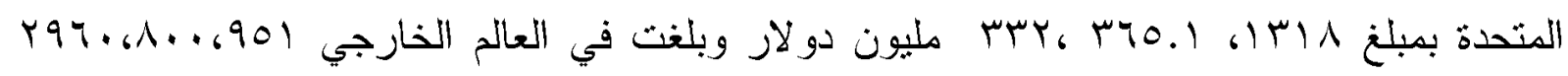

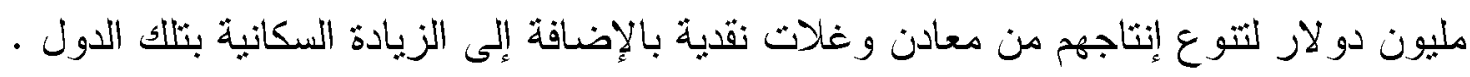
المحور الثالث: صور التدخل الأمريكي العسكرى في منطقة حوض النيل اعتمدت السياسة الأمريكية في نحديد علاقاتها بدول حوض النيل على عدة صور من التداخلات بحجة

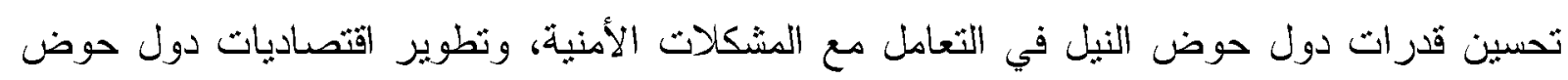
النيل بجانب التخل الوقائي الطبي للحد من انتثار الأمراض المتوطنة وساعد على زيادة التنخل والهيمنة الأمريكية غياب الإجماع والخلافات بين دول الإقلقيم مع الخلاف الدائم حول صياغة رؤية موحدة لإدراك المخاطر التى تهدد دول الإقليم.

أولاً: التدخل الأمريكي في دول حوض النيل أمنياً وعسكرياً: أصبحت الو لايات المتحدة الأمريكية بعد أحداث 11 سبتمبر | ...بم تتظر إلى دول حوض النبل من

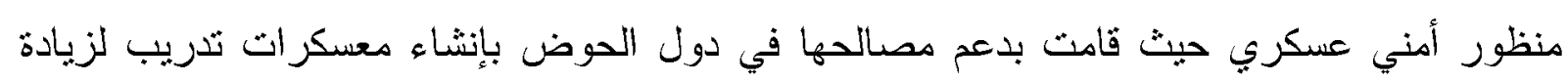

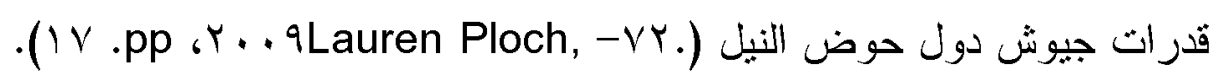

وتعزيز التعاون الإقليمي خاصة في قطاعات الدفاع والأمن الأمريكي وتحقيقاً للمصلحة الأمزيكية

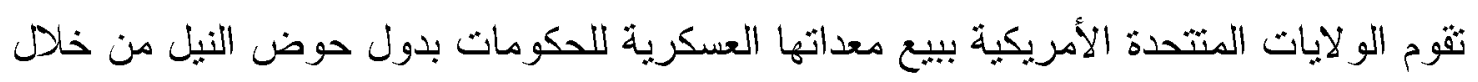

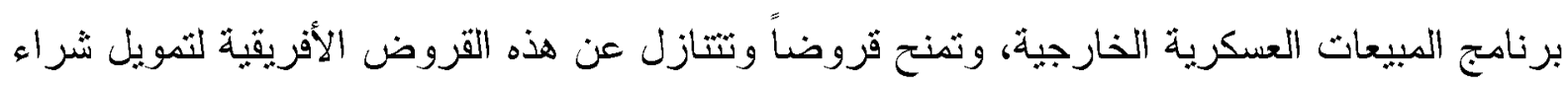

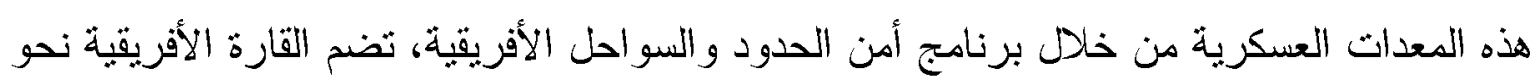

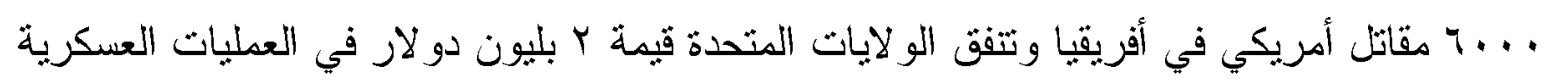

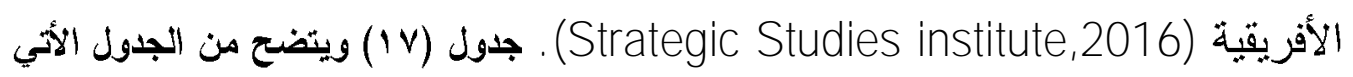


جدول ر قم (V)حجم قيمة الإنفاق على القو أعد الأمريكية العسكرية الأسلحة إلى دول حوض النيل عام 17 ـ.

\begin{tabular}{|c|c|c|}
\hline$\%$ & مليار دولار & الدولة \\
\hline 11.4 & 1.1 & بوروندي \\
\hline 0.7 & $\cdots 9$ & الكونغو الديمقراطية \\
\hline 11.1 & 1.9. & مصر \\
\hline $1 \wedge .$. & Y.q. & أريتريا \\
\hline o.. & $+\wedge$ & أثثيوبيا \\
\hline$\wedge .1$ & 1.5 & رواندا \\
\hline $1 \leq .4$ & Y.T & أو غندا \\
\hline $11 . r$ & 1.1 & السودان \\
\hline $1 \leqslant .9$ & Y.\&. & جنوب ألسودان \\
\hline $1 \ldots$ & 19.1 & الإجمالي \\
\hline
\end{tabular}

Y. 1 YSource: Strategic studies Institute, U.S Army war college

Lauren Ploch, Africa comonandi' US. Strategic interests and the role of the US military in .rะ.. rAfrica" CRS Reports RC

يتضح من الجدول أن حجم تداول الأسلحة بين دول حوض النيل عدا مصر قد ارتفع من •ب مليون

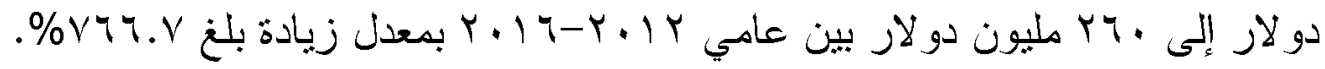

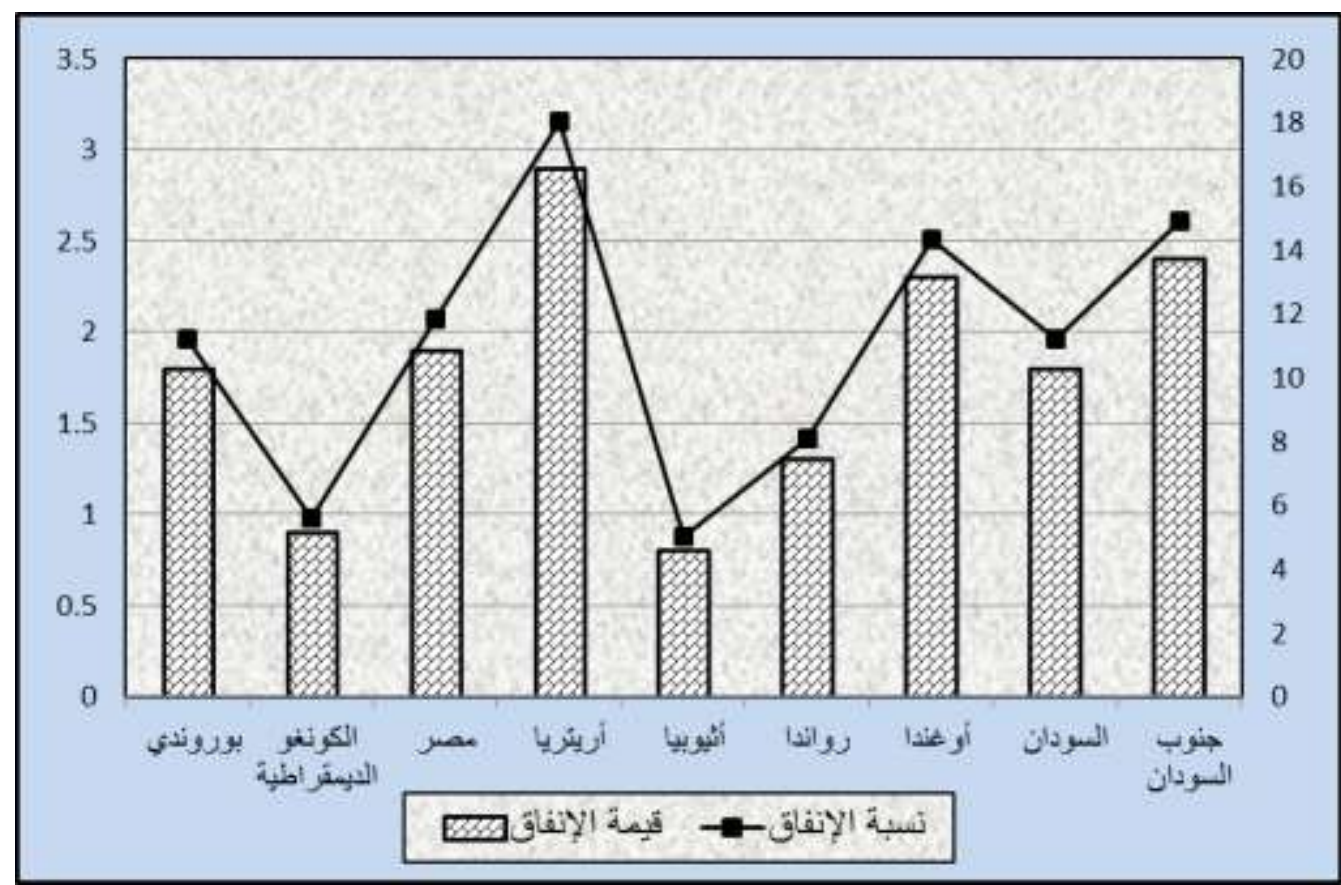

شكل (ع 1) احجم قيمة الإنفاق على القو اعد الأمريكية العسكرية الأسلحة إلى دول حوض النيل عام 17 ـب 
بلغ إنفاق الولايات المتحدة على قواعدها وتداول الأسلحة بين دول حوض النيل 1. 17 ملبار دولار

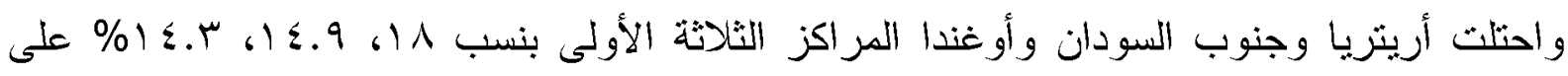

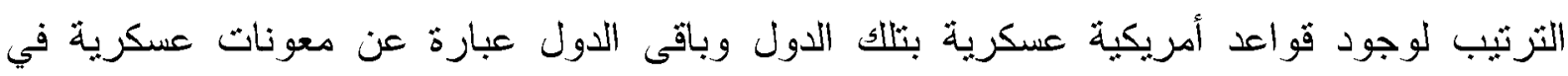

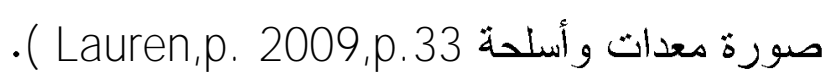
وتتمثل صور البرامج والمبادارت العسكرية في الأتى: 1- 1 درجة الاستجابة للأزمات الأفريقية 999 19 اقترح وارن كريستوفر Warn Christopher إنشاء قوة حفظ السلام تابعة لأفريقيا بعد أزمة بوروندي حيث تضم قوات عسكرية من دول أفريقية يثم تجهيز ها بمساعدة القوة العسكرية الأمريكية ،وتتنتر في مناطق الاضطر ابات ولم يلق هذا الاقتراح استجابة من دول الحوض النيل أنه نوع من الإمبريالية الأمريكية بحارب معارضة حلفاء أمريكا من الأوربيين .

199a Crisis Response InitiativeAfric : ץ-مبادرة الاستجابة للأزمات الأفريقية جاءت بناء على اقتراح السفير الأمريكي في أفريقيا "مارشال مكالي Marshal Maccallie" وتهدف إلى الندريب العسكري، مجال الإمداد بالمواد الإنجابية، وأن قرار نشر قوات حفظ السلام التابعة لها

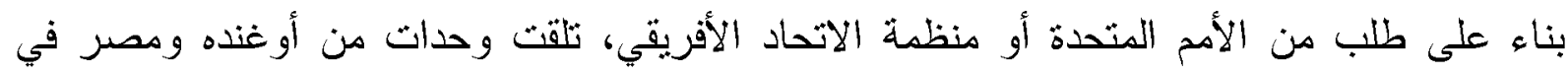
1999 تدريبات من هذه الجهة وشاركت تلاك الوحدات في حفظ السلام في سير اليون وغينيا بيساو وجميورية أفريقيا الوسطى، ثم امتدت المبادرة في النوسع مع وضع برامج بتحسين النعاون بين المنظمات الأفريقية غير الإقليمية.( السادك - الأيكواس جماعة شرق أفريقيا) .

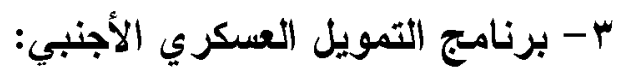

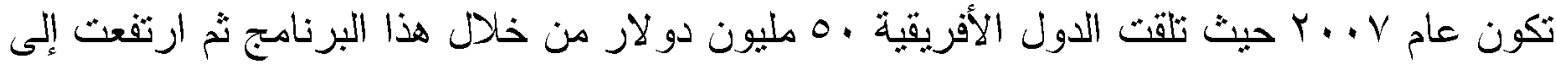

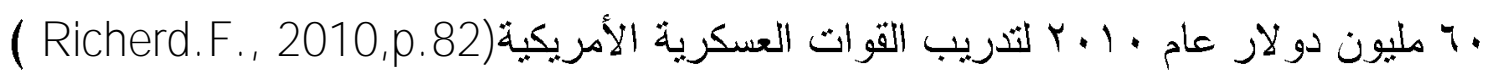
؛ - الطوارئ الأفريقية للمساعدة و التدريب: 
أسسه "بوش الابن "ـ . ب ويقوم بتدريب الجيوش الأفريقية لإجراء عمليات إحلال السلام مع تزويد

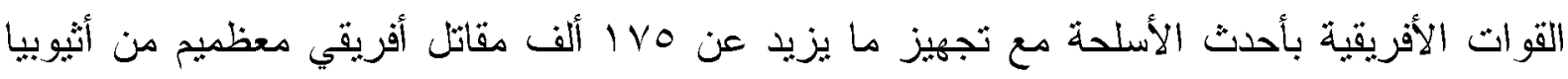
وكينيا ورو اندا وتتز انيا وأو غندا وغيرها من دول القارة.

ه- مبادرة مكافحة الإرهاب عبر الصحراء وشرق أفريقيا:

كانت في ب...r بتخصيص • (1 ملايين دولار لإنفاقها على دول القرن الأفريقي بغرض حماية

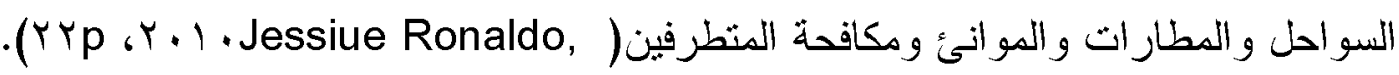
ج- قوة العمل المثتركة للقرن الأفريقي:

أنشئت عام Y . . Y وتهثم بالقضاء على الجماعات الإزهابية التي تعمل داخل تلك الدول وتضم ما يزيد

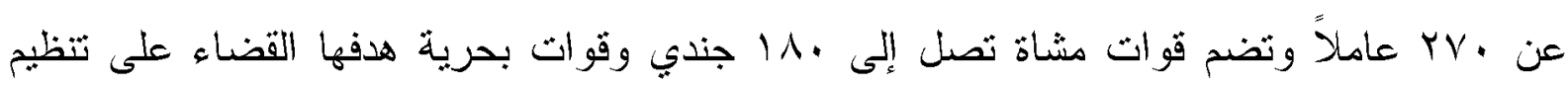
القاعدة و الإزر هاب بالمنطقة .

قامت هذه القوات بنغطية ميادين وفضاءات جوية في كينيا، السودان، أثيوبيا، أرينزيا بجانب الصومال وجيبوني، مع فرض هيمنة بحرية في البحر الأحمر وخليج عدن والمديط الهندي.

و الخلاصة هذه القوة ساعدت الولايات المتحدة الأمريكية في مكافحة الإزهاب في الثرق وتعزيز

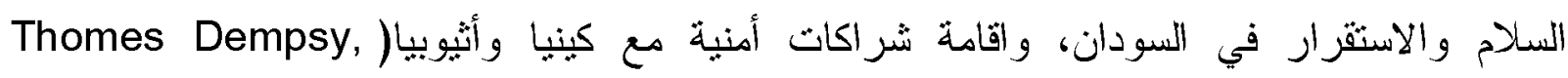
$\cdot(r) . P$. Y.. T

ثانياً: القيادة العسكرية الأمريكية في دول حوض النيل: قامت "إدارة جورج بوش" بإنشاء القيادة العسكرية المستقلة لأفريقيا حيث أن دول حوض النيل و أفريقيا تثطلب المزيد من الاهتمام من الولايات المتحدة الأمريكبة لتزايد أهميثها بالنسبة للمصالح الاستراتيجية لها، بجانب ما ثقاسيه القارة ودول حوض النيل من غياب الأمن، وعدم الاستقرار و انتشار التهديدات الإرهابية بها، في سبيل ذلك قامت بإنشاء:

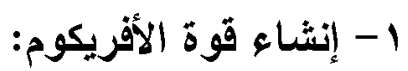


تم إنشاء هذه القوة العسكرية بعد نجاح الإسلاميين في السيطرة على مقالبد الحكم في الصومال

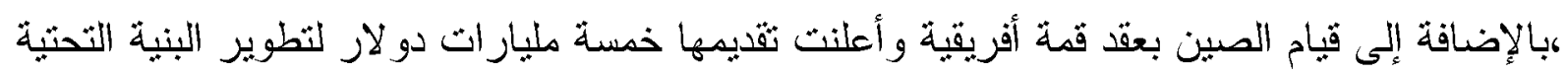
في دول حوض النيل و أفريقيا مقابل حصولها على النفط .

لا شكك أثنارت مخاوف الولايات المنحدة على مصالحها في دول حوض النيل وأفريقيا مما استخعى

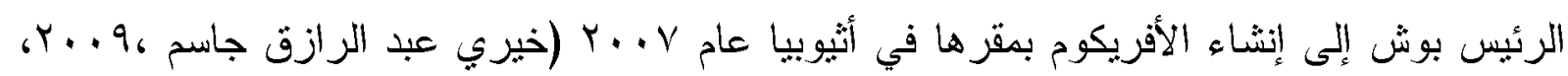

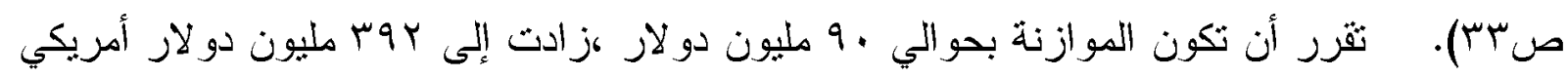

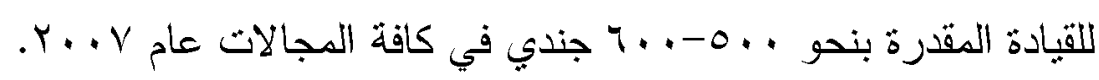

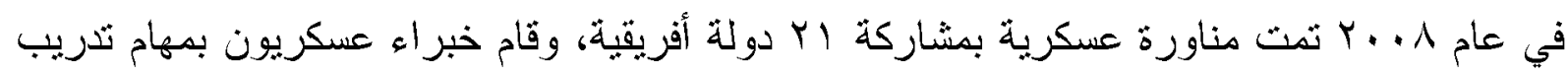

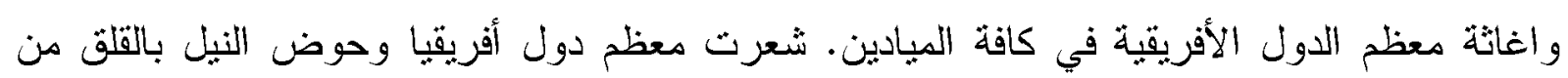
الأفريكوم، وهو شكل جديد من أنثكال الاستعمار لعسكرة القارة أمريكباً. .

\section{تعدد الأسباب لإنثاء الأفريكوم وأهمها:}

- محاولة الو لايات المتحدة جعل علاقتها بدول حوض النيل و أفريقيا عسكرية. - اعثماد الولايات المتحدة على نحو منز ايد على أفريقيا وحوض النيل لنوفير النفط ،مع نزايد إمدادها

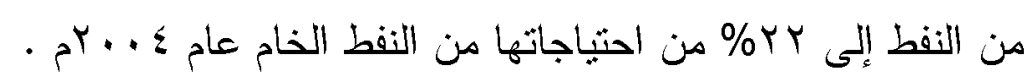
- أن معظم دول حوض النيل و أفريقيا تثبع نظم الحكم الديكتانورية. - خوف الو لايات المتحدة الأمركيية من ضعف معظم هذه الدول مما مهز الطريق إلى الإرهابيين . يشكل تأسيس قيادة أفريكوم انعطافاً بارزاً في خريطة البنتاجون على نحو هنح دول حوض النيل وزناً

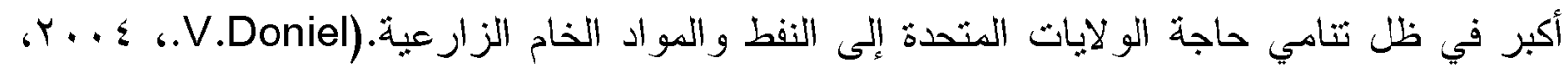

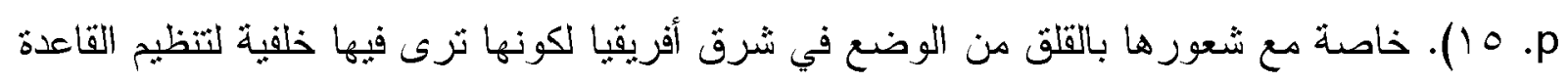

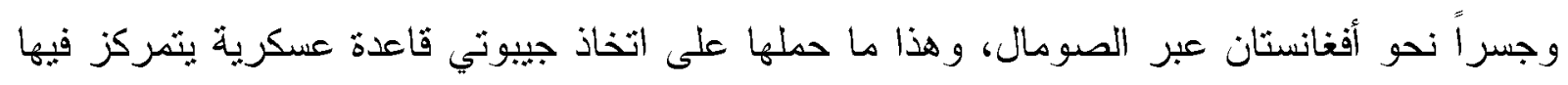
11. . . جندي من المارينز مع ثركز مجموعة من القوات البحرية والجوية الأمريكية .

تخطط الو لايات المتحدة لمزيد من الوجود والتمركز والانتثار في دول حوض النيل بنعزيز حضورها

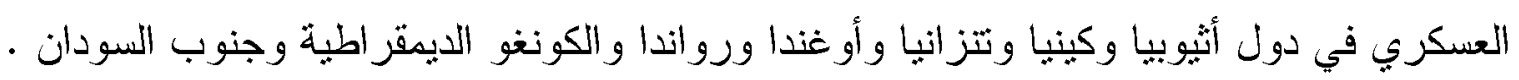


يمكن استتناج أن الوجود العسكري الأمريكي في دول حوض النيل أوجد إحساساً لاى دولها بالاستثواء في معادلة علاقاتها مع مصر، مما بدفعها إلى ثنبي سباسة خارجية عدو انية تجاه مصر ل توضح الخريطة الثالية المواقع الثي تثركز فيها القوات الأمريكية التابعة للأفريكوم في بعض دول

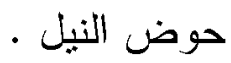

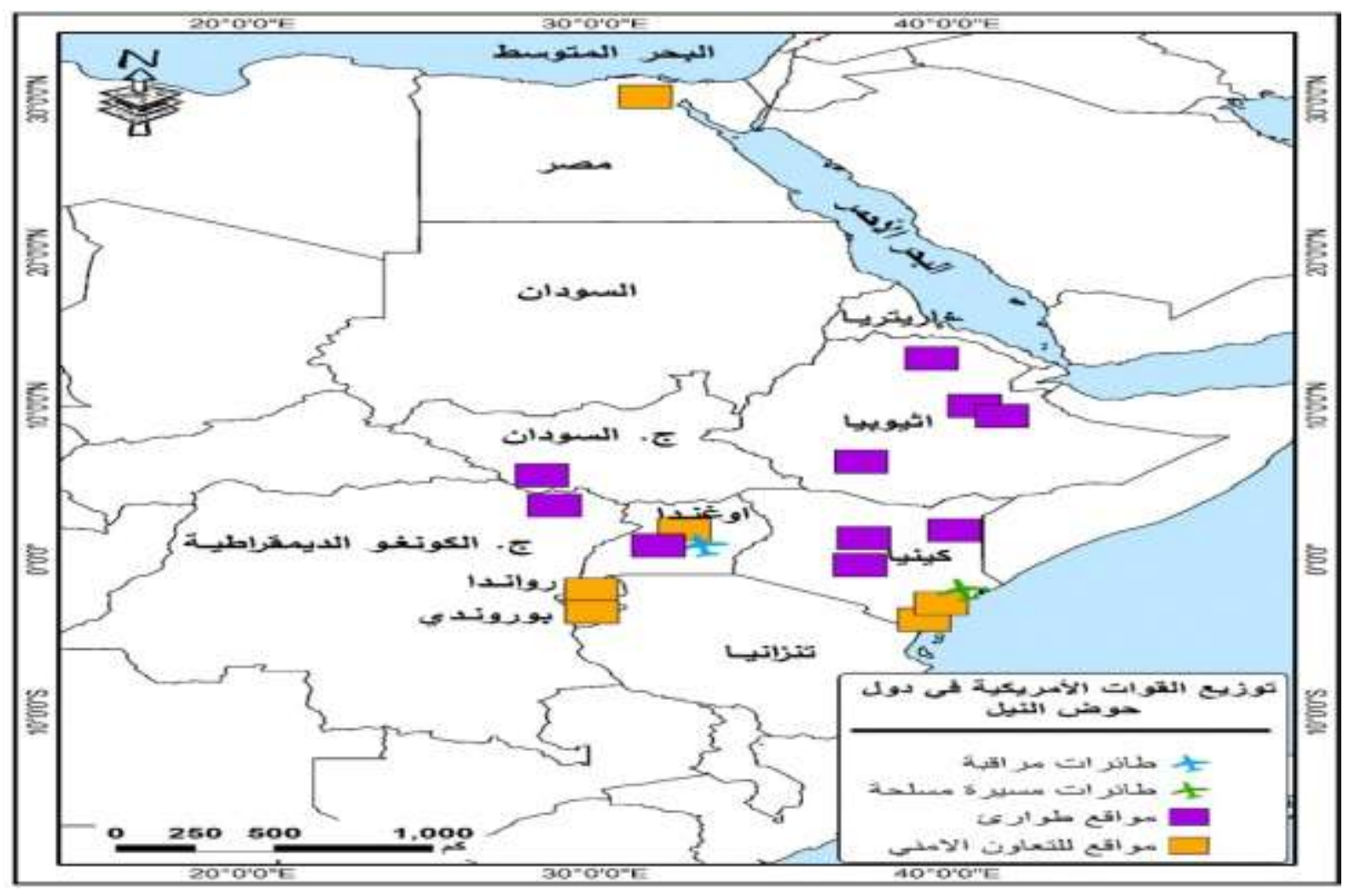

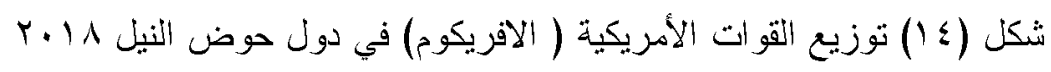

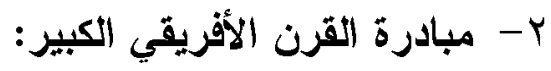

نظراً لما يمثلك القرن الأفريقي من الناحية الجيوسياسية بأهميثه لدى الولايات المتحدة الأمريكية ،حيث تعد المنطقة تثكل سوق للمنتجات الأمريكية، حيث تتنج ع ا\% من إجمالي صادرات النفط لممنطقة وتبلغ نسبة الواردات ا\% من إجمالي الواردات الأمريكية، وأعلن "ييل كلينتون" عام ـ199 عن مبادرة القرن الأفريقي الكبير، وتضم عشر دول منهم ثلاث دول من حوض النيل . طرحت الولايات المتحدة الأمريكية مبادرة مكافحة الإرهاب في شرق أفريقبا عام ب...r، قامت بتشكيل قوة العمل المشتركة بالقرن الأفريقي بهدف ثعزيز قدرات المؤسسات العسكرية الإقليمية، 
وقامت هذه القوة بنوفير التدريبات والمعدات لدول أثثيوبيا، وأوغندا، وكينيا، من الواضح أن أثيوييا تنتحوذ على الاهتمام الأمريكي في تلك المنطقة الاستراتيجية .

في عام r Y.r صدر ثقرير مهم من الاستخبارات الأمريكبة للأمن المائي العالمي، وجاء نهز النيل على قمة الثرتيب، ونم وضع نهز النيل على قمة أولويات السياسة المائية الأمريكية، وتبعها زيارة "باراك أوباما" 10 ـ ب إلى أثيوبيا و أكد دعمه لأمن أثثيوبيا القومي، خاصة في مشكلاتها مع مصر

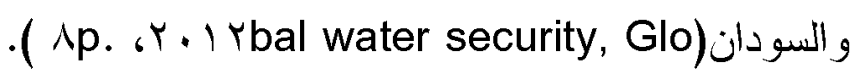
ثاثثاً: النزاعات بين حوض النيل والتدخل الأمريكي. تعاني بعض دول حوض النيل من النزاعات الداخلية المثركزة على النزاعات العرقية والكراهية بين القبائل و الجماعات المختلفة، ويمكن أيضاً تفسير ثلاك النزاعات بسبب الثقسيم القصري للحدود في بداية النظام الاستعماري أدى إلى قطع العلاقات بين القبائل، ومن هنا أصبحت الأثيبة مدخلاً للتكوينات السياسية، وتم ذلك وفق استراتيجية إستعمارية لإبقاء قبائل موقوتة تتحكم فيها لأطعماع الاستعمارية

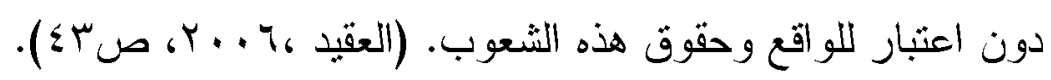

وفيما يلي إلقاء الضوء على أهم المشكلات في دول حوض النبل و التذخل الأمريكي.

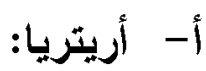

تعاني أريتريا من بعض التعقبدات، حيث بتكون مجتمعها من التيجرانيين( 0\%) من السكان و التقراء والكانما ويمنلون (•ـ\%) مع أقلية من العفر والساهو، ومن هنا تعاني من مشكلة سبيها الثقافة و الهوية، حيث بنقسم المجتمع إلى أقلبة مسيحية مسبطرة على السلطة وأغليية مسلمة ثرنبط بالدول العربية، ويتحدث سكانها اللغة العربية، ويثدثث المسيحيون اللغة التيجرانية، فمن المؤكد أن هناك صراع ثادم من خلال جبهة إسلامية لمقاومة النظام الحاكم . ب- أثثيوبيا:

تتصف بتعدد قومياتها وتلقب بمتحف الشعوب وتثميز ثلك القوميات بعدم تجانسها ناحية الأرومو الذين

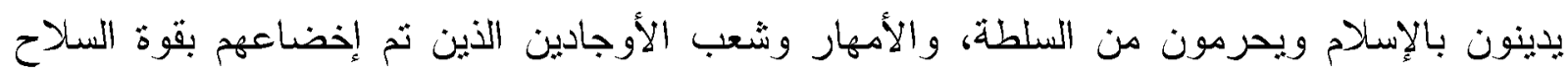

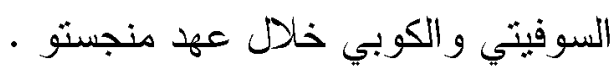


نثأت معظم التنظيمات السياسبة أساساً كحركات نحرر في الإقليم نطالب بالانفصال عن أثيوبيا ويأني الخطر من نسييس هذا التتوع في العرقيات واستخدامه كأداة لتحقيق مطالب سياسية.

جعلت من أثيوبيا مركز القيادة الأفريكوم وتقف بجانب الحكومة الأثيوبية ضد التنظيمات السباسبة،

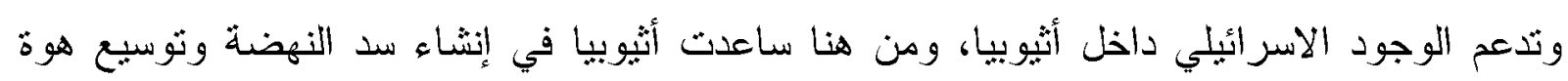
الخلاف بينها وبين مصر والسودان .

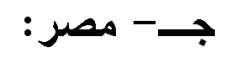

- اهتمت الولايات المتحدة بتكريس هيمنتبا الجيوستراتيجية وتمكين حلفائها من داخل حوض النيل

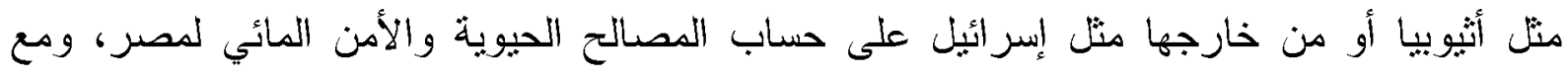

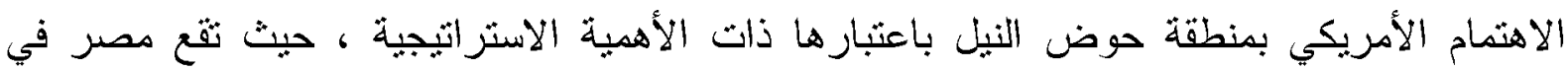
شمال الحوض وثرتبط بميزة مباشرة بالبحيرات العظمى في امتداد طيبعي حتى وسط القارة الأفريقية

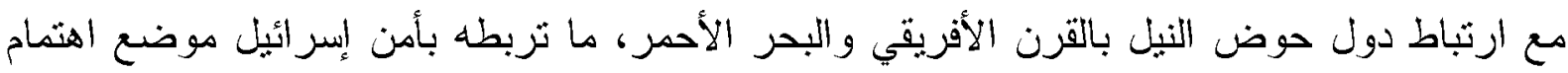

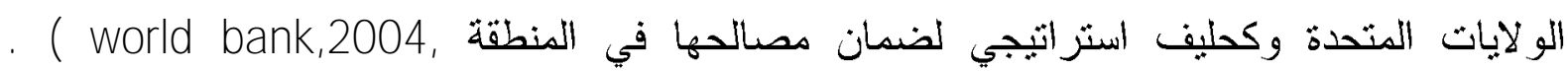

- فمنذ حقبة الخمسينات من القرن العشرين استمر الوجود الأمريكي في أثثوبيا من خلال قاعدة

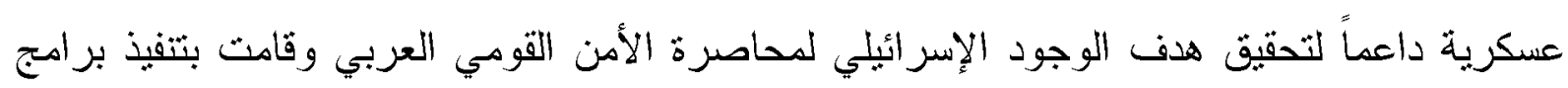

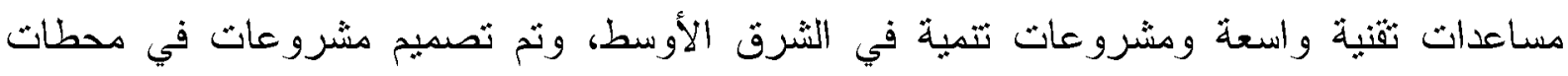
معالجة مباه الصرف أو دراسات الجدوى لبناء السدود .

وخلال حقبة الثمانينات ركزت الولايات المتحدة على الوجود الإسر ائيلي من خلال التمويل الأمريكي

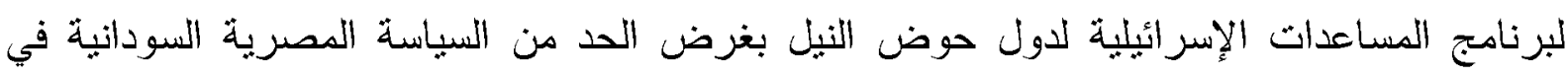

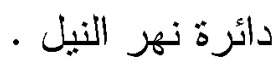

في التسعينات ركزت الولايات المتحدة بالثتأثير على الخزان المائي خاصة في منطقة النيل الأزرق

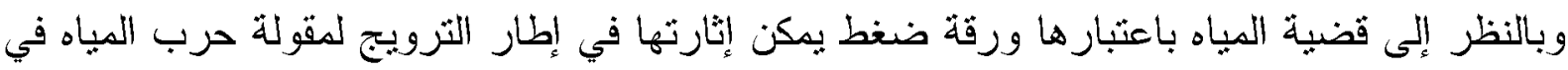

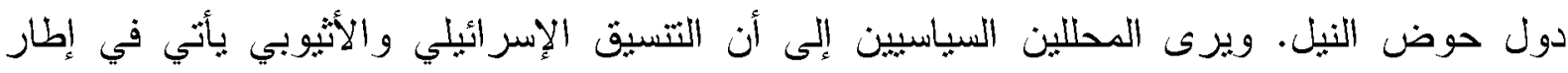

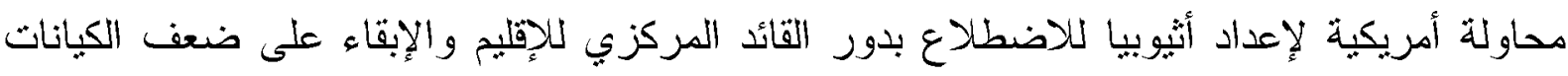

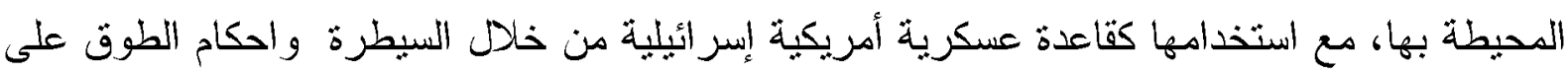

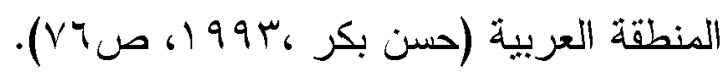


استهفت السياسة الأمريكية منطقة البحبرات الاسنو ائية وساعدت دولة أوغنده في إنهاء حكم الأغليية الهوتو في رواندا ومساعدة لوران كابيلا وتولية الحكم في الكونغو الديمقر اطية والهدف حصار مصر و السودان عامة من خلال التحكم في منابع النيل.

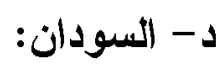

يعاني السودان العديد من المشكلات الداخلية والحدودية وأهمها مشكلة جنوب السودان، منذ عام . 199 وبسبب الاستعمار الإنجليزي بنطييقه سياسة الأ ارضي المققولة حتى يحدث الخلاف بين الثنمال

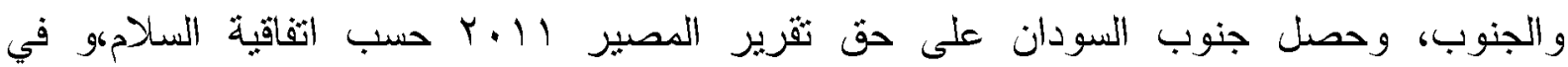

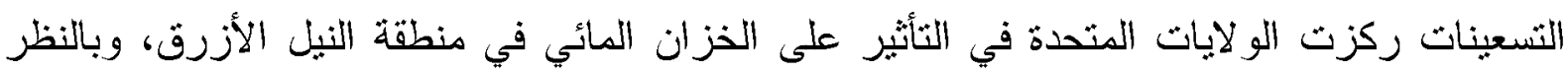
إلى قضبة المياه باعثبارها ورقة ضغط بمكن إثارنها في إطار النرويج للقولة حرب المياه في دول

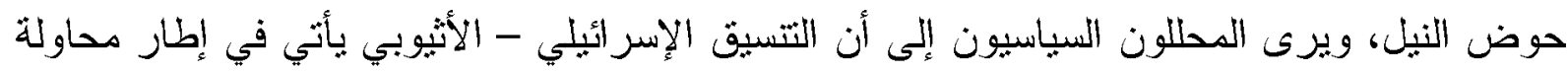

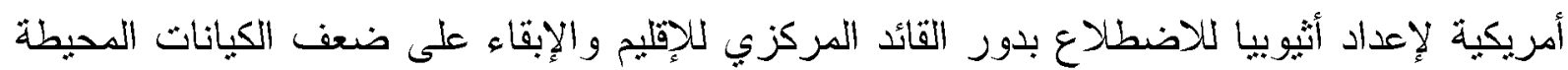

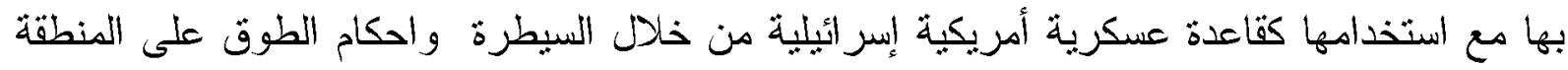

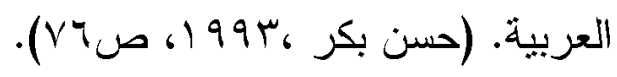

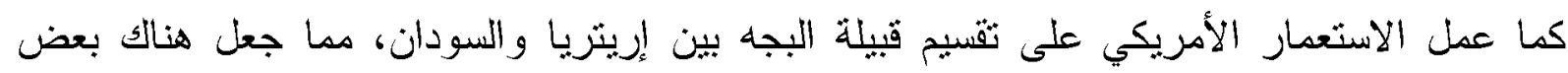
التعقيدات الحدودية و السياسية بين البلدين ،ساعدت في قيام تمرد بشرق السودان .

بالإضافة إلى مشكلة دارفور الحالية التي تسببث فيها الولايات المتحدة ودول أوربا حيث أخرجتها بثكل غير حقبقي للعالم وحولتها من مشكلة محلية تتصارع فيها القبائل الرعوية والزارعية على بلى

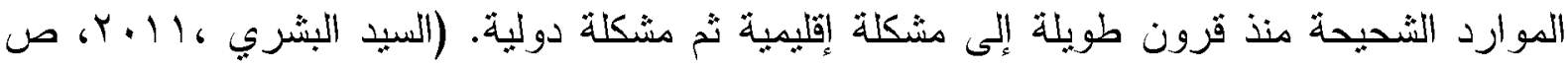

(rNt,r人t

وتمثل دور الولايات المتحددة الامريكية بثدويل الأزمة وركزت جهودها في السودان منذ عهد إدارة "بوش" رغم أن الأزمة سببها سهولة تدفقات السلاح إلى دارفور خاصة من الجنوب، وطمع الولايات المنحدة بثروات دارفور الطبيعية بجانب غياب التتمية المستدامة في الإقليم من الحكومة السودانية ونتيجة لهذه الأسباب فقد شهد الإقليم صراعات مستمرة وقامت الولايات المتحدة الأمريكية بتدعيم المتمردين منها جيش التحريز السوداني ،وحركة العدل و المساواة، ولذلك شـاركت الو لايات المتحدة في مفاوضات دارفور التي انعقدت في أبوجا ونيروبي، حتى نم نوقيع اتفاق سلام دارفور مع وجود قوات 
دولية بالإقليم، رغم معارضة الحكومة السودانية التي قررت معها الولايات المتحدة فرض عقوبات اقتصادية وسياسية وفرض حظر جوي فوق دارفور وحصار بحري على بورسودان.

\section{د- دينيا:}

ورثت كينيا من الاستعمار مشكلة الإقليم الصومالي ،الذب بشكل حوالي خمس مساحتها و كينبا

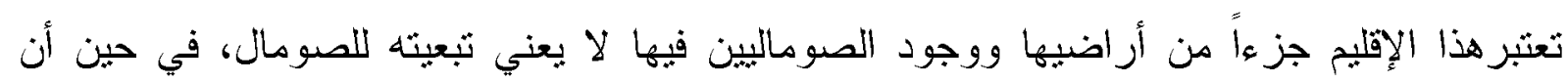

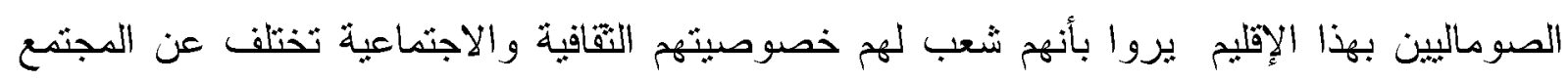
الكيني ،ولذا يجب إعطائهم حق تقريز المصبر بما يعني عودنهم للصومال الوطن الأم .

تعاني كينيا من مشكلات عديدة أخرى أهمها مشكلة التعقيد القبلي، حيث تضم خمس قبائل تثراوح نسبها بين ||

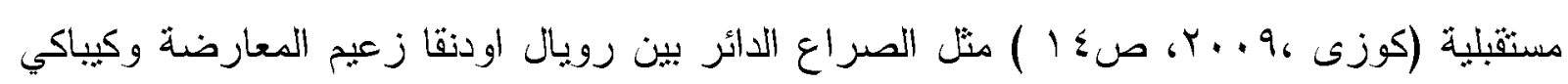

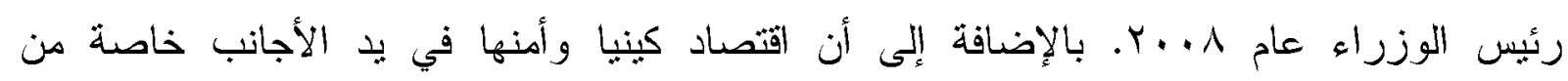

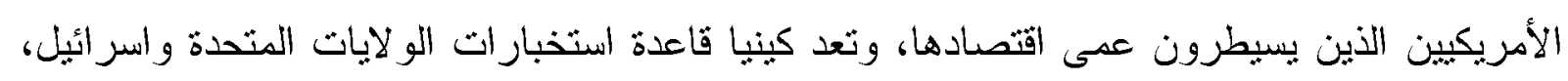
و الفساد بيسطر على البلاد .

رابعاً - الصارعات الداودية و التدخل الأمريكى:

سبيها الاستعمار عند تخطيطه للحدود لم يراع الاعثبارت (السلالية والثقافية والتاريخية والجغرافية

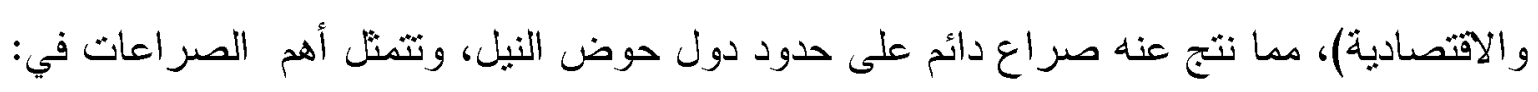
أ- الصراع الحدودي بين الصومال وأثيوبيا: فيما ينعلق بإقليم أوجادين والذي حسم عسكرياً بصورة

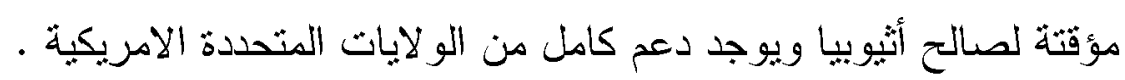

ب-الصراع الحدودي بين الصومال وكينيا: ويدور حول إقليم الأنفني المقتطع من الصومال، حيث

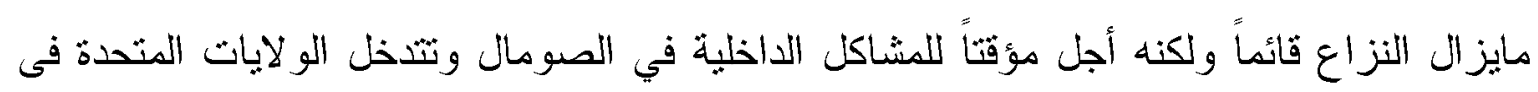
انساع الفجوة بينهما.

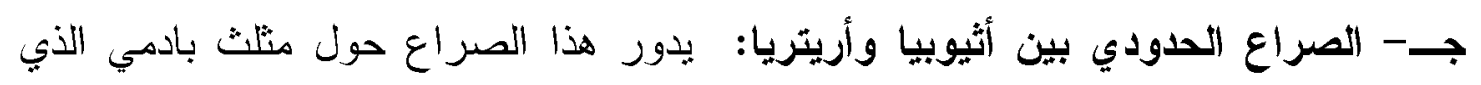

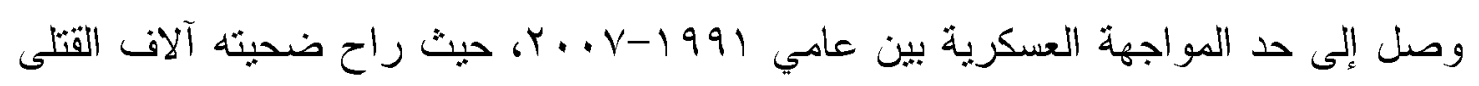


بين الدولثين، وان كانت حسمت المعارك لصالح أثثوبيا إلا أن كلا الطرفين بحثدان الجيوش دان

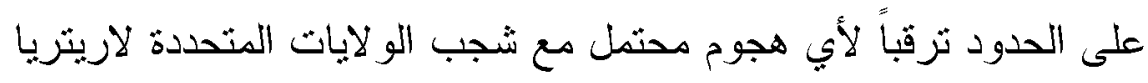
د- النزاع بين السودان وأثيوبيا: اتههت إثيوبيا السودان في محاولة إغنبال الرئيس المصري مبارك في يونيو 1990 مما زاد من تعقيد الامور بين الدولتين ، ناهيك عن نوتز العلاقات السودانية المصرية، كما اتهمت الدول الغربية السودان بدعم الجماعات الإسلامية في الصومال.

ويتمثل النزاع السوداني الإثيوبي في الحدود الثرقية حيث المزارع الخصبة المتتازع عليها ولم يكن إرجاع الأسباب إلى عدم دقة صياغة القو انين المتعلقة بالحدود ولكن الدولتين بصدد حل ودي للقضية برمنها بفضل ندخلات مصر.

\section{هـ- النزاع بين السودان وكينيا:}

حيث نحتل كينيا مثلث ألمى السوداني وهي منطقة يدور فيها الصراع بين قبائل التبوسا السودانية و البورون الكينبة وتلقى المشكلة تجاوب أمريكي مع الكينيين. خاصة مع اعثبار السودان منطقة إثنعاع حضاري خلال حكومة الإنقاذ الوطنى الثي ساهمت في نثاط الجماعات الإسلامبة في بعض الدول المجاورة خاصة حركة الجهاد الإسلامي في كينيا و إريثريا (El- Bushra,2005,pp.15) رابعاُ - مشكلات إقليمية سياسية: تتمثل في محاولة بعض دول الإقليم التخخل في الثؤون الداخلية لدول أخرى لتحقيق بعض الأهداف

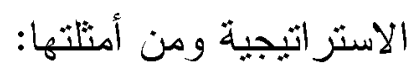
أ- - التدخل الأثيوبي في الصومال:

تبذل إثيو ييا أقصى مساعبها بثدخلها المباثر في شؤون الصومال الداخلبة لإضعاف أبي مباد رة لوحدة

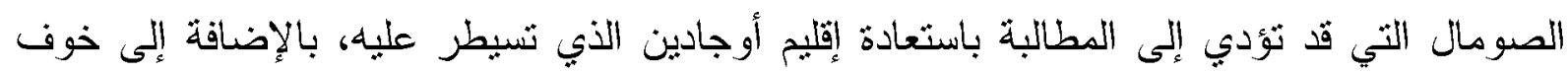

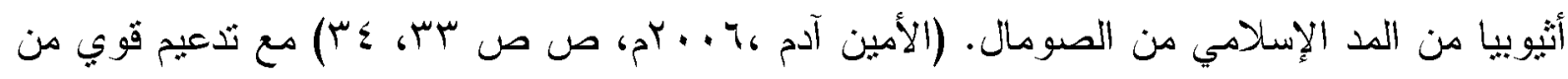
الو لايات المثحدة الأمريكية. 
ب- التدخل الأريتري في السودان: - (ان

بسبب طموحات رئيس الدولة أسباسي أفورقي، وبمساعدات أمريكية و أوربية وأفريقية جعلت منه جلاداً لنتفيذ أجندتها السياسية. ندخلت أرينربا في الثؤون الداخلية السودانبة لإسقاط نظام الحكم، بثقيم الدعم اللوجسني والمادي لجبهة الثرق، وبعد نوقيع اتفاقية السلام بين الجنوب والثمال والحوار

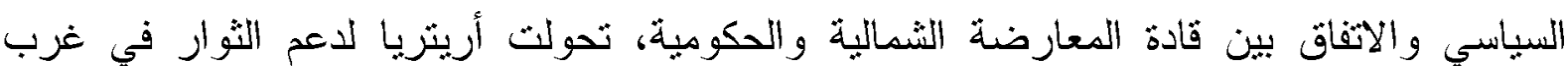
السودان وفشلت مساعيها للاختلافات الإثثية .

بعد هزيمة إرينزيا من قبل أثيوبيا ووقوف الدول الغربية والولايات المتحدة مع أثيوبيا، قامت أرينريا بتحسين علاقتها مع السودان والدول العربية ـ ولعبت مصر دور في إنجاح مفاوضات السلام بين

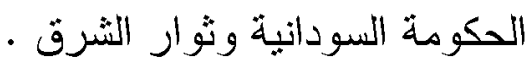
ج- - السودان والمد الإسلاهي: - (المي

تبنت السودان مشروع المد الإسلامي خلال الفترة الأولى من حكومة الإتفاق الوطني، مما أدى إلى

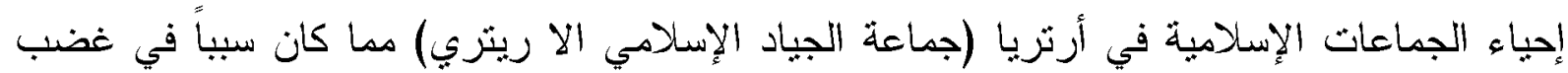
الحكومة الا ريترية التي قامت بثكوى السودان للأمم المتحدة مع اعتبار الولايات المتحدة أن السودان يحوي عدداً من الجماعات الإرهابية، خاصة مع اتهام الدول الغربية والو لايات المتحدة للسودان بدعم الجماعات الإسلامية في الصومال ،نتج عنه حصار إقليمي ودولي للسودان بدعم من الولايات المنحدة

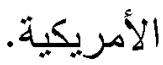

المحور الرابع : مظاهر الهيمنة الاقتصادية الأمريكية في دول حوض النيل نظراً لغنى القارة بالموارد الطييعية وحاجة الصناعة الأمريكية لهذه الثروات الطبيعية، مما اسهم إلى سعي الو لايات المنحدة الأمريكية البحث عن أسواق تصدير منتجاتها في ظل المنافسة مع الصينيين ودول أوربا الغربية، وفي ضوء ما سبق اتخذت الولايات المتحدة مجموعة التدايير للهيمنة الاقتصادية

أولاً: الإتفاقيات الاقتصادية مع دول الحوض: 
عملت إدارة كلينتون على نطوير التجارة مع دول الإقليم رافعة شعار التجارة أفضل من المساعدات ومن أهم هذه الاتفاقيات:

| - تثريع قانون للنمو والفرص الأفريقي (اغوا AGOA )

بدأ كلينتون بوضع ثصور لهذا القانون طبقاً لرؤيثه المستقبلية لدول حوض النيل ووافق الكونجرس

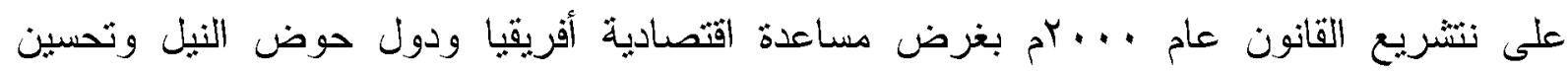
العلاقات بينها وبين الو لايات الدتحدة ودول حوض النيل .

يقوم البرنامج على نظام الأفضليات التجارية من جانب والذبي بسمح لبعض منتجات دول حوض النيل

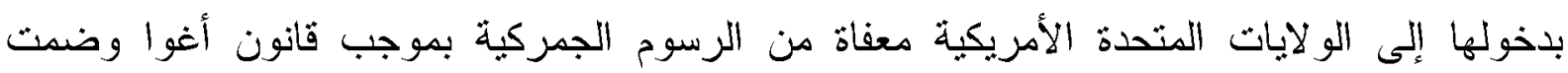

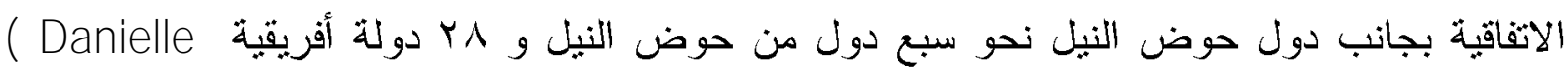
Longton,2008,pp. 34- 35) اهنم ممنلي التجارة الدولية من الأمريكيين بدعم جهود الدول الأفريقية من حوض النيل التي تثوم

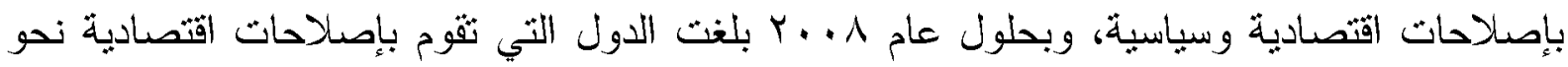

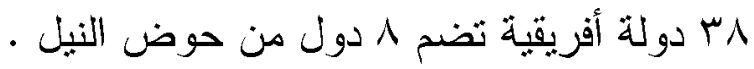

لاثتك أن قانون أغوا أسهم في زيادة الصاد ارت الأمريكية إلى دول حوض النيل بنحو r.0 مليار

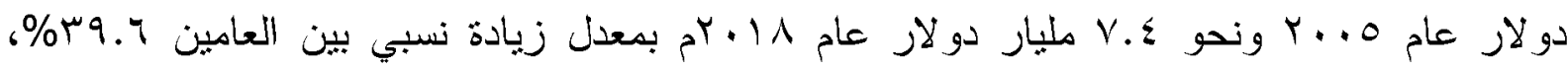

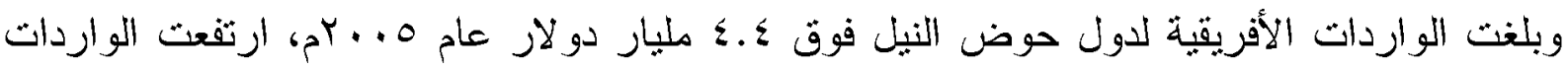

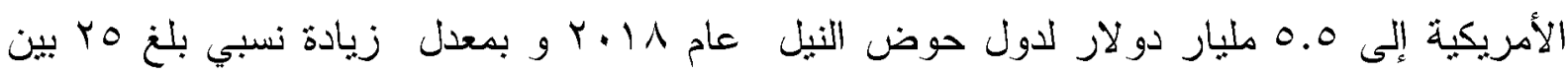

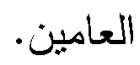

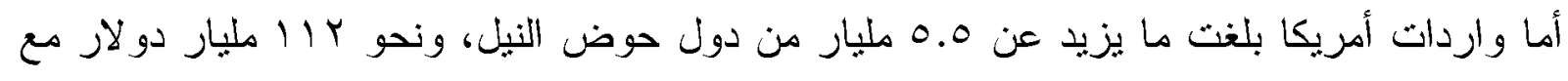

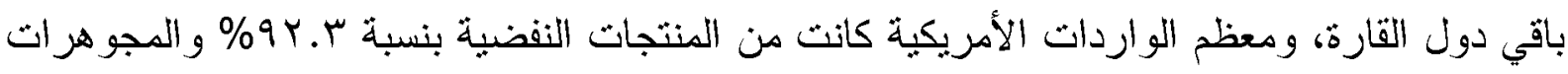

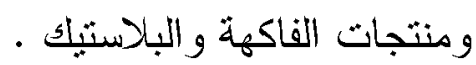

والواضح أن حجم التجارة بين الولايات المتحدة الأمريكية ودول حوض النيل وأفريقيا جنوب

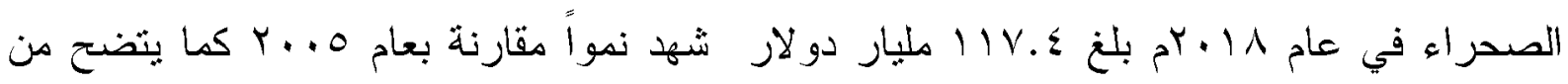

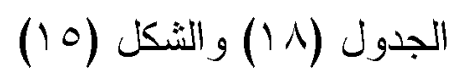


جدول (1 1) تجارة الو لايات المتحدة مي دول حوض النيل مقارنة بدول أفريقيا جنوب الصحر اء (القيمة بمليون دولار)

\begin{tabular}{|c|c|c|c|c|c|c|c|c|}
\hline \multicolumn{2}{|c|}{$r+\backslash \lambda$} & \multicolumn{2}{|c|}{$r \cdot T^{\prime}$} & \multicolumn{2}{|c|}{$r \ldots \lambda$} & \multicolumn{2}{|c|}{$b^{r \cdots o}$} & \multirow[b]{2}{*}{ الصاد ارت / الو اردات } \\
\hline$\%$ & القيمة مليار & $\%$ & القيمة & $\%$ & مليار & $\%$ & مليار & \\
\hline$\wedge . . \wedge$ & MIYrIT & $V V .9$ & YYYYI & Vo.r & $1 \times \leq 97.1$ & 70.7 & $1 . r 1 \cdot V$ & جنوب الصحراء الصاء الصزيكية أقريقيا \\
\hline 19.5 & $V \leq r \leq 1$ & YY.I & $T \leqslant Y r T$ & $r \leq . \Lambda$ & $7111 \mathrm{~V}$ & $r \leq . \varepsilon$ & orotr & تول حوض النيل \\
\hline $1 \cdots$ & rAY $\leqslant 0 Y$ & $1 \cdots$ & $r A \cdot \leqslant r T$ & $1 \ldots$ & $Y \leq Y \cdot V \Lambda$ & $1 \ldots$ & 100779 & الإجماني \\
\hline & $11, \ldots$ & 90 & $9 \vee \cdot \leq r . \leqslant$ & $q \leq . V$ & NY.OTV & 91.9 & $0.47 \leq 4$ & جنوب الصحر اءهاء الأمزيكية أفريقيا \\
\hline & $00 \leqslant \cdot \varepsilon$ & 0 & $0 \mid Y \cdot r$ & $0 . r$ & $\leq \vee \backslash \Lambda \leq$ & ᄉ. 1 & $\leq \leqslant$ SYY & دول حوض النيل \\
\hline & & $1 \cdots$ & D. YIYTV & $1 \cdots$ & $q . \wedge r ! 1$ & '.. & DEV৭VY & \\
\hline
\end{tabular}

Source: U. S of commerce, bureau of cansus various years

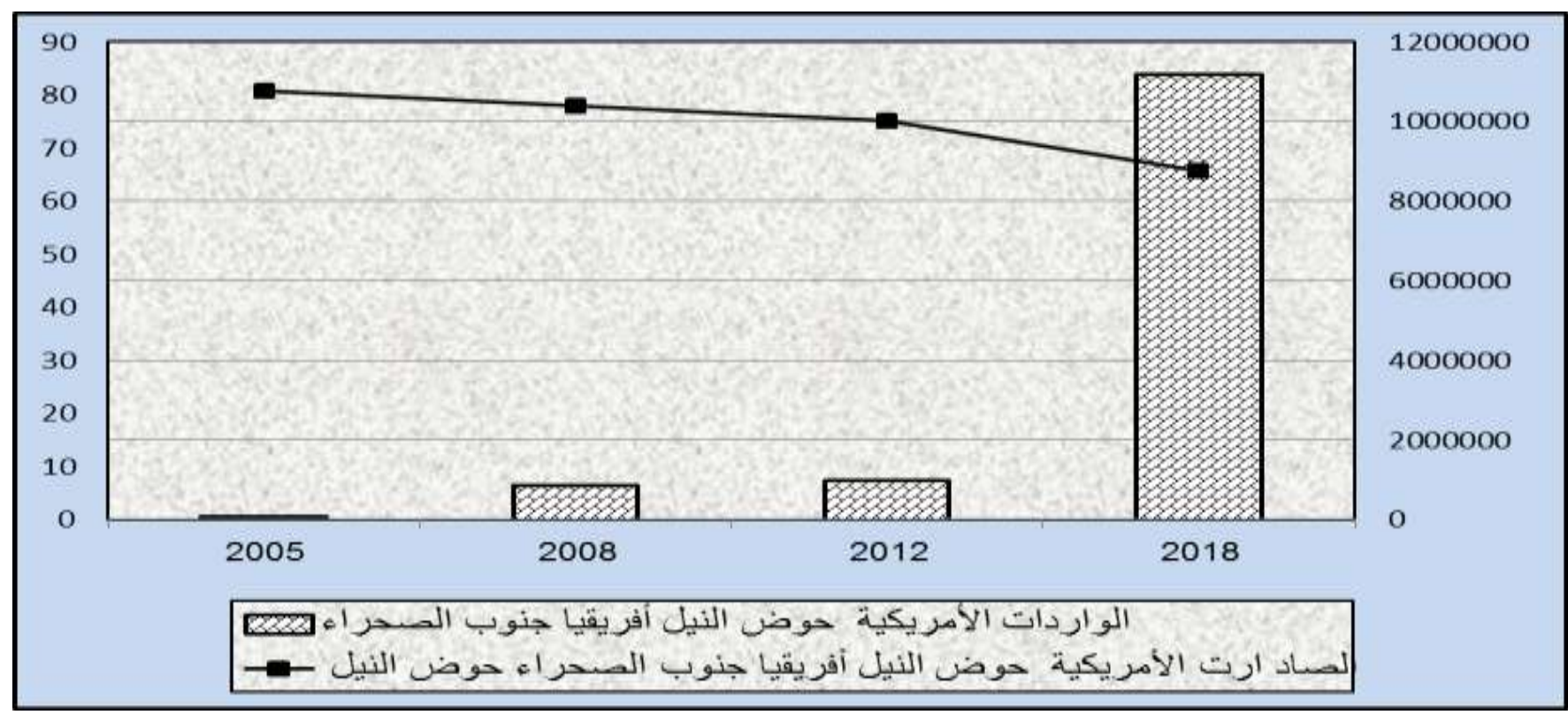

شكل (0 ) تجازة الو لايات المتحدة مع دول حوض النيل مقارنة بذول أفريقيا جنوب الصحراء 
ادعت الولايات المتحدة أن الديمقراطية في دول حوض النيل شرطاً لعلاقات قوية مع الولايات المتحدة الأمريكية لنتئجيع التحول الديمقر اطي ودعم حقوق الإنسان واتخذت في سبل ذلك الخطوات الآتية: 1- خفضت إدارة بوش الأب المساعدات الاقتصادية إلى الحكام الأفارقة الدبكتاتوريين مثل (موي) في

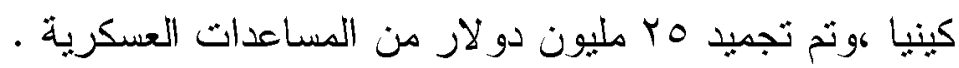
r- أعلن الرئيس كمينتون اهتمامه بقضايا حقوق الإنسان و الديمقر اطبة في القارة. r- خفت الو لايات المتحدة المساعدات الاقتصادية للسودان عام 990 ام بسبب السباسة الديكتانورية

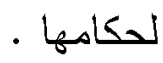

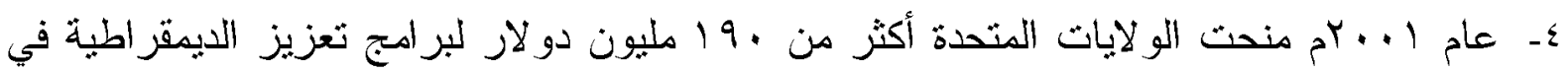

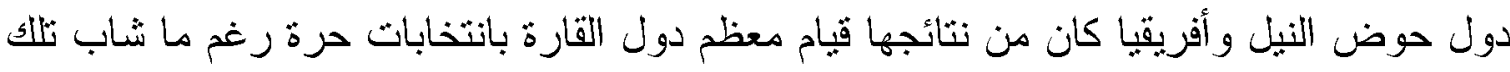

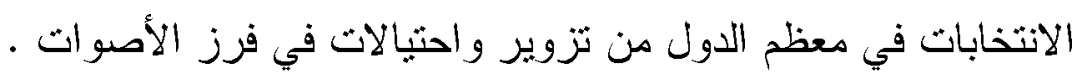
هـ تغاضت الولايات المنحدة عن تعنت الايكتانور رئيس الوزارء الأثيوبي مياس زيناوي وقضائه

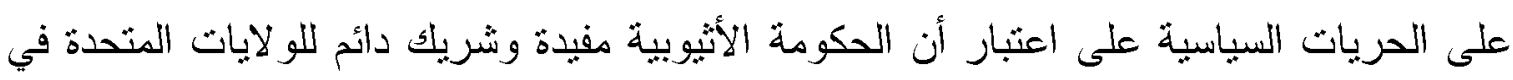

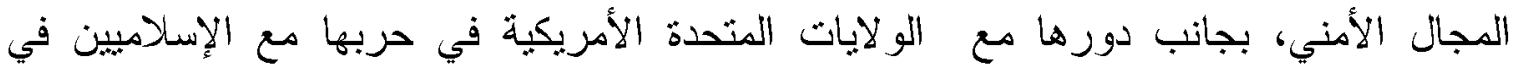

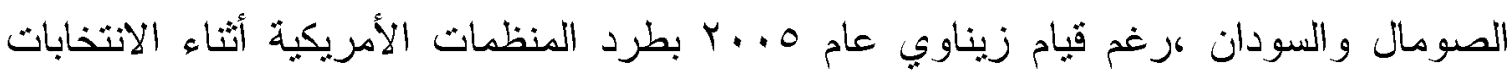

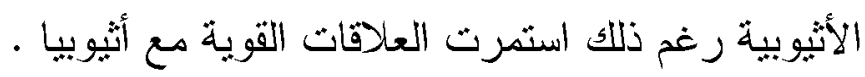

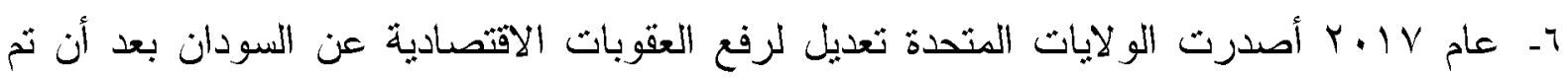

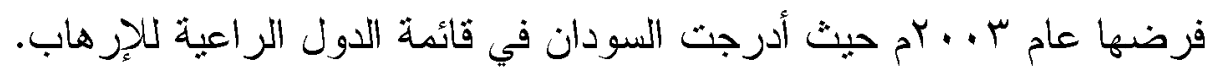

V- شهدت العلاقات المصرية الأمريكية نقلة نوعية منذ فنرة حكم الرئيس محد أنور السادات و استمرت خلال فترة حكم الرئيس الأسبق محمد مبارك.

^- تنتلك مصر الهيمنة في الدوائر السياسية والعسكرية والثقافية والدبلوماسية العربية والأفريقية،

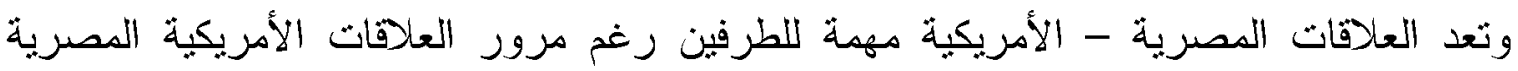
خلا عزل الرئيس مرسي بمرحلة من الفتور خاصة وأن من عزل مرسي كانت المؤسسة مرونة 
العسكرية ولكن الرئيس الأمريكي ثزامب أعاد العلاقات لقونها، وأكد محورية الجيش المصري في

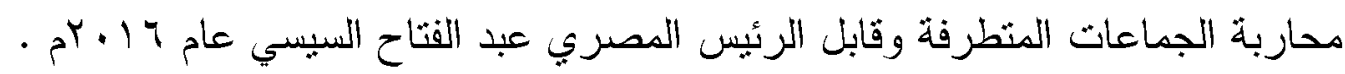

ثُأثاً: فرض الهيمنة الأمريكية في المجال الصحي:

اهنمت الولايات المتحدة الأمريكية بدراسة أقدم الأمراض في قارة أفريقيا معتقدة أن هذا

الإجراء سيكسبها تعاطف الشعوب معها، إنما الغرض الحقيقي أن مرض مثل الإيدز ييدد القوات

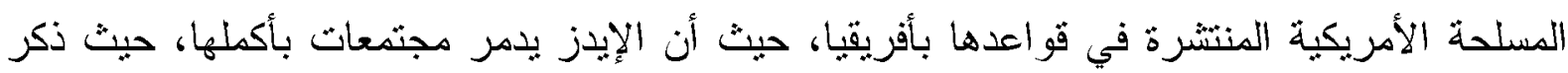

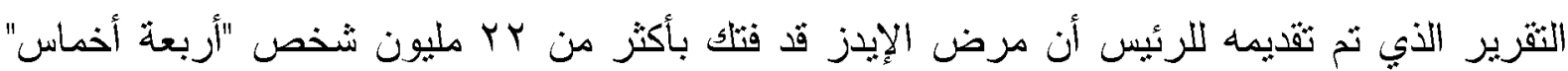
في أفريقيا ودول حوض النيل، واهتمت إدارة بوش في مكافحة هذا الوباء وأنفق نحو ل. .0 مليون دو لار لمكافحة المرض مع إطلالة خطة للإغاثة من الإيدز وهو برنامج خصص له آ مليار دولار على مدة بينية مدنها خمس سنو ات منذ عام ... .بم .

أعداد الضحايا من مرض الإيدز نخطى العشرة مليون بدول حوض النيل ، ، با ألفاً بسبب الملاريا

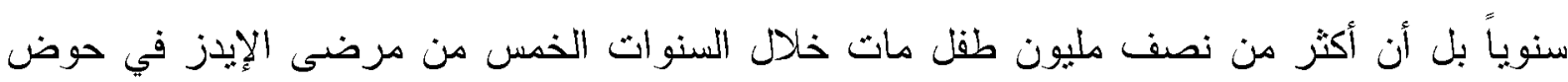
النيل ويموت ؛ مليون شخص من الأمر اض التنفسية .

أكدت مصادر الصحة العالمية أن علاج الأمراض وتكلفة صناعة الدواء نكلف دول القارة الأفريقية

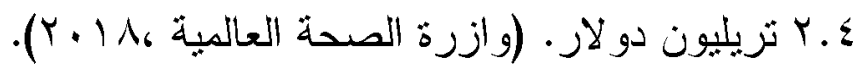

حرصت الحكومات الحالية الأمريكية على صرت ما يزيد عن ·r مليار دولار في القارة الأفريقية

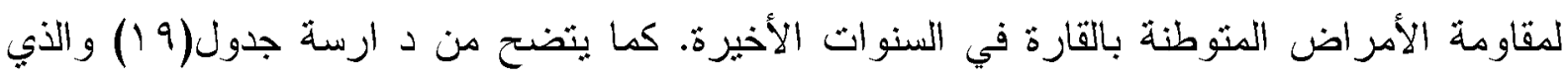

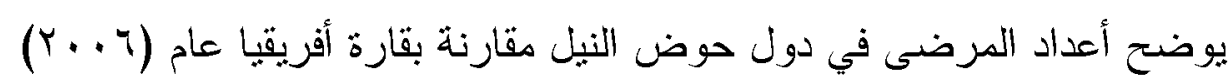
جدول (9 (1) أعداد المرضى في دول حوض النيل مقارنة بقارة افريقيا (Y . . T ) مليون مريض

\begin{tabular}{|c|c|c|c|c|c|c|c|c|c|c|}
\hline \multicolumn{2}{|r|}{ الحصبة } & \multicolumn{2}{|r|}{ الملازيا } & \multicolumn{2}{|c|}{ الالتهاب الكبدي } & \multicolumn{2}{|r|}{ الإِيدز } & \multicolumn{2}{|r|}{ السل } & \multirow{2}{*}{ أعداد المرضى } \\
\hline$\%$ & مليون & $\%$ & مليون & $\%$ & | مليون & $\%$ & مليون & $\%$ & |مليون & \\
\hline$r 9.9$ & $r$. & ro.9 & $v$. & $r$. & $\wedge$ & ro & 11 & ro.r & 1.1 & حوض النيل \\
\hline
\end{tabular}




\begin{tabular}{|c|c|c|c|c|c|c|c|c|c|c|}
\hline$v \cdot .1$ & $\leq V$ & $y \leq .1$ & Iro & A. & r & Yo & r" & $V \leq . \varepsilon$ & Y.Y & أفريقيا \\
\hline $1 \ldots$ & $7 V$ & $1 \ldots$ & 190 & $1 \ldots$ & $\varepsilon$. & $1 \ldots$ & $\leqslant \leqslant$ & $1 \ldots$ & 纟.r & الإجماني \\
\hline
\end{tabular}

المصدر: تقاريرمنظمة الصحة العالمية عام 14. بام .

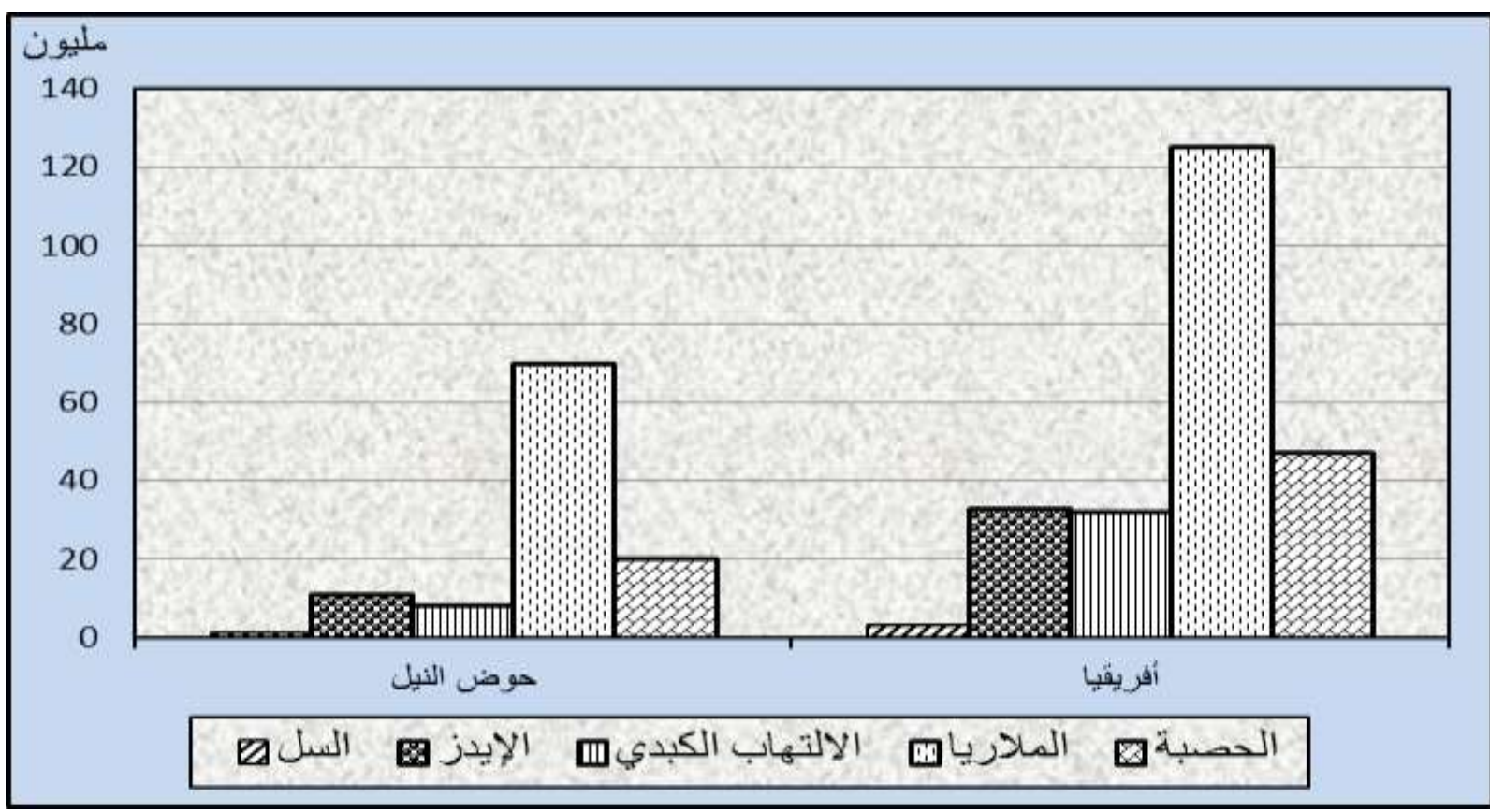

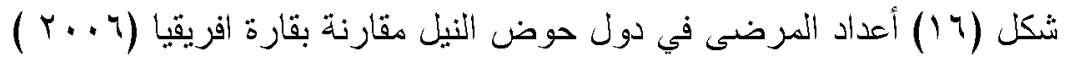

المحور الخامس: التحديات التي تواجه الولايات المتحدة في منطقة حوض النيل:

تواجه الولايات التنحدة تحديات في علاقاتها بدول حوض النبل خاصة وانها

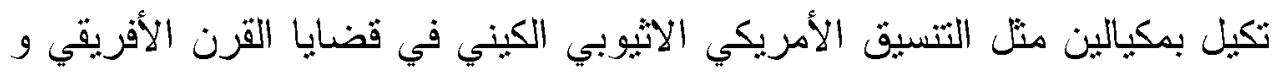

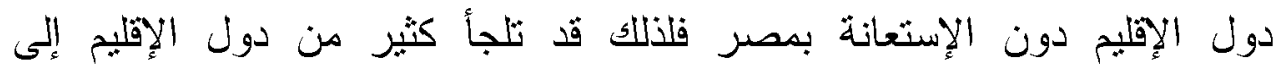

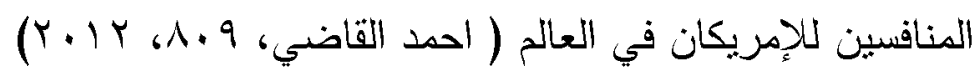

أولاً: المنافسة الصينية:

اهنمت الصين بأفريقيا لكثرة ثرواتها ومواردها الطبيعية من معادن ونفط في أو اخر القرن الماضي لم

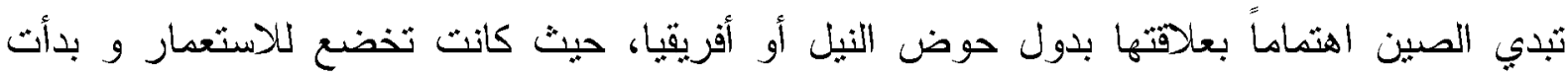

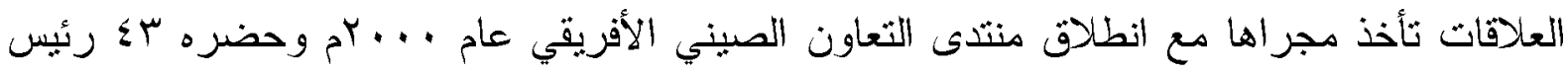

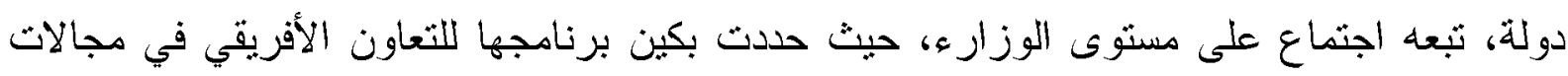

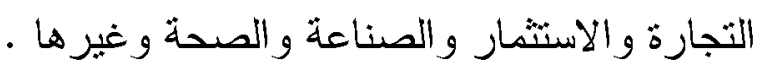


تم عمل اجنماع ثاني في أديس أبابا عام ب...rم قامت الصين بإلغاء الديون على نحو ابـ دولة

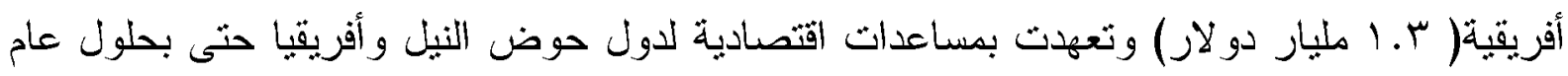

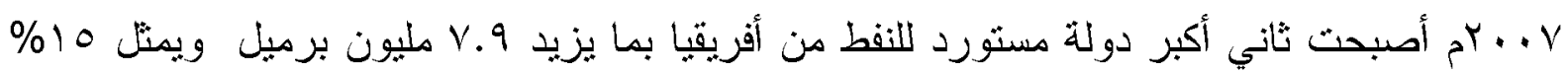

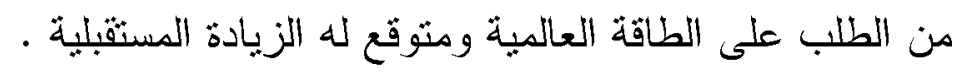

أكد خبراء الطاقة إلى أن الواردات النفطية من أسيا أقل من احتباجاتها وبالتالي أصبحت أفريقيا ودول

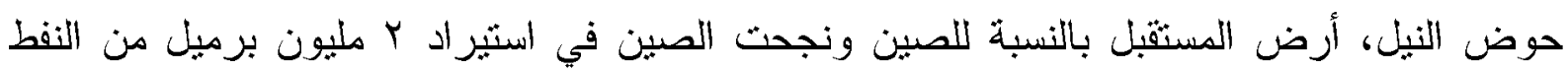

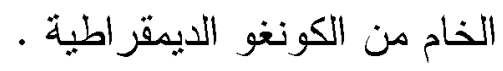

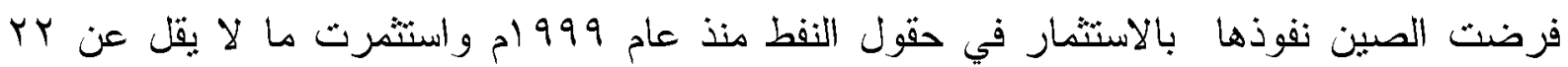

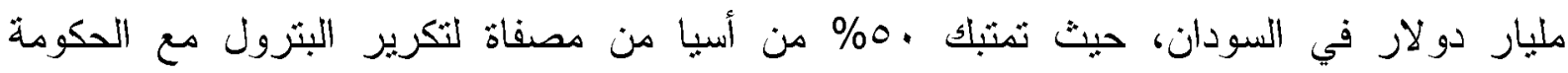

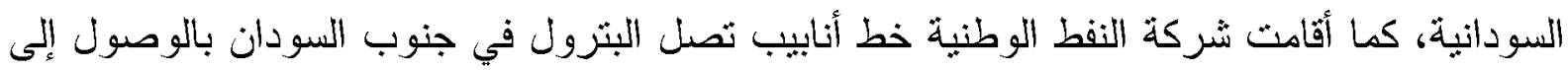
بوسودان، حبث يتم تحمبل النفط إلى ناقلات صينية.

تشثهلك الصبن نحو ر٪ من النفط القادم من جنوب السودان بما بعادل . ... . 00 برميل يومياً بجانب

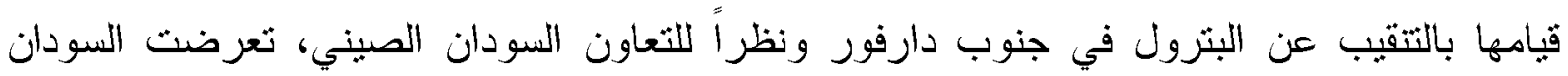

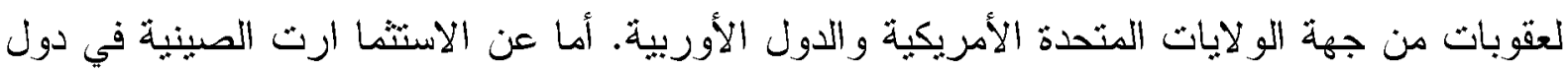

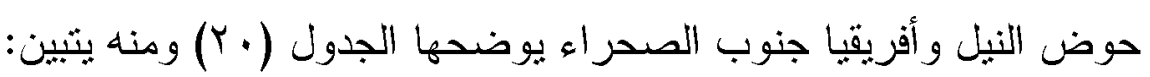

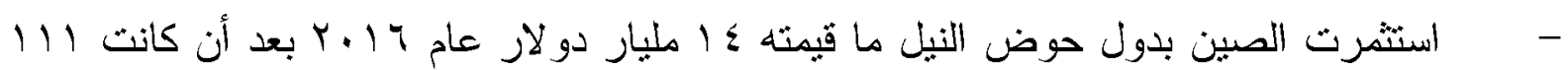

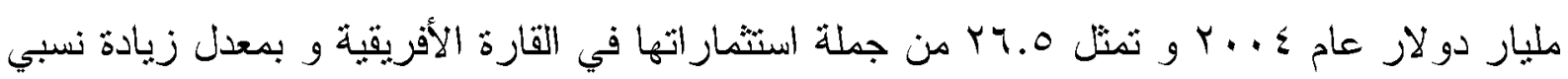

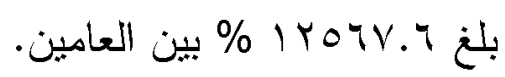
جدول(·r) الاستثمار ات الصينيه في دول حوض النيل و أفريقيا عام 14 .ب " مليون دولار"

\begin{tabular}{|c|c|c|c|}
\hline \% من أفريقيا & دول حوض النيل & أفريقيا (مليون دو لار) & العام \\
\hline ro & 111 & MIV & $r \ldots \varepsilon$ \\
\hline$\leq 7 . \leqslant$ & IAr & rar & r..o \\
\hline$\leqslant 1 \ldots$ & Ar. O & $r . . \varepsilon$ & $r .11$ \\
\hline$r 4.00$ & $1 \leq .71$ & or..o... & $r .17$ \\
\hline
\end{tabular}

المصدر : البنك الأفريقي لهتنمية QNB عام 7 . r. 


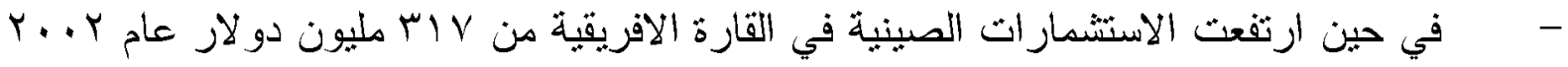

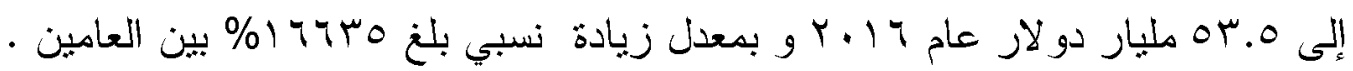
يتوزع الاستثار الصيني في قطاع التصنيع في أفريقيا( با\%) مقابل( ^ب\%) في قطاء البناء ،

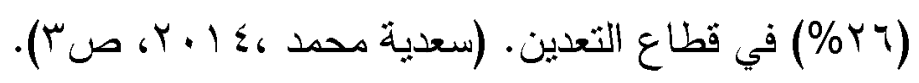

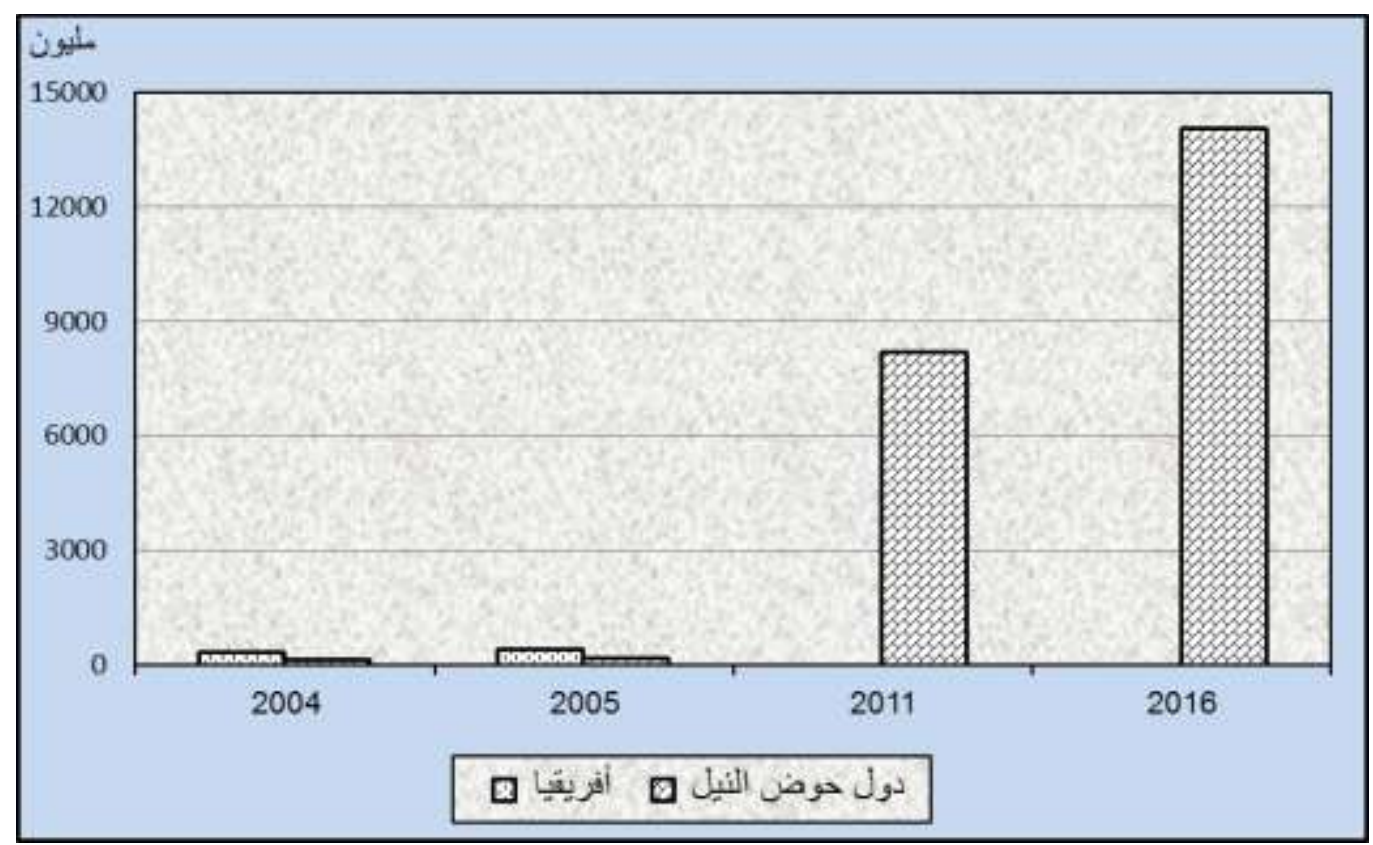

شكل (lV) الاستثمارات الصينيد في دول حوض النيل و أفريقيا عام 14.

معظم صداد ارت الصبن في دول حوض النيل الآلات، معدات النقل، المنسوجات، الأحذية، في حين نقوم دول حوض النيل بتصدير النفط الخام، و المعادن والمواد الخام . تحرص الصين على المشاركة في قوات حفظ السلام في دول حوض النيل، حيث أرسلت قوات إلى دارفور وجنوب السودان، والكونغو الديمقراطية .

قامت الصبن عام V. . r. بتأسبس الصندوق الصبني الأفريقي برأس مال قدره خمسة مليا ارت دو لار

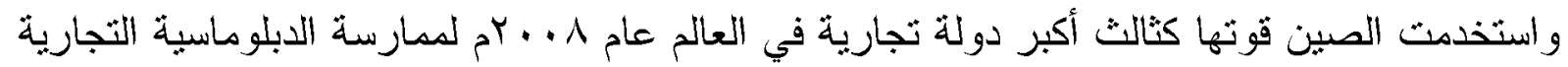

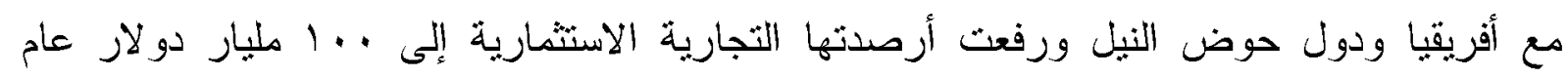

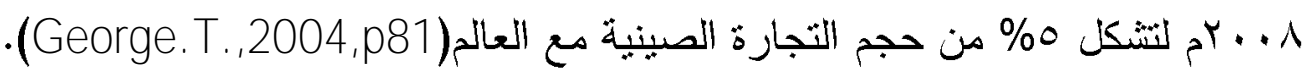




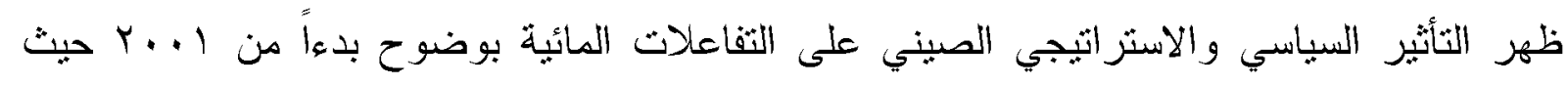

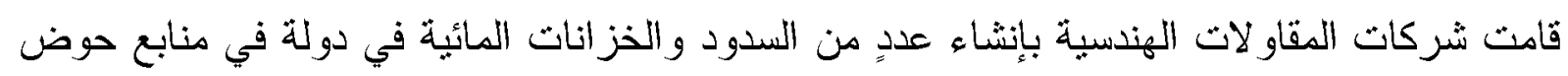

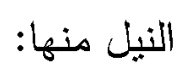

Tekeze Hydropower Dam سد تيكيزى

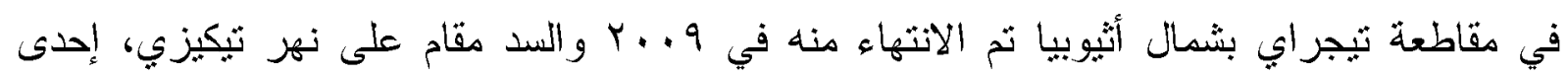

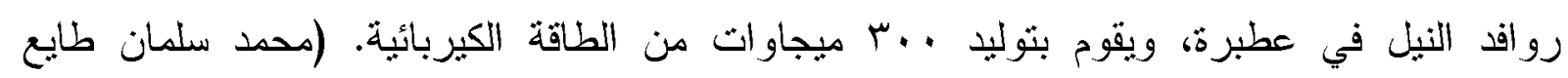

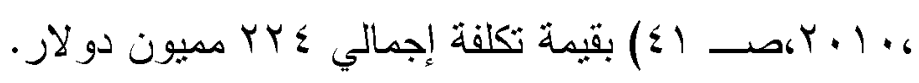

Chemoga yeda r سد شيموجا يبيا

يقوم على بناء خمسة سدود في شيموجا ويبدا وسينزوجنيلا وأنيار بوجينا بنكلفة 000 مبيون دو لار

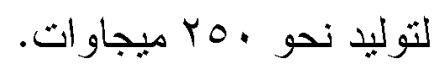

\section{Dawa III Genale-r سد جينال داو الثثالث}

ستبلغ تكلفته 1 •ـ مليون دو لار وسينتج گ ب ميجاو ات ويقع على الحدود بين أوروما والصومال . ثانياً: المنافسة الأوربية الأمريكية:

تثوم بعض الدول الأوربية بدور المانح للمشروعات الثتموية والمائية في عدد من دول حوض النيل

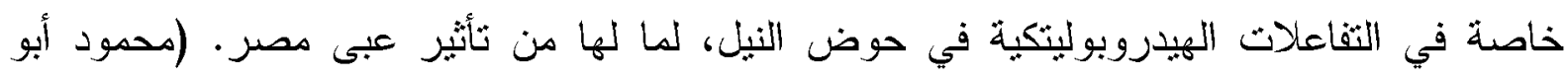

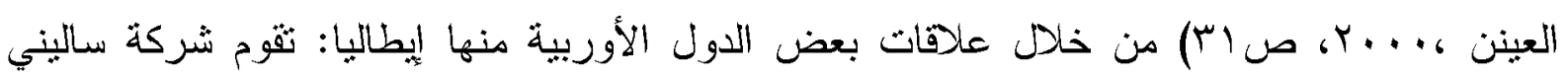

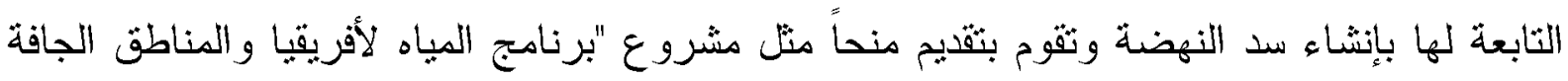

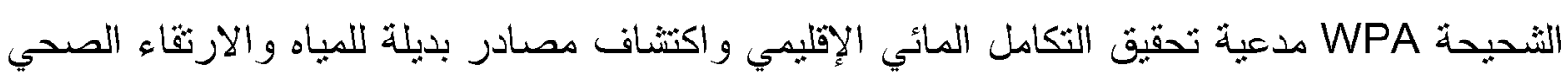
للمواطنين من خلال فحص مصادر المياه العذبة، من خلال عقد السينما ارت وورش العمل العل ونبادل

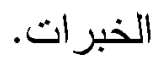

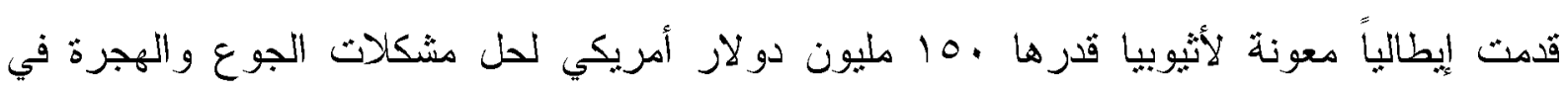

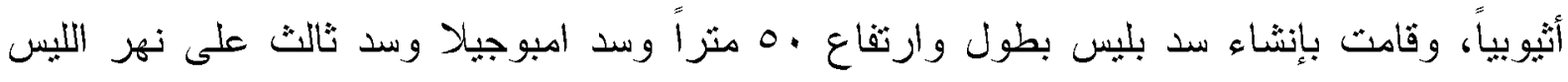

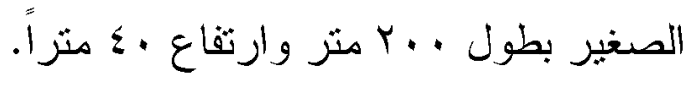

قامت أيضاً بيناء جيبه Geligl Gibe من خلال تحويل مياه نهر جلجل جيبه إلى نهر أومو مع نوليد

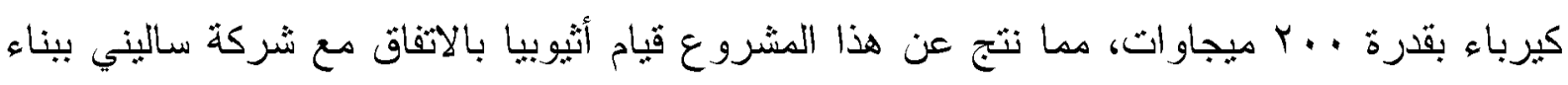


سد النهضة. (أحمد نصر الدين ،... ب، ) لا شك أن السياسة الإيطالية المنتهة في بناء السدود

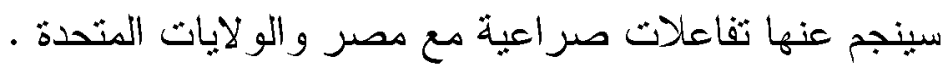

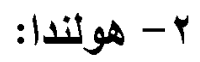

قامت مولندا بإطلاق مبادرة حوض النيل بالنعاون مع مصر، بنقديم منح در اسية لدول حوض

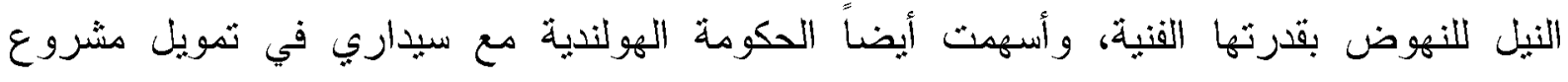

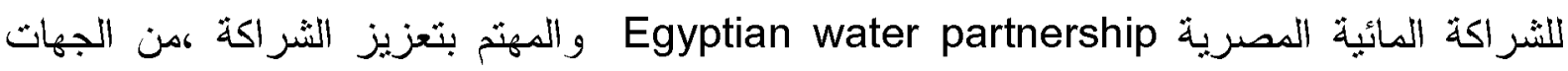
الحكومية والجهات الأكاديمية والبحثية في تفعيل دور الإدارة المنكاملة للموارد المائية، ومن هنا تلعب

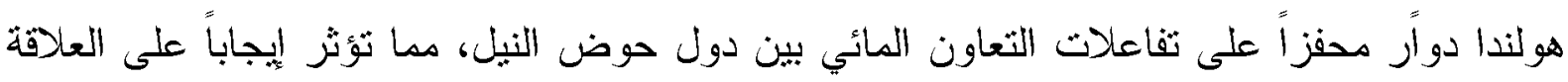

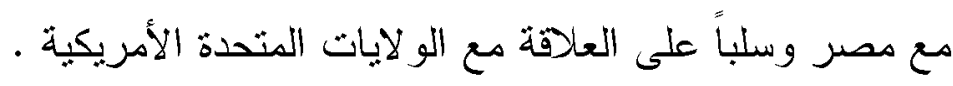

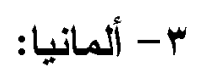

دورها فعال كمانح ومقاول هندسي في حوض النيل، حبث قامت بثمويل دراسة الجدوى بمشروع سد

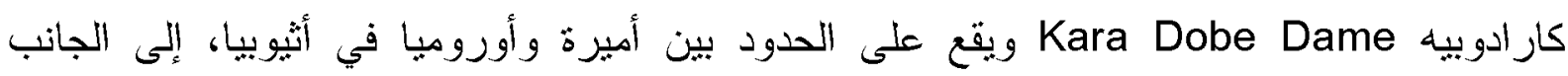

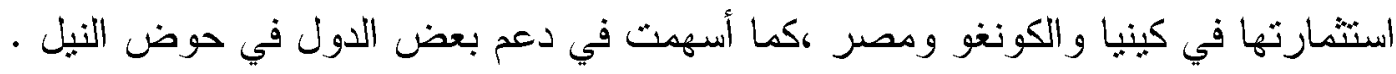

$$
\text { צ- روسيا: }
$$

حرص الاتحاد السوفيتي على علاقة استراتيجية مع دول حوض النيل من منتصف القرن العشرين،

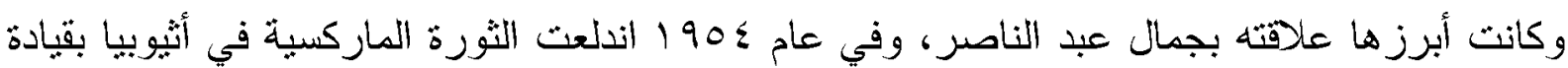
منجستو هايلا ماريام والذي أسقط نظام هيلاسلاسي بانقلاب عسكري مها وطد العلاقة بالاتحاد

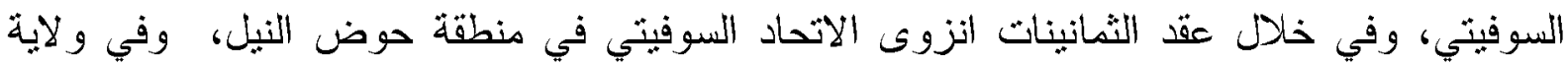

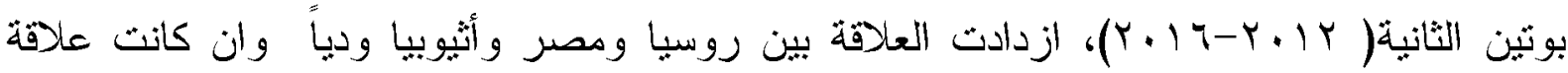

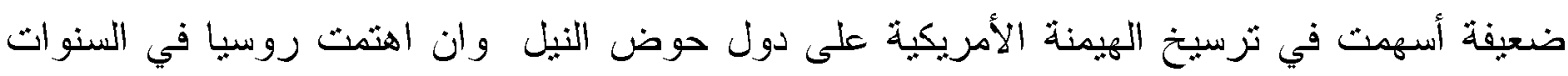

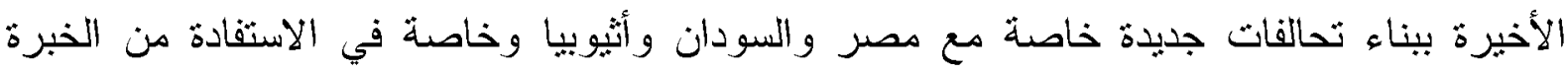

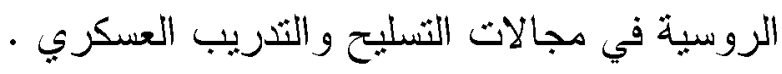


بدأ التخل الياباني مع دول حوض النيل اعتبارًا من عام 19 19V حبث ظهرت كدولة مانحة للمساعدات الرسمية وفي عام 910 ام انتهجت سياسة جديدة قائمة على المساعدات والتبادل التقافي وحفظ السلام

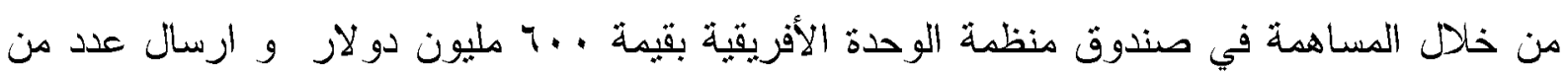

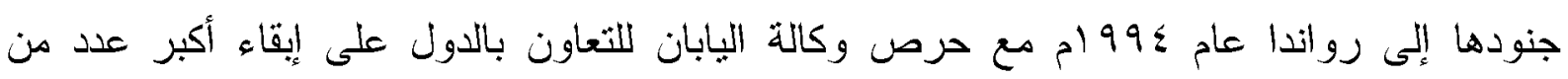
العاملين بدول حوض النيل وعسكرياً وتتحاثى التداخل في النزاعات بين دول حوض النيان النيل.

$$
\text { דا }
$$

تثتثل الخطة الاستراتيجية الإسر ائيلية للنحرك داخل القارة الأفريقية ودول حوض النيل من خلال عقد

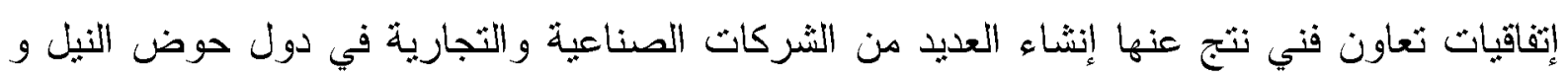

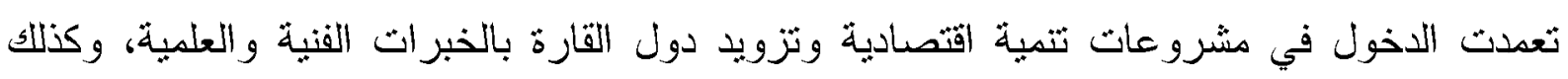

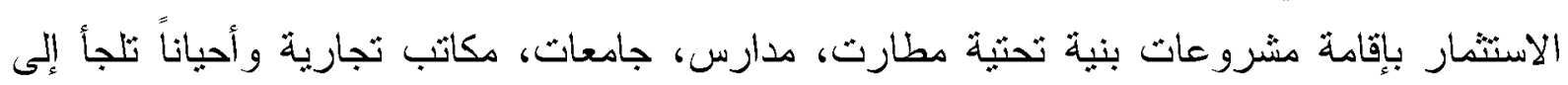

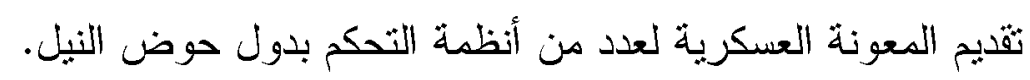

وبدأ التغلغل الإسرائيلي في دول حوض النيل منذ عام ب...rم مع الغزو الأمريكي للعراق ،وكونها

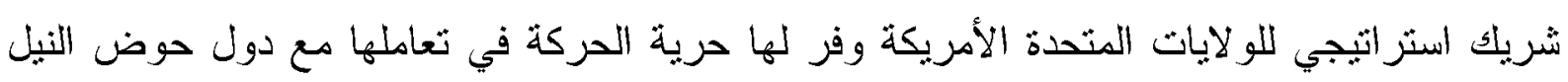
وتهدف إسر ائيل في تغلغلها في دول حوض النيل إلى:

() أهمية دول حوض النيل الاستراتيجية لامتلاكها ممرات حيوية للتجارة الدولية ومنافذ وموانئ عربية هامة على المحبط الهندي.

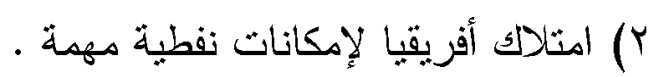

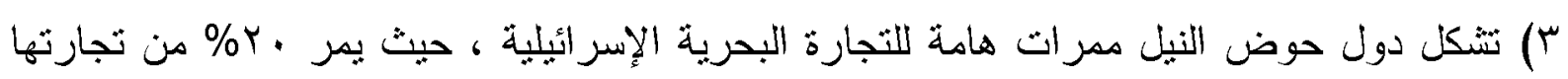

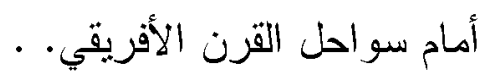
§) ثهذف إسرائيل الخروج من عزلتها بإقامة علاقات دبلوماسية مع دول حوض النيل كوسيلة لنفي

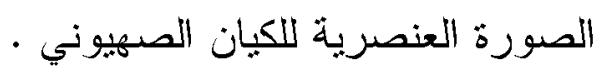
0) يشكل البحر الأحمر أهمية اترانتيجية للمصالح الإسرائيلية في تجارنها مع أفريقيا وأسيا و استراليا

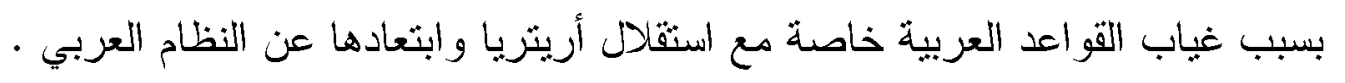

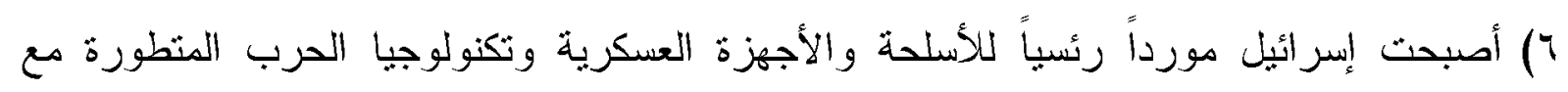

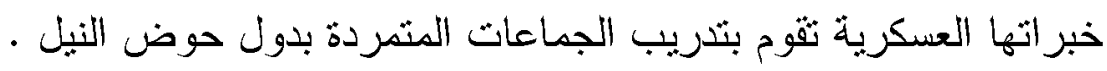


V تهدت إسر ائيل إلى فتح أسواق للمنتجات الإسرائلية بالحصول على المواد الخام الأولية مع تثنغيل فائض العمالة لديها من خبر اء وفنيين داخل القارة .

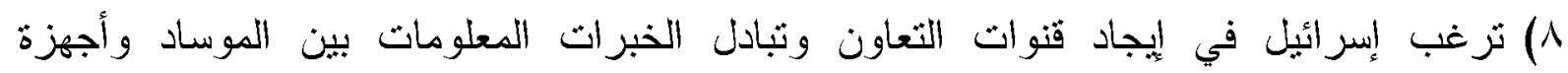
الاستخبارات الأفريقية بهدف المساهمة في زيادة حدة عدم الاستثرار السياسي وتشتيع الحركات

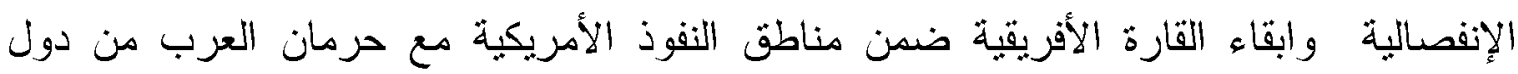

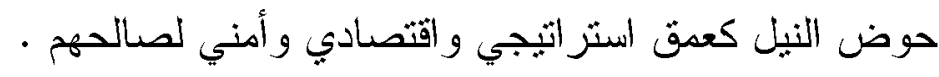

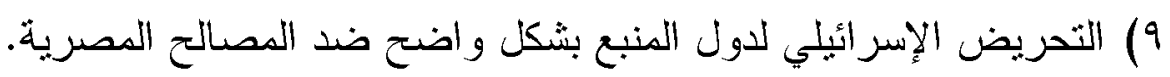

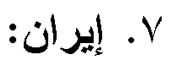

تزتبط العلاقات الإيرانية بدول حوض النيل بمدى ثوافر المساعدات والمعونات المالية بجانب

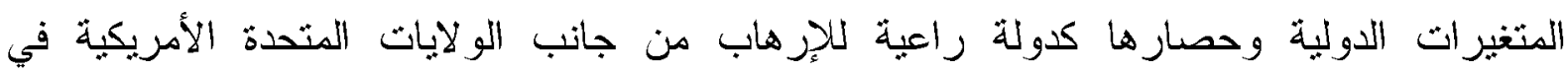
التسعينات من القرن الماضي اهنم رئيس إيران ارفسنجاني بزيارة دول من حوض النيه النيل (السودان،

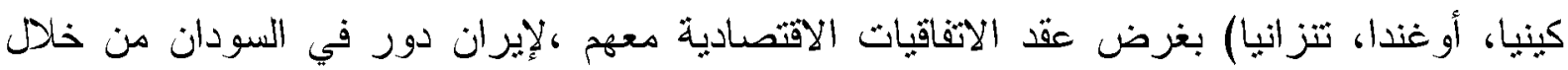

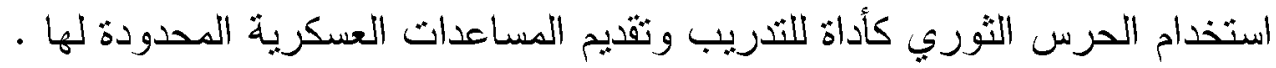
تهذف إيران إلى نحقيق انتشار فكرها العقائدي من خلال المذهب الثيعي خاصة مع دولة السودان التي يوجد بها مذهب شيعي بجانب عدد محدود من الثنيعة في نتزانيا وكينيا ومصر وني وأرينريا. (محمود

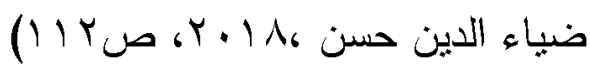

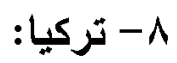

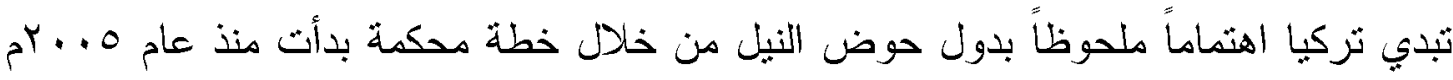

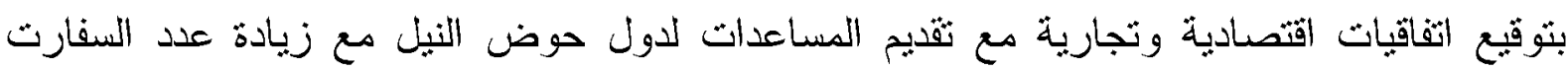

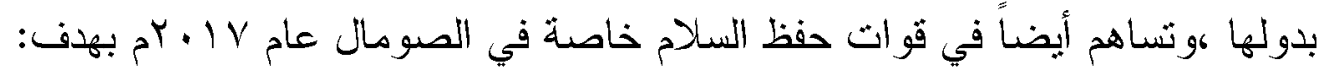
- مواجهة تنامي نفوذ بعض القوى الإقليمية والدولية بثقديم نفسها كبديل إقليمي لتحقيق وحماية مصالح القوى الغربية في المنطقة.

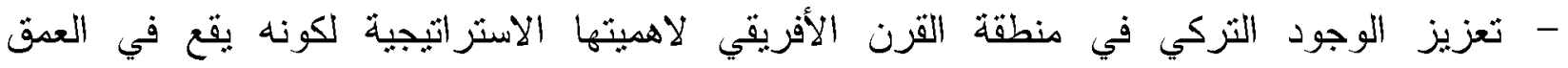

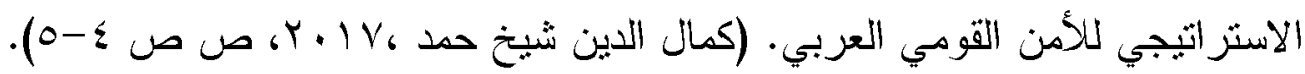

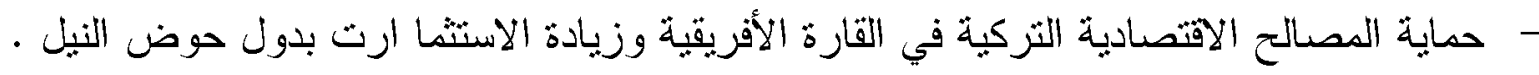

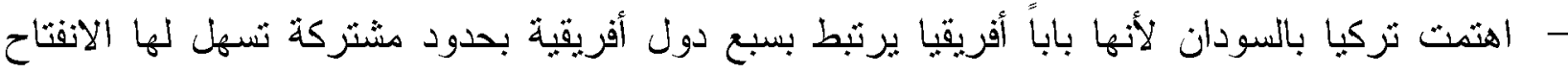

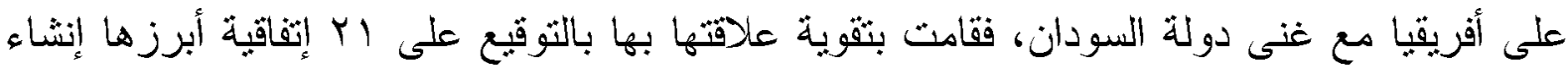


مطار جديد بالسودان وقاعدة عسكرية ثركية في سواكن، مما أثر في العلاقة المصرية السودانية

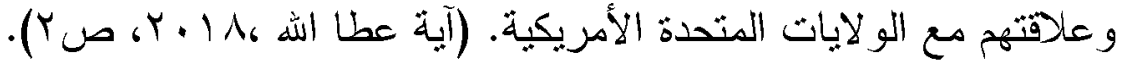

الخاتمة - - المة

نخلص من الدراسة لبعض النتائج و الثوصبات على النحو النالي: أولا: النتائج

بضم إقليم حوض النيل العديد من الدول مما يجعله إقليما جغرافيا منسع المساحة فريد من نوعه مما

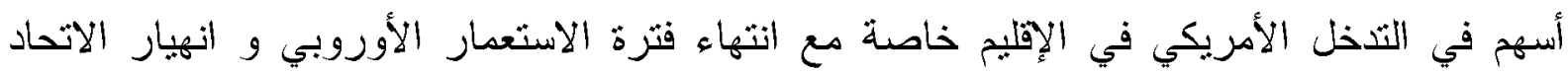

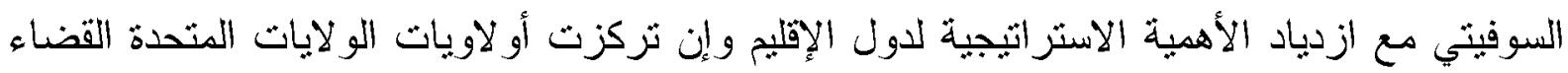

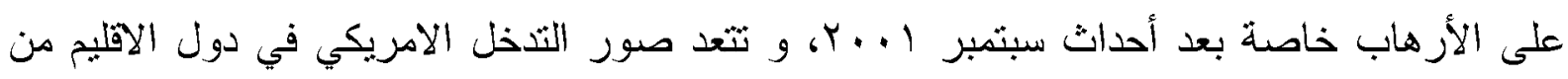

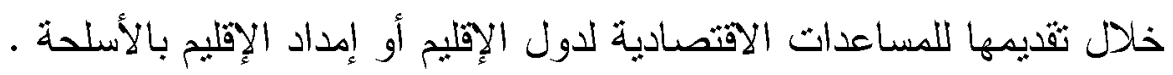

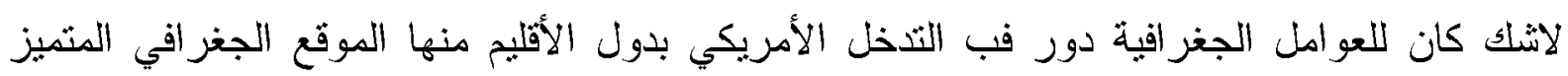

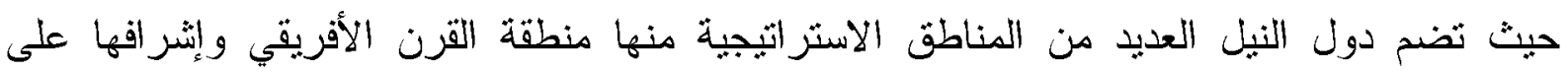

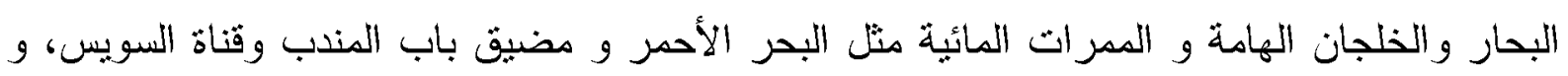

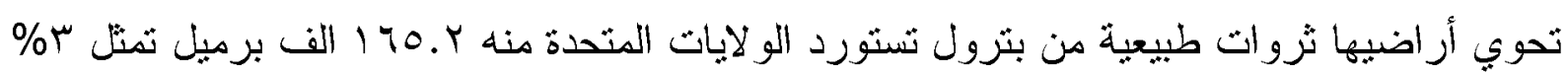

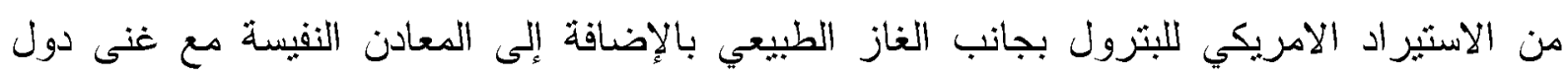

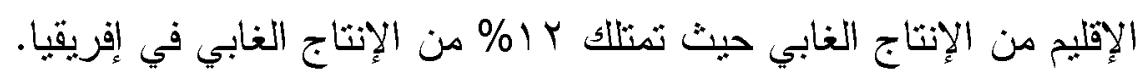

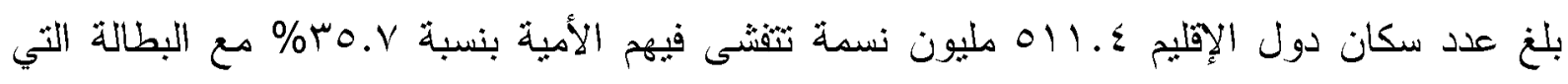

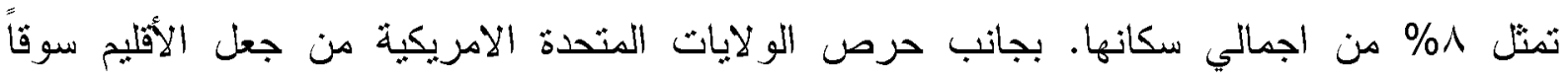

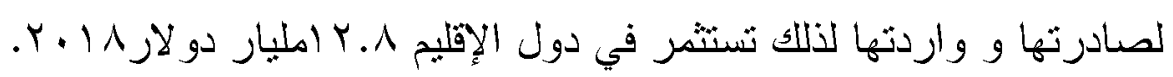

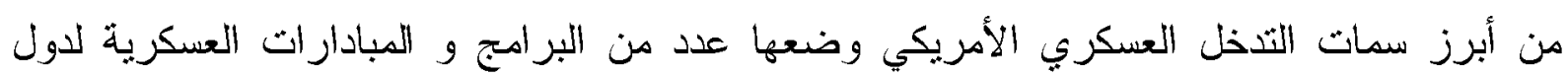
الإقليم ومنها القبادة العسكرية الامريكية و إنشاء قوة الأفريكيوم.

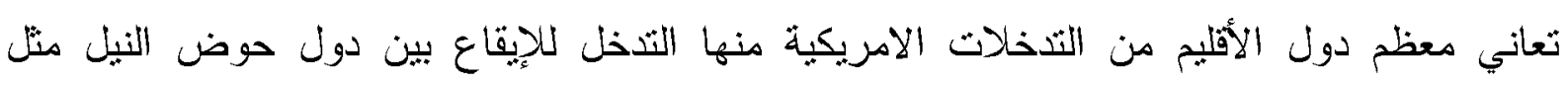

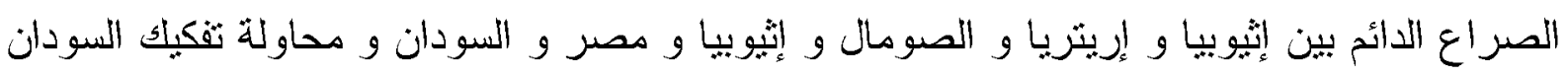

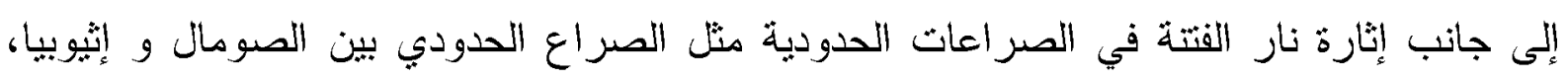

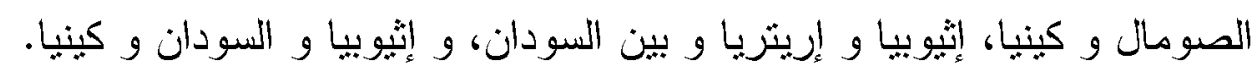

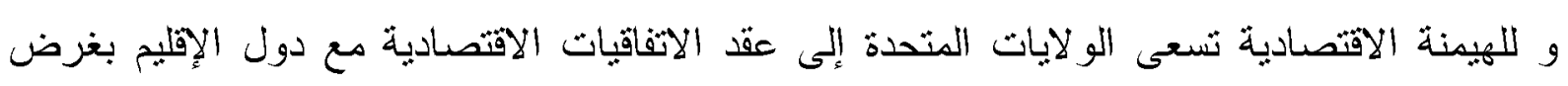
الحصول على المواد الخام من دول الإقليم ونصدير الفائض إليها. 


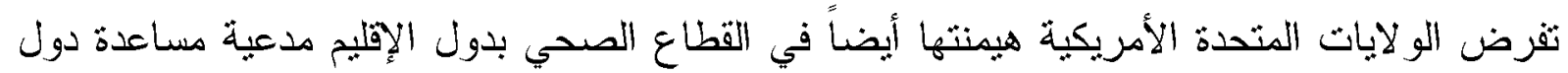
الإقليم بالتخلص من الأمراض مثل السل و الأيدز و الماتلاريا من خلال الألتفاق المالي.

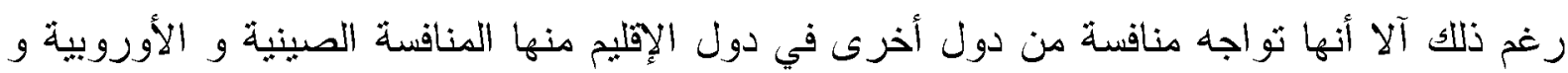
الروسية و إن سمحت اسر ائيل بتتفيذ خطتها الاستر اتيجية بدول دول الإقليم. ثانياً: التوصيات بناء على النعقيدات الداخلية و الإقليمية و الدولية أصبح الأمر صعباً على دول الإقليم على مواجهة هذه التحديات بصوة فردية لذا من الو اجب على دول حوض النيل عمل الأثى:

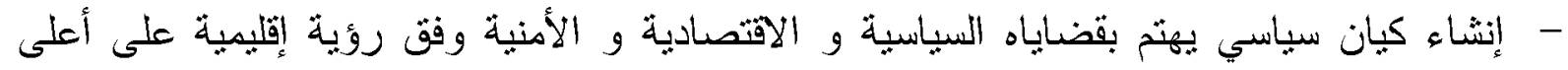
درجات الوعي بالدخاطر المحيطة بدول الإقليم.

- الاهتمام بالتكتل الإقليمي في كافة المجالات الاقتصادية و الأمنية و السياسبة، فقي هذا التكتل بمكن

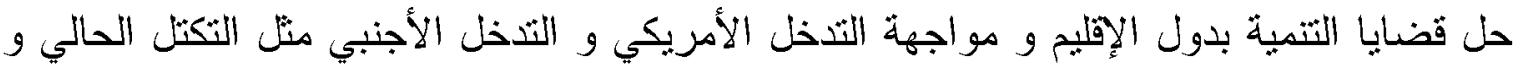

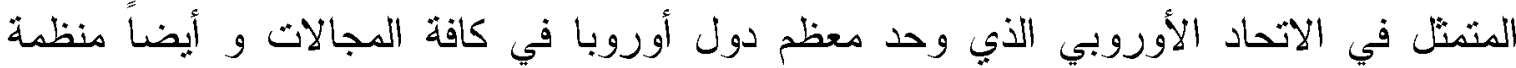

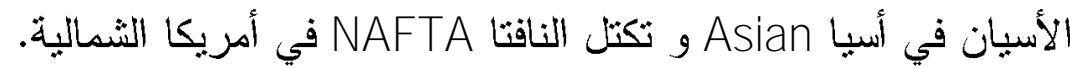

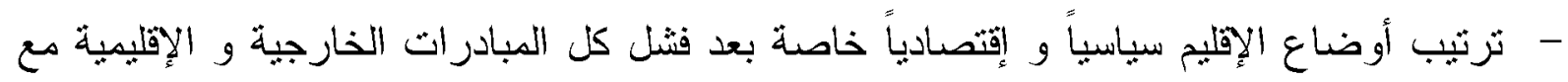
الإهتمام بالقضاء على مو اطن الصراع السياسي بدول الإقليم.

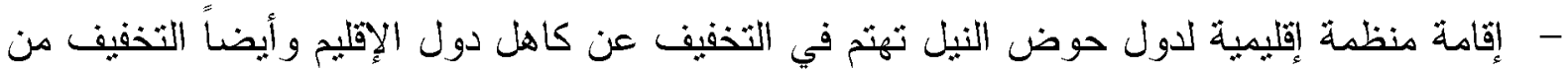

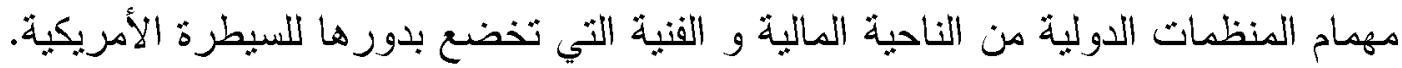
- إعطاء تلك المنظمة دور فعال في حل المنازعات الثي نتشأ بين الدول الأعضاء في المنظمة الإقليمبة. - تعزيز التجارة بين دول حوض النيل لتحقيق الإكتفاء الذاتي لدول حوض النيل منعاً للسبطرة

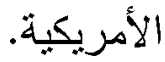
- تأمين السلام و الإستثرار لدول حوض النيل كثرط أساسي للتتمبة الإقتصادية. - الاهنمام بمبدأ تقاسم المنافع من خلال النعاون بين دول حوض النيل من أجل الإستفادة من الموارد

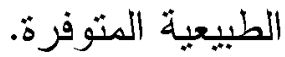

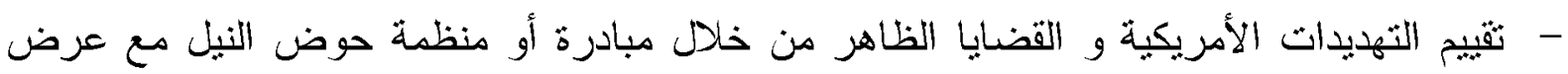

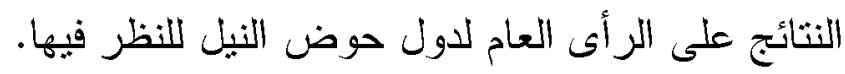




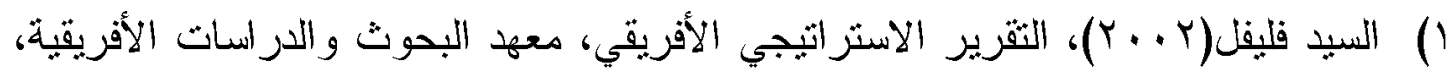

جامعة القاهرة .

Y) أحمد القاضي (Y (Y. (Y)، رؤية مستقبلية لتسوية الأزمة المالية، مؤثمر حوض النيل

$$
\text { الثرقي. }
$$

") خيري عبد ال ارزق جاسم (2009) ، "قيادة عسكرية أمريكية جديدة لأفريقيا فرصة أمريكية ومحنة أفريقية" المجلمة العربية للعموم السباسية، بيزوت، مركز دراسات الوحدة

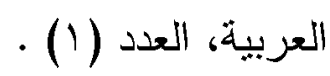

0) سبد أحمد عثمان العقبد(؟ . . Y)، مصير القرن الأفريقي في القرن التاسع عشر المبلادي،

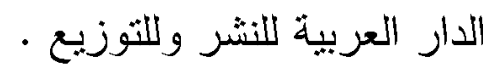

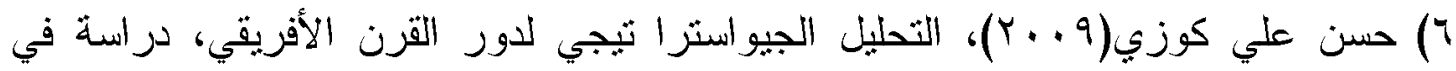
الجغر افيا السياسية ،رسالة دكتواره "غير منشورث"، كلية الد ارسات العليا، الخرطوم . V) الأمين عبد القادر ادم (T ( . Y)، التشخلات الخارجية وأثزها على الاستثرار في الصومال في الفترة من 1991-19 . . . م، شركة مطابع السودان، الخرطوم. ^) حمدي عبد الرحمن حسن(^ . . r) "إدارة بوش وعسكرة السياسة الأمريكية تجاه افريقيا،

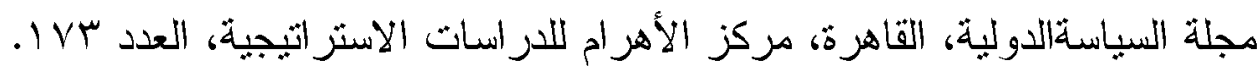
9) توفيق المدني(991(1)، "جولة كلينتون الأفريقية، مجلة شؤون الثرق الأوسط، بيروت، مركز الدراسات الاستر اتيجية، العدد Y V.

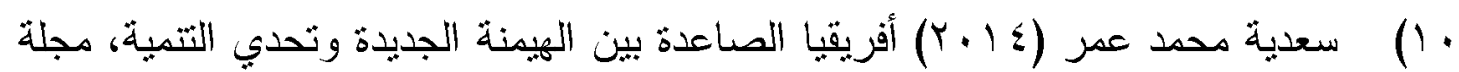
اتجاهات المستقبل، العدد . ب.

(1) محمد سالمان طايع،(· ( ( ) "المشروعات المائية في حوض النيل"، رؤية تحميمية من منظور هيدروبولوثيكي، أحوال مصر، القاهرة، مركز الدراسات السياسية

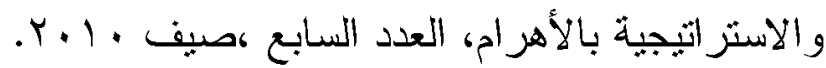
Y (ا) م محود أبو العينين: العلاقات السياسية بين مصر ودول الكوميسا (المسثوى الثاني)، في آفاق أفريقية، العدد الأول ، ... . ب، أكاديمية ناصر العسكرية، القاهرة . 
د/ حسن محمد إبر اهيم

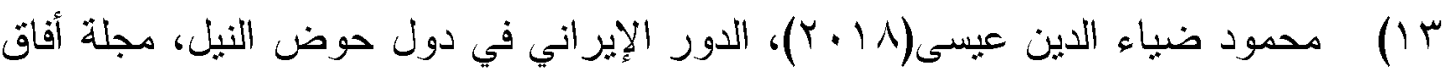
أفريقية، العدد V乏، الييئة العامة للاستعلامات، القاهرة .

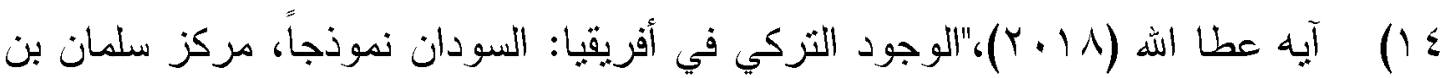

زايد لدراسات الثرق الأوسط، القاهرة .

10)

اللاعبين الإقليمين ،مركز الجزيرة للار اسات الاستراثيجية، الدوحة .

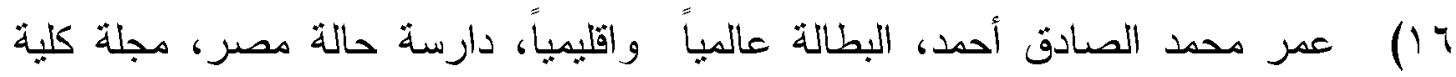
الدراسات الإنسانية، جامعة الأزهر، العدد التاسع عشر، الجزء الجئ الثاني، القاهرة.

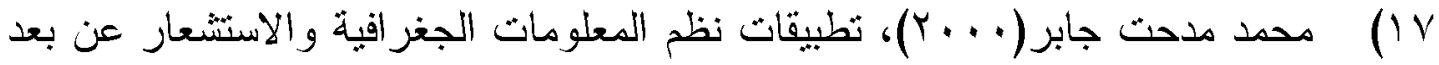
في مجال الجغر افبا الطبية،المجلة الجغر افية العربية، العدد الخامس والثالثون، ؤالجزء

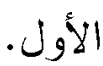

11 أحمد طه محمد: أفريقيا، أفريقيا و النظام العالمي الجديد، مجلة السياسة الدولية، مركز

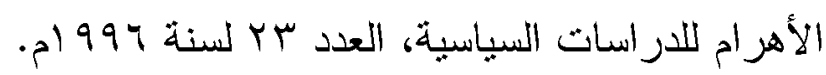

19) موسن حسين، السياسة الأفريقية في القرن العشرين، مجلة السياسة الدولية، القاهرة،

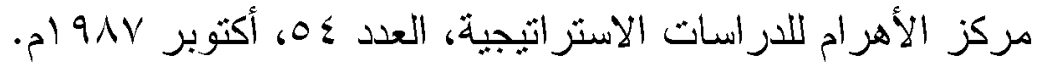

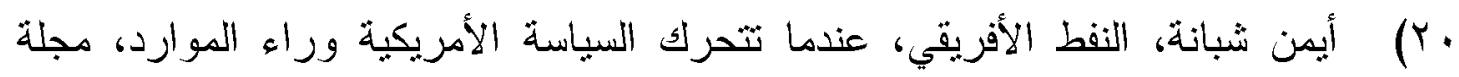

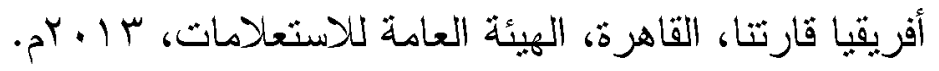

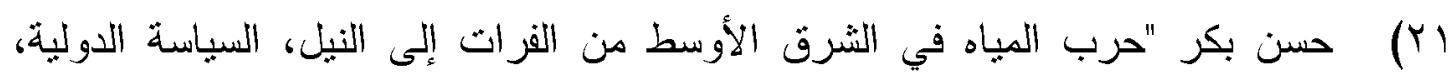
العدد( (111) (1) القبرن

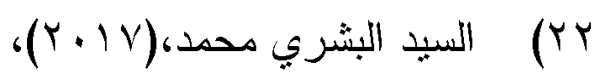

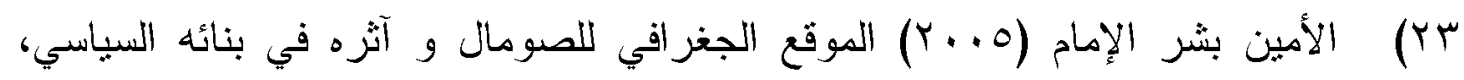

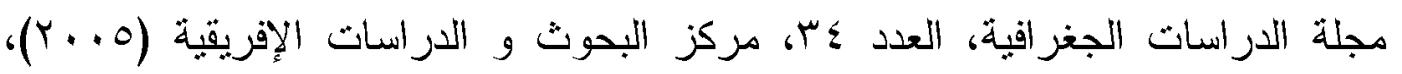

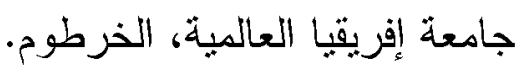

25) 'Lauren Ploch, (2009) ,Africa comonandi' US. Strategic interests .$r \varepsilon$. rand the role of the US military in Africa" CRS Reports RC. 
/ إ حسن محمد إبر اهيم

العدد الثاثث والاثشرين بونيو • ب + م

حسونة

26) Richard F. Grimmet, (2010), International Military and training " program" GRS Report.

27) Thomas Dempsay ،(2006), Counlies" ter Terroism in Africa faild sta challenges and potential solution (strategic studies mstitule, US Army ."war college

28) Bushra, El Sayed-El,(2000), International Boundaries and the " New World order: An Islamic perspective", Bulletain of Egyptian . VrGeographical Society, Vol.

29) ivelle LantonDar,(2008), US Trade and Inrestentent with subsharan Africa; The Africa Grouth and opportunity Africa beyond', . MVVYCRS Report RL

30) World bank, (2004), ment indicators, Washington world develop DC.

31) Global water security, (2002) ,Intelligence Community Assessment" ICA.

32) Daniel Volman, (2004), The Bush Administration and Afrrican " rgy policy, A Gas BUllution, ciel: The security Inplications of U.S. Ene TN6.

33) George T Yu, "China Africa and Globalization", The "China, Alternative, Asia PAPER, Instructive for security and Development .r. . spolicy, June,

34) a from war to peace, Poul B. Nenece, The Han of Afric .Y...'، Hang Kon

35). .1991Macmillan, 
د / حسن محمد إبر اهيم

الاعدد الثالث و العشرين بونيو ، ب + م

حسونة

36) ommand official web site: United States African C http:www.african.mill

37) Sulayman S, Nayang, "Their America: The U.S in the eyes of the Rest of the world" social research international Quarterly: Volume 72.

38) Gwendolyn Mikell, Africa policy in an era of finance, American cooperation, Washington, foundation Robert schuman, 2004.

39) Raymond W. Copson, "Africa Bockgrounder: History, US, policy, principal congressional Actions, "CRS Report RL 30029 January 2001.

40) Daniel H; Simpson, U.S. Africa Policy; Some Possible course adjustment, (strategic studies Institute, U.S Army War Colleye) 1994.

41) U.S of commerce, bureau of cansus.

42) World investemnet Report

43) Stargitic studies instatue, (2016), US Army war collage.

44) Jessiue Ronaldo, 2010.

45) Woodward, Peter (1996), the Horn of Africa : State Politics and international Relations, Tauris Academic studies, London. 